UNIVERSIDADE DE BRASÍLIA

INSTITUTO DE CIÊNCIAS BIOLÓGICAS

DEPARTAMENTO DE FITOPATOLOGIA

PROGRAMA DE PÓS-GRADUACÃO EMFITOPATOLOGIA

Análise Proteômica Comparativa de Cultivares de Soja (Glycine max) Suscetível e Resistente à Ferrugem Asiática (Phakopsora pachyrhizi)

GLÁUCIA GARCIA FIGUEIRÓ

Brasília-DF 


\title{
Análise Proteômica Comparativa de Cultivares de Soja (Glycine max) Suscetível e Resistente à Ferrugem Asiática (Phakopsora pachyrhizi)
}

\section{GLÁUCIA GARCIA FIGUEIRÓ}

\begin{abstract}
Tese apresentada ao Programa de Pós-graduação em Fitopatologia do Instituto de Ciências Biológicas da Universidade de Brasília como parte dos requisitos necessários para obtenção do título de Doutora em Fitopatologia
\end{abstract}

Orientador: Prof. Dr. Luiz Eduardo Bassay Blum

Co-orientadora: Profa. Dra. Mariana de Souza Castro

\section{Brasília-DF}




\section{FICHA CATALOGRÁFICA}

FIGUEIRÓ, Gláucia Garcia.

Análise proteômica comparativa de cultivares de soja (Glycine max) suscetível e resistente à ferrugem asiática (Phakopsora pachyrhizi) /Gláucia Garcia Figueiró. - Brasília, DF [s.n.], 2016

Número de páginas p. 160 il.

Tese (Doutorado). Instituto de Ciências Biológicas da Universidade de Brasília/

Departamento de Fitopatologia.

Orientador: Luiz Eduardo Bassay Blum.

Bibliografia. 
Trabalho realizado junto ao Departamento de Fitopatologia do Instituto de Ciências Biológicas da Universidade de Brasília, sob orientação do professor Dr. Luiz Eduardo Bassay Blum, com apoio do Laboratório de Bioquímica e Química de Proteinas (LBQP/UnB), Coordenação de Aperfeiçoamento de Pessoal de Nível Superior (CAPES) e do Conselho Nacional de Desenvolvimento Científico e Tecnológico (CNPq).

Análise proteômica comparativa de cultivares de soja (Glycine max) suscetível e resistente à ferrugem asiática (Phakopsora pachyrhizi)

\title{
Gláucia Garcia Figueiró
}

TESE APROVADA EM: 11/07/2016

\section{EXAMINADORES:}

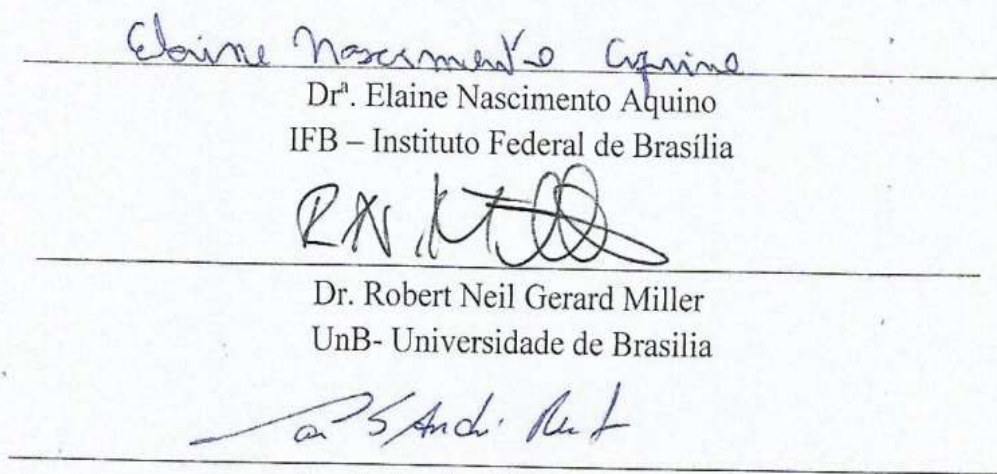

Dr. Carlos André Ornelas Ricart

UnB- Universidade de Brasilia

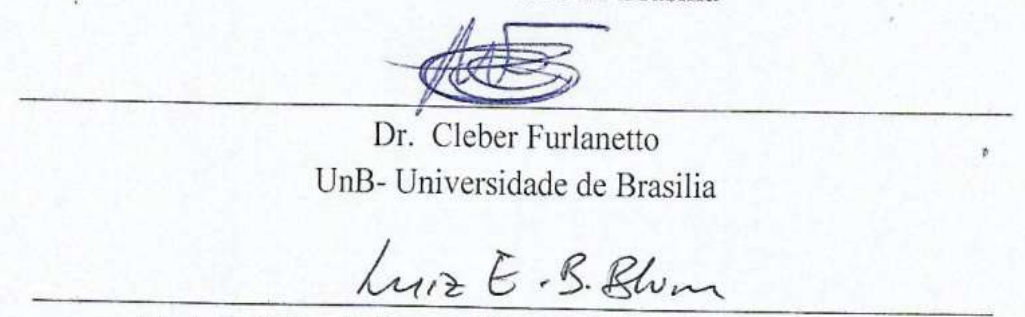

Dr. Luiz Eduardo Bassay Blum - Orientador (Presidente)

UnB- Universidade de Brasilia

\author{
BRASÍLIA - DISTRITO FEDERAL \\ BRASIL \\ 2016
}


"Aos meus queridos pais Victor Hugo e Maria Elena pelo amor incondicional e por estarem sempre ao meu lado me dando forças".

\section{DEDICO}

"Tudo tem o seu tempo determinado, e há tempo para todo propósito debaixo do céu". Eclesiastes 3:1

"Quem sai andando e chorando enquanto semeia, voltará com júbilo trazendo os seus feixes”. Salmos $126: 6$ 


\section{AGRADECIMENTOS}

Agradeço primeiramente a Deus pelo dom da vida, por sempre me capacitar a persistir por meus sonhos, renovar minhas forças e por todo conhecimento que me permitiu adquirir nos últimos anos tanto profissional como pessoal;

Aos meus pais Victor Hugo P. Figueiró e Maria Elena Garcia Figueiró por sempre me incentivarem e acreditarem em meus sonhos e aos meus irmãos Dener, Heriton e Ilton;

Ao programa de Pós-Graduação em Fitopatologia da Universidade de Brasília pela oportunidade oferecida para realização do doutorado;

A Capes e ao CNPq pela bolsa de estudos oferecida;

Ao meu noivo Gerrard Cristiano pelo companheirismo e amizade;

Ao meu orientador professor Dr. Luiz Eduardo Bassay Blum pelos ensinamentos, confiança, paciência e amizade nestes anos de estudo;

À minha co-orientadora professora Dra. Mariana de Souza Castro pela oportunidade oferecida junto ao Laboratório de Bioquímica e Química de Proteínas (LBQP) para o desenvolvimento da tese e também por seus ensinamentos, amizade, confiança e colaboração durante todo o trabalho;

À professora Dra. Consuelo Rodrigues Medeiros de Lima pelos ensinamentos diários na bancada, paciência, amizade e força nos momentos difíceis;

Ao professor Dr. Wagner Fontes pela amizade e colaboração nas análises estatísticas e por seu rico ensinamento no uso de softwares;

Aos professores do departamento de Pós-Graduação em Fitopatologia que contribuíram para o conhecimento adquirido em cada disciplina cursada; 
Aos funcionários da Estação Experimental em Biologia que deram suporte na fase de experimentação: Sr. Fábio Borges, Evandro Calixto, Aldo, Geraldo e demais servidores que puderam ajudar nesta etapa,

Aos amigos e colegas de departamento que tive o prazer de conviver nos últimos anos, pelas horas de estudo e amizade: Kamilla Araújo, Justino Dias, William Soares, Nancy Niño Castanheda, Érika Santos, Cecília Rodrigues, Eliane Armando, Maria do Desterro e Cezar Castro;

Aos colegas do LBQP pela amizade e colaborações: Anne Dias, Marcello, Helena, Elaine, Diana, Luz Elena, Jaques, Adelson, Nuno, Rayner, Aline, Muhhamed, Micaella, Agenor, Alan e Aguinelo;

Às queridas amigas da Colina: Fernanda Paulini, Anádria Stephanie e Keidna Oliveira pela amizade e companheirismo e também as demais colegas que tive a oportunidade de conhecer nesta temporada: Anailde, Ana, Jessica e Kezya pelos bons momentos de interação que tivemos juntas,

A Carla Giovana e Fabiano Borges por terem me acolhido quando cheguei em Brasília e por sua amizade;

Aos meus primos Ruben Figueiró de Oliveira e Ana Amélia de Oliveira Hoff pela atenção e companheirismo em um dos momentos mais difíceis durante esta caminhada;

A todos os amigos e membros da Igreja Presbiteriana da Alvorada (IPA) que sempre estiveram ao meu lado;

E a todos aqueles que estiverem torcendo por mim nesta caminhada ou contribuíram de alguma forma e acreditaram no meu trabalho. 


\section{LISTA DE TABELAS}

Tabela 1. Pareamento dos géis obtidos das cultivares BRSGO-7560 e MSOY-8001 nas condições não inoculada (NI) e inoculada (I) com P. pachyrhizi com o gel de referência (master) no Image Master 5. 34

Tabela 2. Pareamento dos géis obtidos da análise intra e inter cultivares nas condições não inoculada (NI) e inoculada (I) com P. pachyrhizi.

Tabela 3.Total de spots com abundância relativa aumentada ( $\uparrow$ ) e spots exclusivos resultantes da análise intra cultivares para BRSGO-7560 (resistente) e MSOY-8001 (suscetível) nas condições não inoculada (NI) e inoculada (I) com P. pachyrhizi.

Tabela 4. Spots com abundância relativa aumentada obtidos em BRSGO-7560 na condição não inoculada (NI) resultantes da análise comparativa intra cultivar com a condição inoculada (I) com Phakopsora pachyrhizi.

Tabela 5. Spots exclusivos obtidos em BRSGO-7560 na condição não inoculada (NI) resultantes da análise comparativa intra cultivar com a condição inoculada (I) com Phakopsora pachyrhizi.

Tabela 6. Spots com abundância relativa aumentada em BRSGO-7560 na condição inoculada (I) com P. pachyrhizi resultantes da análise comparativa intra cultivar com a condição não inoculada $(\mathrm{NI})$.

Tabela 7. Spots exclusivos obtidos em BRSGO-7560 (cultivar resistente) na condição inoculada (I) resultantes da análise comparativa intra cultivar com a condição não inoculada (NI)...... 53

Tabela 8. Spots com abundância relativa aumentada obtidos em MSOY-8001 na condição não inoculada (NI) resultantes da análise comparativa intra cultivar com a condição inoculada (I) com Phakopsora pachyrhizi.

Tabela 9. Spots exclusivos obtidos em MSOY-8001 na condição não inoculada (NI) resultantes da análise comparativa intra cultivar com a condição inoculada (I) com Phakopsora pachyrhizi.

Tabela 10. Spots com abundância relativa aumentada obtidos em MSOY-8001 na condição inoculada (I) com P. pachyrhizi resultantes da análise comparativa intra cultivar com a condição nã inoculada (NI).

Tabela 11. Total de spots com abundância relativa aumentatada ( $\uparrow)$ e spots exclusivos resultantes da análise inter cultivares para as cultivares BRSGO-7560 (resistente) e MSOY8001 (suscetível) nas condições não inoculada (NI) e inoculada (I) com P. pachyrhizi. ........ 71

Tabela 12. Spots com abundância relativa aumentada obtidos em BRSGO-7560 na condição não inoculada (NI) resultantes da análise comparativa inter cultivares com MSOY-8001 na condição não inoculada (NI). 
Tabela 13. Spots exclusivos obtidos em BRSGO-7560 na condição não inoculada (NI), resultantes da análise comparativa inter cultivares com MSOY-8001 na condição não inoculada (NI). .79

Tabela 14. Spots com abundância relativa aumentada obtidos em MSOY-8001 na condição não inoculada (NI), resultantes da análise comparativa inter cultivares com BRSGO-7560 na condição não inoculada (NI). 80

Tabela 15. Spots com abundância relativa aumentada obtidos em BRSGO-7560, resultantes da análise comparativa inter cultivares entre BRSGO-7560 e MSOY-8001 na condição inoculada (I) com P. pachyrhizi. .88

Tabela 16. Spots exclusivos obtidos em BRSGO-7560, resultantes da análise comparativa inter cultivares entre BRSGO-7560 e MSOY-8001 na condição inoculada (I) com P. pachyrhizi. 90

Tabela 17. Spots com abundância relativa aumentada obtidos na análise comparativa inter cultivares entre MSOY-8001 e BRSGO-7560 na condição inoculada com $P$. pachyrhizi..... 91

Tabela 18. Spot exclusivo obtido em MSOY-8001, resultante da análise comparativa inter cultivares entre MSOY-8001 (cultivar suscetível) e BRSGO-7560 (cultivar resistente) na condição inoculada (I) 92 


\section{LISTA DE FIGURAS}

Figura 1. Ciclo da ferrugem asiática da soja (Phakopsora pachyrhizi) (Blum, 2016 - não

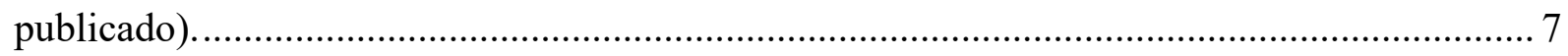

Figura 2. Fluxograma das etapas experimentais adotadas durante o estudo proteômico realizado com folhas de duas cultivares de soja não inoculada (NI) e inoculada com o fungo Phakopsora pachyrhizi.

Figura 3. Plantas das cultivares de soja BRSGO-7560 e MSOY-8001 cultivadas (V3/V4) em casa de vegetação. 28

Figura 4. Fluxograma das análises após espectrometria de massas. 40

Figura 5. Mapa proteômico de folhas de soja da cultivar BRSGO-7560 obtido por eletroforese bidimensional resultante da análise intra cultivar a partir de plantas não inoculadas (NI) e inoculadas com P. pachyrhizi. Os spots com abundância relativa aumentada significativos estão identificados pelo número Match ID e circundados em verde.

Figura 6. Mapa proteômico de folhas de soja da cultivar BRSGO-7560 obtido por eletroforese bidimensional resultantes da análise intra cultivar a partir de plantas não inoculadas (NI) e inoculadas (I) com P. pachyrhizi. Os spots exclusivos estão identificados pelo número Match ID e circundados em azul.

Figura 7. Mapa proteômico de folhas de soja da cultivar MSOY-8001 obtido por eletroforese bidimensional resultantes da análise intra cultivar de plantas não inoculadas (NI) e inoculadas (I) com P. pachyrhizi. Os spots exclusivos (presente em pelo menos 5 geis de uma condição e ausente na outra) estão identificados pelo número Match ID e circundados em verde. 44

Figura 8. Mapa proteômico de folhas de soja da cultivar MSOY-8001 obtidos por eletroforese bidimensional resultantes da análise intra cultivar de plantas não inoculadas (NI) e inoculadas (I) com P. pachyrhizi. O spot exclusivo (presente em pelo menos 5 geis de uma condição e ausente na outra) está identificado pelo número Match ID e circundado em azul. 45

Figura 9. Diagrama de Venn de proteínas com abundância relativa aumentada resultantes da análise intra cultivar para BRSGO-7560 nas condições não inoculada (NI) e inoculada (I)... 54

Figura 10. Distribuição das proteínas com abundância relativa aumentada em função de suas propriedades moleculares resultantes da análise intra cultivar de BRSGO-7560 nas condições não inoculada (NI) e inoculada (I). A-condição não inoculada; B- condição inoculada. .55

Figura 11. Distribuição das proteínas com abundância relativa aumentada em função dos processos bilógicos resultantes da análise intra cultivar de BRSGO-7560 nas condições não inoculada (NI) e inoculada (I). A-condição não inoculada; B- condição inoculada. 56

Figura 12. Distribuição das proteínas com abundância relativa aumentada em função dos compartimentos celulares resultantes da análise intra cultivar para BRSGO-7560 nas condições não inoculada (NI) e inoculada (I). A- condição não inoculada; B- condição inoculada. .57 
Figura 13. Distribuição das proteínas provenientes dos spots exclusivos em função de suas propriedades moleculares resultantes da análise intra cultivar para BRSGO-7560 nas condições não inoculada (NI) e inoculada (I). A- condição não inoculada; B- condição inoculada. ........ 58

Figura 14. Distribuição das proteínas provenientes dos spots exclusivos em função dos processos biológicos resultantes da análise intra cultivar para BRSGO-7560 nas condições não inoculada (NI) e inoculada (I). A- condição não inoculada; B- condição inoculada................5 59

Figura 15. Distribuição das proteíns provenientes dos spots exclusivos em função dos compartimentos celulares resultantes da análise intra cultivar para BRSGO-7560 nas condições não inoculada (NI) e inoculada (I). A- condição não inoculada; B- condição inoculada. 60

Figura 16. Diagrama de Venn de proteínas com abundância relativa aumentada resultantes da análise intra cultivar para MSOY-8001 nas condições não inoculada (NI) e inoculada (I).... 65

Figura 17. Diagrama de Venn de proteínas com abundância relativa aumentada resultantes da análise intra cultivar para BRSGO-7560 e MSOY-8001 nas condições não inoculada (NI) e inoculada (I).

Figura 18. Distribuição das proteínas com abundância relativa aumentada em função de suas propriedades moleculares resultantes da análise intra cultivar de MSOY-8001 nas condições não inoculada (NI) e inoculada (I). A- condição não inoculada; B- condição inoculada.

Figura 19 - Distribuição das proteínas com abundância relativa aumentada em função dos processos biológicos resultantes da análise intra cultivar para MSOY-8001 na condição não inoculada (NI).

Figura 20. Distribuição das proteínas em função dos compartimentos celulares resultantes da análise intra cultivar para MSOY-8001 na condição não inoculada (NI). .68

Figura 21. Distribuição da proteína proveniente do spot exclusivo em função de suas propriedades moleculares- análise intra cultivar para M-SOY-8001 na condição não inoculada (NI), resultante da análise comparatativa com a condição inoculada (I). 69

Figura 22. Distribuição da proteína proveniente do spot exclusivo em função dos processos biológicos- análise intra cultivar para M-SOY-8001 na condição não inoculada (NI), resultante da análise comparatativa com a condição inoculada (I). 70

Figura 23. Distribuição da proteína proveniente do spot exclusivo em função dos compartimentos celulares- análise intra cultivar para MSOY-8001 na condição não inoculada (NI), resultante da análise comparatativa com a condição inoculada (I). .70

Figura 24. Mapa proteômico de folhas de soja das cultivares BRSGO-7560 e MSOY-8001 obtidos por eletroforese bidimensional a partir de plantas não inoculadas (NI) com $P$. pachyrhizi. Os spots com abundância relativa aumentada estão identificados pelo número Match ID e circundados em verde.

Figura 25. Mapa proteômico de folhas de soja da cultivar BRSGO-7560 e MSOY-8001 obtido por eletroforese bidimensional a partir de plantas não inoculadas (NI) com P. pachyrhizi. Os spots exclusivos estão identificados pelo número Match ID e circundados em azul. 
Figura 26. Mapa proteômico de folhas de soja das cultivares BRSGO-7560 e MSOY-8001 obtidos por eletroforese bidimensional a partir de plantas inoculadas (I) com P. pachyrhizi. Os spots com abundância relativa aumentada estão identificados pelo número Match ID e circundados em verde.

Figura 27. Mapa proteômico de folhas de soja das cultivares BRSGO-7560 e MSOY-8001 obtidos por eletroforese bidimensional a partir de plantas inoculadas com P. pachyrhizi. Os spots exclusivos estão identificados pelo número Match ID e circundados em azul. 75

Figura 28. Diagrama de Venn de proteínas com abundância relativa aumentada resultantes da análise inter cultivares entre BRSGO-7560 e MSOY-8001 na condição não inoculada....... 81

Figura 29. Distribuição das proteínas com abundância relativa aumentada em função de suas propriedades moleculares resultantes da análise inter cultivares entre BRSGO-7560 e MSOY8001 na condição não inoculada (NI). A- não inoculada (BRSGO-7560); B- não inoculada (MSOY-8001). 82

Figura 30. Distribuição das proteínas com abundância relativa aumentada em função dos processos biológicos resultantes da análise inter cultivares entre BRSGO-7560 e MSOY-8001 na condição não inoculada (NI). A- não inoculada (BRSGO-7560); B- não inoculada (MSOY8001). .83

Figura 31. Distribuição das proteínas com abundância relativa aumentada em função dos compartimentos celulares resultantes da análise inter cultivares entre BRSGO-7560 e MSOY8001 na condição não inoculada (NI). A- não inoculada (BRSGO-7560); B- não inoculada (MSOY-8001).

Figura 32. Distribuição das proteínas provenientes dos spots exclusivos em função de suas propriedades moleculares - resultante da análise inter cultivares entre BRSGO-7560 e MSOY8001 na condição não inoculada (NI).

Figura 33. Distribuição das proteínas provenientes dos spots exclusivos em função dos processos biológicos- análise inter cultivares entre BRSGO-7560 e MSOY-8001 na condição não inoculada $(\mathrm{NI})$...

Figura 34. Distribuição das proteínas em função dos compartimentos celulares - análise inter cultivares entre BRSGO-7560 e MSOY-8001 na condição não inoculada (NI). 86

Figura 35. Diagrama de Venn de proteínas com abundância relativa aumentada $(\uparrow)$ resultantes da análise inter cultivares para BRSGO-7560 e MSOY-8001 na condição inoculada (I).......93

Figura 36. Distribuição das proteínas com abundância relativa aumentada em função de suas propriedades moleculares resultantes da análise inter cultivares entre BRSGO-7560 e M-SOY 80001 na condição inoculada (I) com P. pachyrhizi. A- condição inoculada (BRSGO-7560); Bcondição inoculada (MSOY-8001).

Figura 37. Distribuição das proteínas com abundância relativa aumentada em função dos processos biológicos resultantes da análise inter cultivares entre BRSGO-7560 e MSOY-8001 na condição inoculada (I). A- condição inoculada (BRSGO-7560); B- condição inoculada (MSOY-8001). 
Figura 38. Distribuição das proteínas com abundância relativa aumentada em função dos compartimentos celulares resultantes da análise inter cultivares entre BRSGO-7560 e MSOY8001 na condição inoculada (I) com P. pachyrhizi. A- condição inoculada (BRSGO-7560); Bcondição inoculada (MSOY-8001).

Figura 39. Distribuição das proteínas provenientes dos spots exclusivos em função das suas propriedades moleculares resultantes da análise inter cultivares entre BRSGO-7560 e M-SOY 80001 na condição inoculada (I) com P. pachyrhizi. A- condição inoculada (BRSGO-7560); Bcondição inoculada (MSOY-8001).

Figura 40. Distribuição das proteínas provenientes dos spots exclusivos em função dos processos biológicos resultantes da análise inter cultivares entre BRSGO-7560 e MSOY-8001 na condição inoculada (I). 98

Figura 41. Distribuição das proteínas provenientes dos spots exclusivos em função dos compartimentos celulares resultantes da análise inter cultivares entre BRSGO-7560 e MSOY8001 na condição inoculada (I) com P. pachyrhizi. A- condição inoculada (BRSGO-7560); Bcondição inoculada (MSOY-8001).

Figura 42. Diagrama de Venn de proteínas com abundância relativa aumentada resultantes da análise inter cultivares entre BRSGO-7560 e MSOY-8001 nas condições não inoculada e inoculada com P. pachyrhizi. 100 


\section{LISTA DE ANEXOS}

Anexo 1. Análise estatística para Spots com expressão aumentada em BRSGO-7560 (NI) na condição BRSGO-7560 (NI) x BRSGO-7560 (I). 134

Anexo 2. . Análise estatística dos Spots com expressão aumentada em BRSGO-7560 (I) na condição BRSGO-7560 (I) x BRSGO-7560 (NI). 135

Anexo 3. Análise estatística dos Spots com abundância relativa aumentada em MSOY 8001 (NI) na condição MSOY 8001 (NI) x MSOY 8001 (I) 136

Anexo 4. Anexo 4. Análise estatística dos Spots com abundância relativa aumentada em MSOY 8001 (I) na condição MSOY 8001 (I) x MSOY 8001 (NI)... 136

Anexo 5. Análise estatística dos Spots com com abundância relativa aumentada em BRSGO7560 (NI) na condição BRSGO-7560 (NI) x MSOY 8001 (NI).

Anexo 6. Análise estatística dos Spots com abundância relativa aumentada em MSOY 8001 (NI) na condição MSOY 8001 (NI) x BRSGO-7560 (NI).

Anexo 7. Análise estatística dos Spots com abundância relativa aumentada em BRSGO-7560 (I) na condição BRSGO-7560 (I) x MSOY 8001 (I).

Anexo 8. . Análise estatística dos Spots com abundância relativa aumentada em MSOY 8001 (I) na condição MSOY 8001 (I) x BRSGO-7560 (I). 


\section{LISTA DE SIGLAS E ABREVIATURAS}

ATP- Adenosin Triphosphate

2DE- Eletroforese bidimensional

BLAST- (Basic Local Alignment Search Tool (Ferramenta Básica de Busca por Alinhamento Local)

BSA- Bovine Serum Albumin (Soro Albumina Bovina)

CBB- Coomassie brilliant blue

DTT- Ditiotreitol

EDTA- Ethylenediaminetetraacetic acid (Ácido Etileno-diamino-tetraacético)

ESI-TOF- Electrospray - time of flight

FDR- False Discovery rate (Taxa de Identificações Falsas)

HPLC- High Performance Liquid Chromatography

IEF: Isoelectric Focusing

IPG Immobilized pH gradient (Gradiente Imobilizado de $\mathrm{pH}$ )

HSP- Heat shock protein

IPG- Immobilized pH gradient

kDa- Kilodalton

LC-MS/MS- Liquid Chromatography Coupled to Tandem Mass Spectrometry (Cromatografia Líquida Acoplada a Espectrometria de Massa em Tandem)

MALDI- Matrix-Assisted Laser Desorption/Ionization (Ionização por Dessorção a Laser Assitida por Matriz)

MALDI-TOF- Matrix Assisted Laser Desorption Timeof Flight

mM- milimolar

MW-Molecular weight

MS- Mass Spectrometry (Espectrometria de Massa) 
PEP- Posterior Error Probability of the identification

PMF- Peptide Mass Fingerprints

PTM- Post-translational modification

ROS- Reactive Oxygen Species

RuBisCo- Ribulose bisphospahte Carboxylase Oxygenase

SDS- Sodium dodecyl sulphate (Dodecil Sulfato de Sódio)

SOD- Superoxide Dismutase

TFA- Acid Trifluoroacétic

TOF- Time of Flight (Tempo de Voo)

$\boldsymbol{\mu} \mathbf{L}-$ microlitro 


\section{ÍNDICE}

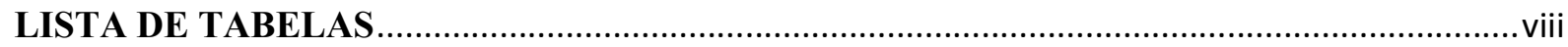

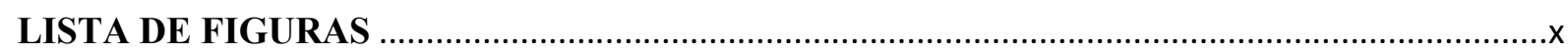

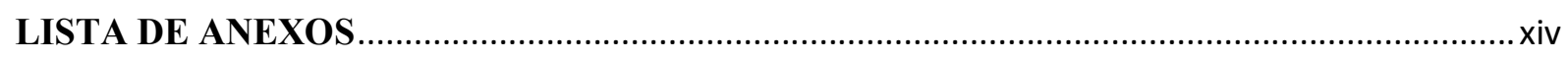

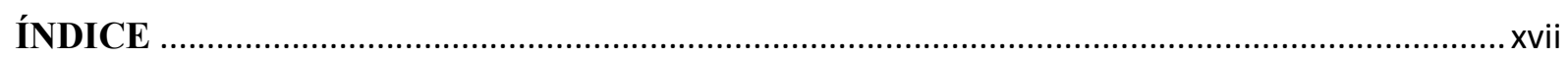

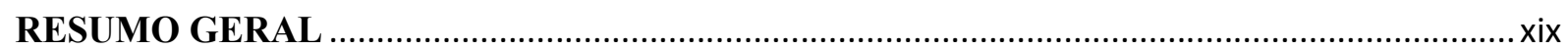

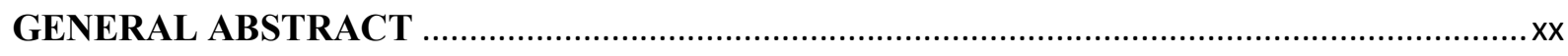

1. INTRODUÇÃ

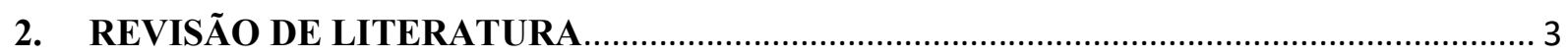

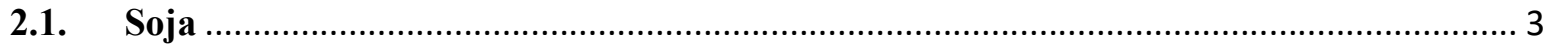

2.2. Ferrugem asiática da soja (Phakopsora pachyrhizi) .................................................. 4

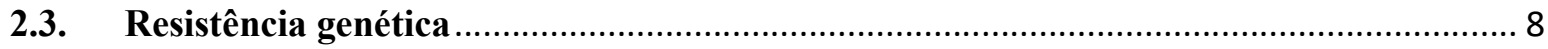

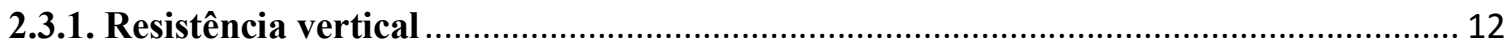

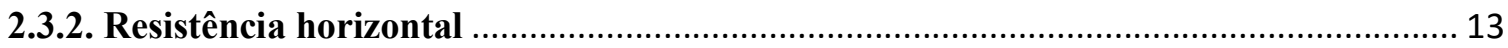

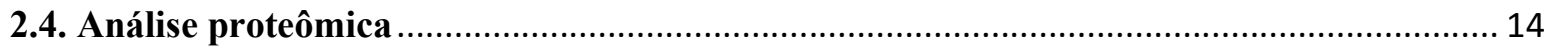

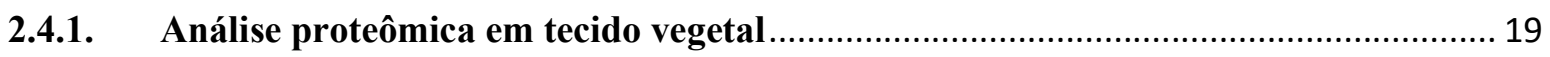

2.4.2. Proteômica na interação soja e fungos ..................................................................... 21

2.4.2.1. Ferrugem asiática da soja (Phakopsora pachyrhizi) ......................................... 21

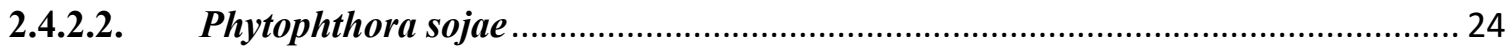

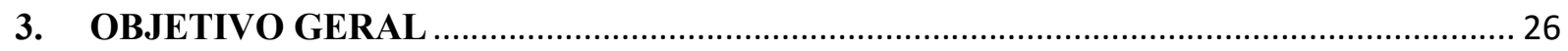

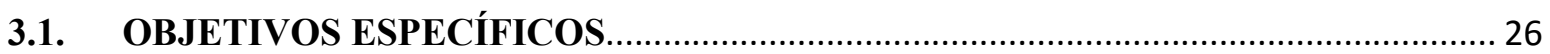

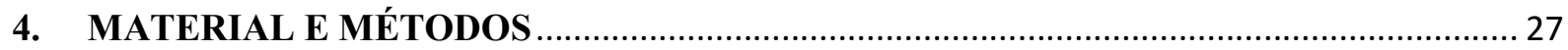

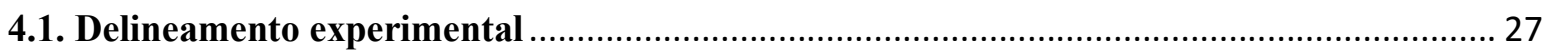

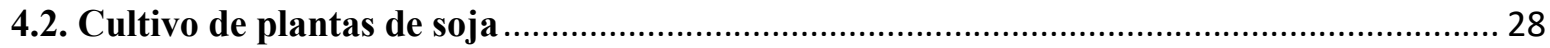

4.3. Coleta de folhas e inoculação das cultivares de soja com $P$. pachyrhizi............................... 28

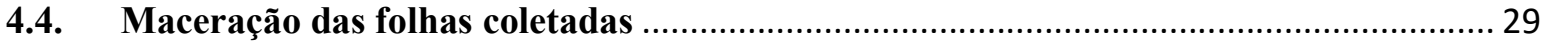

4.5. Extração de proteínas de folhas de soja ………………................................................. 29

4.6. Quantificação de proteínas extraídas de folhas de soja ............................................... 30

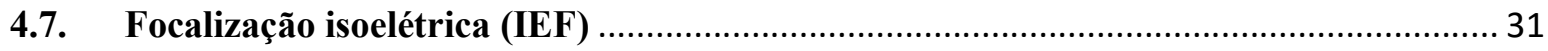

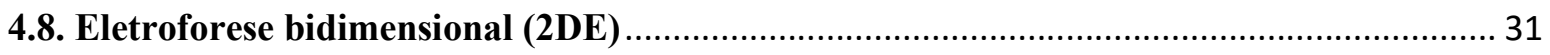

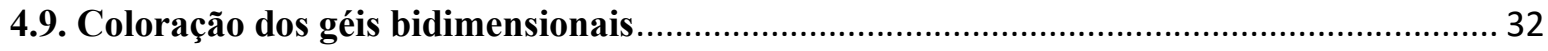




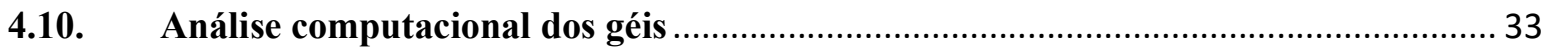

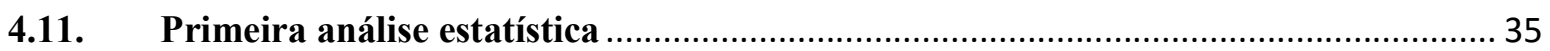

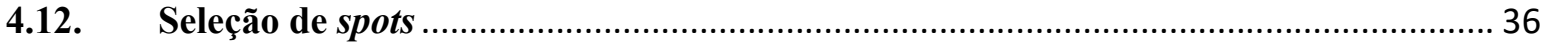

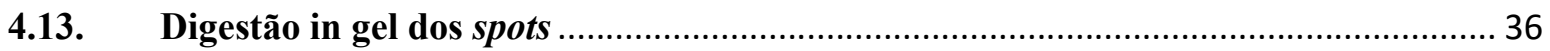

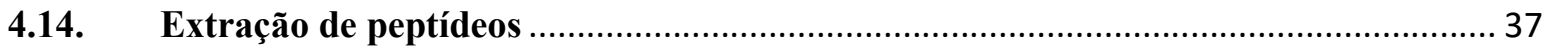

4.15. Análise dos peptídeos por espectrometria de massas ................................................ 37

4.16. Segunda análise estatística após espectrometria de massas..................................... 38

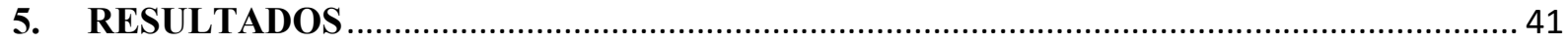

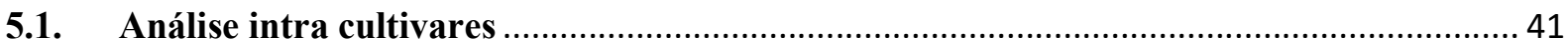

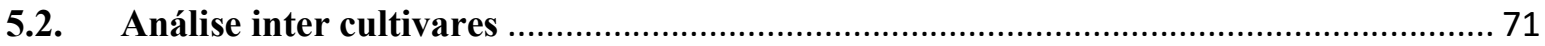

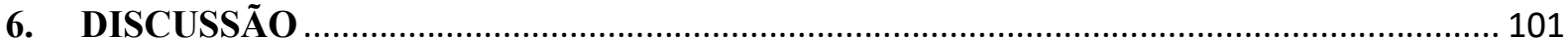

6.1. Proteínas com abundância relativa diferencial identificadas a partir dos mapas

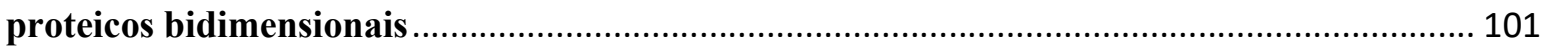

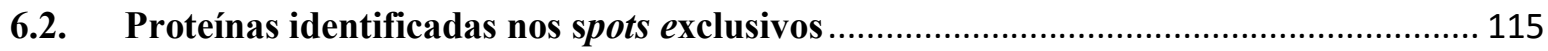

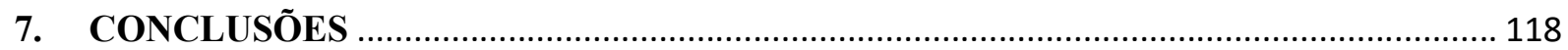

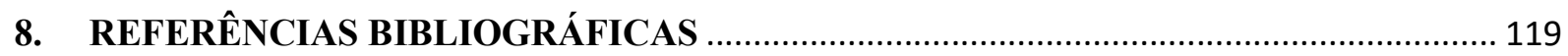

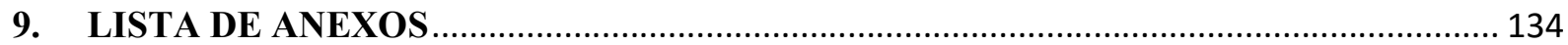




\section{RESUMO GERAL}

FIGUEIRÓ, G.G. Análise proteômica comparativa de cultivares de soja (Glycine max) suscetível e resistente à ferrugem asiática (Phakopsora pachyrhizi). 2016. 160 p. Tese (Doutorado) -Departamento de Fitopatologia/Instituto de Ciências Biológicas. Universidade de Brasília, Brasília, DF. 2016.

A cultura da soja (Glycine max) é afetada negativamente por uma variedade de fatores abióticos e bióticos. Entre os fatores bióticos, destacam-se as doenças e, entre elas, a ferrugemasiática da soja, causada pelo fungo Phakopsora pachyrhizi. De modo a contribuir no entendimento das relações planta-patógeno, um estudo proteômico foi proposto a fim de verificar proteínas envolvidas na defesa da planta contra este patógeno, o qual tem causado grandes perdas sobre esta cultura. Duas cultivares de soja foram utilizadas: BRSGO-7560 (resistente) e M-SOY-8001 (suscetível). No estádio V3/V4, folhas de plantas de ambas as cultivares na condição não inoculada foram coletas e também inoculadas com P. pachyrhizi, as quais foram coletas setes dias após a inoculação. As folhas coletadas em ambas as condições foram submetidas à extração de proteínas na presença de TCA/acetona. Mapas proteômicos bidimensionais (pI 4 a 7) a partir de folhas foram gerados nas condições não inoculada e inoculada, a fim de correlacionar os proteomas de ambas as cultivares visando à identificação de proteínas com abundância relativa significativa. Os peptídeos foram identificados por cromatografia líquida acoplada à espectrometria de massas (LC-MS/MS). Neste estudo foram encontradas proteínas relacionadas à defesa contra o patóteno, tais como: proteínas de choque térmico (HSP70), 1-desoxi-D-xilulose-5-fosfato reductoisomerase, glutamina sintetase, glutationa S-transferase classe DHAR, superóxido dismutase, proteína cloroplástica potencializadora de oxigênio, frutose-bifosfato aldolase, ascorbato peroxidase 1 citosólica e anidrase carbônica. Os resultados obtidos indicam a estratégia proteômica como uma abordagem a ser explorada no estudo das interações planta-patógeno.

Palavras chave: Glycine max, proteína, eletroforese bidimensional, espectrometria de massa. 


\section{GENERAL ABSTRACT}

FIGUEIRÓ, G.G. Comparative proteomic analysis of soybean (Glycine max) susceptible and resistant to Asian rust (Phakopsora pachyrhizi). 2016. 160 p. Tese (Doutorado)Departamento de Fitopatologia/Instituto de Ciências Biológicas. Universidade de Brasília, Brasília, DF. 2016.

Soybean (Glycine max) is negatively affected by a variety of abiotic and biotic factors. Among the biotic factors, soybean Asian rust, caused by Phakopsora pachyrhizi stands out. In order to contribute to the understanding of this plant-pathogen interaction, a proteomic study was proposed to verify proteins involved in plant defense against this pathogen. Two soybean cultivars were used: BRSGO-7560 (resistant) and M-SOY-8001 (susceptible). In stage V3/V4, leaves of both cultivars not inoculated were colleted and to inoculated with $P$. pachyrhizi, seven days after inoculation leaves were collected and subjected to protein extraction in the presence of TCA / acetone. Two dimensional proteomic maps (pI 4 to 7) from leaves were generated in non-inoculated and inoculated condition, with the objective to correlate the proteomes of both cultivars of proteins with significant relative abundance. Peptides were identified by liquid chromatography coupled to mass spectrometry (LC-MS /MS). In this study were observed proteins related to defense against the pathogen, such as: heat shock proteins (HSP70), 1Deoxy-D-xylulose 5-phosphate reductoisomerase, glutamine synthetase, DHAR class glutathione S-transferase, superoxide dismutase, oxygen-evolving enhancer protein chloroplastic, fructose-bisphosphate aldolase, cytosolic ascorbate peroxidase 1 and carbonic anhydrase. The results obtained are supported in the literature and indicate proteomics strategy as an approach to be explored in the study of plant-pathogen interactions.

Key words: Glycine max, protein, 2-dimensional electrophoresis, mass spectrometry. 


\section{INTRODUÇÃO}

Atualmente, o Brasil ocupa o segundo lugar na produção mundial de soja. Na safra 2014/2015, a produção de soja atingiu 96,243 milhões de toneladas em 32,093 milhões de hectares (CONAB, 2015). O cultivo da soja está concentrado nas regiões Centro-Oeste e Sul tendo como maior produtor brasileiro o Estado do Mato Grosso (CONAB, 2015). Logo, esta cultura que apresenta uma grande importância econômica para o país merece atenção especial dos órgãos e instituições públicas e privadas que desenvolvem ações voltadas ao aumento da produção agrícola do país, bem como, à oferta de cultivares mais resistentes às principais patologias presentes no território nacional.

A produção global de soja em 2016/2017 está projetada para 324,2 milhões de toneladas, com um aumento de até 8,3 milhões em relação a 2015/2016. A lavoura de soja do Brasil está estimada em 103 milhões de toneladas, com até 4 toneladas de incremento (WASDE, 2016).

O desenvolvimento da soja, a produtividade e a qualidade das sementes são negativamente afetadas por uma grande variedade de fatores, tanto abióticos como bióticos (GUTIERREZ-GONZALEZ et al. 2010; MANAVALAN et al. 2009; ZHANG et al., 2001). Entre os fatores bióticos destacam-se as doenças. A ferrugem-asiática da soja (promovida pelo fungo Phakopsora pachyrhizi), é uma das doenças mais severas que incide sobre a cultura da soja, com danos variando de $10 \%$ a $90 \%$ nas diversas regiões geográficas onde foi relatada (SINCLAIR; HARTMAN, 1999; YORINORI et al., 2005).

Tendo em vista as perdas geradas por esta doença na cultura da soja, o presente estudo busca contribuir no entendimento das relações planta-patógeno, de modo a identificar possíveis proteínas envolvidas na defesa da planta, para em estudos futuros intervir nos danos causados por tal doença. 
A estratégia proteômica permite a identificação de proteínas diferencialmente expressas que podem possuir papel relevante na defesa da soja contra este patógeno (AEBERSOLD; MANN, 2003).

As informações a respeito da interacão molecular entre a soja e patógeno $P$. pachyrhizi e as defesas desencadeadas via reconhecimento do patógeno por uma abordagem proteômica são escassas. Diante disso, compreender os mecanismos envolvidos nesta interação é de fundamental importância para planejar estratégias para o controle desta importante doença. 


\section{REVISÃO DE LITERATURA}

\subsection{Soja}

A soja, Glycine $\max ($ L.) Merrill, é originária da China e pertence à família Fabaceae (BROMFIELD, 1984). Tal espécie é uma fonte de proteínas, óleos, nutrientes minerais, e produtos naturais, como isoflavonóides que são benéficos à sáude humana. Os produtos derivados da soja são utilizados em grande escala como fonte de proteína e óleo vegetal no consumo humano, além de sua utilização como suplemtento protéico na alimentação industrial de aves e suínos (GEPTS et al. 2005; O’BRIAN; VANCE, 2007; TRAN; NGUYEN, 2009). A soja também é um dos principais produtos com beneficios secundários, como uso industrial e aplicações farmacêuticas (DURANTI, 2006). Além disso, recentemente, a soja surgiu como uma alternativa para a produção de biodiesel (HILL et al., 2006).

Os maiores produtores de soja do mundo são os Estados Unidos, Brasil, Argentina, seguido pela China e Índia (USDA, 2016). No contexto das grandes culturas produtoras de grãos, a soja foi a que mais cresceu em termos percentuais desde a década de 1970, tanto no Brasil quanto no mundo.

No Brasil, a partir dos anos 70 a produção da soja passou a ter grande relevância para o agronegócio, verificada pelo aumento das áreas cultivadas e, principalmente, pelo incremento da produtividade pela utilização de novas tecnologias (LAZZZAROTTO; HIRAKURI, 2010). O Brasil é o segundo maior produtor, processador mundial da soja em grão do mundo e o segundo exportador mundial de soja, farelo e óleo, garantindo ao país um papel de grande potencial para o produto.

Na safra 2014/2015 a produção mudial de soja foi de cerca de 317 milhões de toneladas, sendo que a produção brasileira, a segunda maior do mundo, foi de aproximadamente 95 
milhões de toneladas. Os estados do Mato Grosso, Paraná e Rio Grande do Sul, nesta ordem, são os maiores produtores nacionais de soja (EMBRAPA, 2016)

A expansão do plantio de soja nas regiões de fronteira agrícola foi, em grande parte, impulsionada pelo domínio das tecnologias de produção no Cerrado, pela abundância de crédito para a compra de máquinas e equipamentos, e também pelo crédito privado para o custeio da produção (BRASIL, 2007). A cultura da soja representa a maior área cultivada no Brasil. Na safra de 2014/2015 a área cultivada foi superior a 32 milhões de hectares, sendo atualmente a principal ‘commodity’ agrícola brasileira (CONAB, 2015). A produção de soja no país assume grande valor sócio-econômico, devido à importância de seus produtos, principalmente farelo, óleo vegetal e seus derivados, tanto para o mercado interno como externo. O Brasil se destaca com um dos principais exportadores de soja do mundo, estando em segundo lugar na posição mundial, logo após a Argentina (USDA, 2016).

\subsection{Ferrugem asiática da soja (Phakopsora pachyrhizi)}

A soja é a espécies mais importante economicamente afetada pela ferrugem asiática, doença causada pelo fungo Phakopsora pachyrhizi. O patógeno pertence ao filo Basidiomycota, subfilo Pucciniomycotina, Classe Pucciniomycetes, Ordem Pucciniales, Família Phakopsoraceae, Gênero Phakopsora (BROMFIELD, 1984; KIRK et al., 2008; INDEX FUNGORUM, 2016).

Esta doença, foi descrita primeiramente no Japão em 1902 (HENNINGS, 1903). Em 1994, P. pachyrhizi foi descoberta em soja no Hawaí (KILLGORE et al., 1994). Em 1996 a doença foi detectada pela primeira vez na África central, e em 2001, espalhou-se pela África do Sul (LEVY, 2005). Em 2001 também foi descoberta no Paraguay (MOREL; YORINORI, 2002) e Argentina (ROSSI, 2003), no mesmo ano foi encontrada no Brasil.

A ferrugem asiática da soja foi detectada pela primeira vez no Brasil no final da safra 2000/2001. Na safra 2001/2002 foi relatada nas principais regiões produtoras, desde o Rio 
Grande do Sul até o Mato Grosso, onde nos casos mais severos, as perdas atingiram até 70\% (YORINORI, 2002). Na safra seguinte disseminou-se praticamente por todas as regiões produtoras de soja, representando uma ameaça para cultura em função dos prejuízos causados e do aumento do custo de produção para seu controle (EMBRAPA, 2006). Até o ano de 2004, a ferrugem asiática da soja já havia sido detectada em todas as regiões produtoras de soja do Brasil, ao sul do equador (YORINORI et al., 2004).

Em novembro de 2004, o Departamento de Agricultura de Louisiania e o Departamento de Agricultura dos EUA (USDA) informaram o primeiro caso documentado da ferrugem asiática da soja nos Estados Unidos, o qual foi confirmado por reação em cadeia de polimerase (PCR) (SCHNEIDER et al., 2005). Desde então, secretarias estaduais de agricultura, universidades, grupos da indústria e o USDA têm colaborado em conjunto para diminuir qualquer possível impacto da doença para a indústria de soja dos EUA (BONDE et al., 2007).

Phakopsora pachyrhizi realiza penetração direta na planta através da cutícula utilizando digestão enzimática e força física (BONDE et al., 2008); EDWARDS; BONDE, 2008). A maioria das ferrugens penetram através de estômatos usando força física, enquanto que outros fungos entram por digestão enzimática da parede celular (AHERN, 2004; POSADABUITRAGO; FREDERICK, 2005). Este patógeno tem uma ampla gama de hospedeiros que inclui mais de 150 espécies em pelo menos 25 gêneros (SLAMINKO et al., 2008). É capaz de infectar uma grande variedade de plantas da família Leguminoseae (SLAMINKO et al., 2008, BONDE et al., 2008). Incluem-se nesta lista muitas plantas daninhas que podem servir como um importante hospedeiro na entre safra, a mais significativa no sudeste dos Estados Unidos é a leguminosa kudzu (Pueraria spp.) (MAGAREY et al., 2007; PIVONIA; YANG, 2004). No Paraguai kudzu também é uma importante hospedeira, por ser uma planta perene amplamente estabelecida e altamente suscétivel à ferrugem (ALMEIDA et al, 2005). 
Dois tipos de esporos são conhecidos em P. pachyrhizi: uredósporos e teliósporos. Os uredósporos (15-24 $\mu \mathrm{m} \times 18-34 \mu \mathrm{m})$ são os mais comuns, os quais constituem a fase epidêmica da doença. Estes são ovoides a elípticos, largos, densamente equinulados e variando de incolor a castanho-amarelo pálido. Os sintomas iniciais da doença são pequenas pústulas foliares, de coloração castanha a marrom-escura. Na face inferior da folha, pode-se observar uma ou mais urédias que se rompem liberando os uredósporos. Um maior número de urédias desenvolvemse na face inferior do que na face superior do folíolo de soja (REIS et al., 2002). As lesões tendem para o formato angular e podem atingir 2 a $5 \mathrm{~mm}$ de diâmetro, podendo aparecer em pecíolos, vagens e caules (SINCLAIR; HARTMAN, 1999).

Este patógeno é um parasita obrigatório, disseminado principalmente pela liberação dos uredósporos no ar (MARCHETTI, et al., 1976; BROMFIELD, 1984), esta liberação ocorre através do ostíolo presente nas pústulas. Uma vez depositados sobre a superfície foliar do hospedeiro, permanecem em repouso até obter condições favoráveis que conduzem ao processo de infecção (YORINORI et al., 2004; REIS et al., 2006). Na presença de água livre e de temperatura favorável, inicia o processo de germinação. As urédias podem se desenvolver de 5 a 10 dias após a infecção e os esporos do fungo podem ser produzidos por até três semanas. A taxa de progresso da doença é dependente da temperatura e água livre disponível na supefície foliar (BONDE et al., 2007). Os uredósporos exigem um mínimo de 6 horas de orvalho para infecção, com níveis ótimos que ocorrem entre 8 e 10 h (MARCHETTI et al., 1976). A infecção é favorecida por temperaturas entre 18 a $26,5^{\circ} \mathrm{C}$ e a formação de lesões entre 9 a $28^{\circ} \mathrm{C}$ (MELCHING et al., 1989). Na figura 1 há uma representação esquematizada do ciclo de vida de $P$. pachyrhizi. 


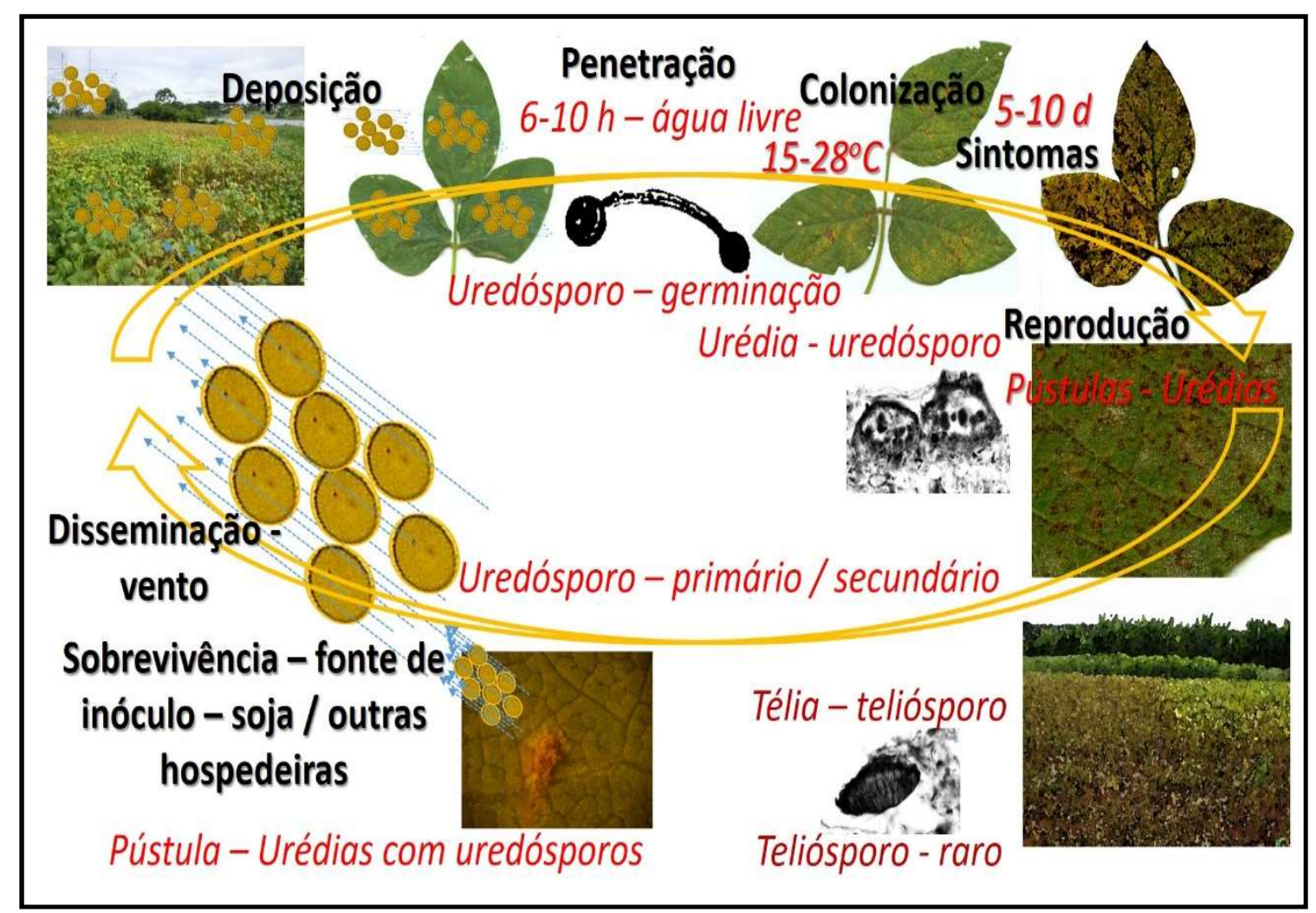

Figura 1. Ciclo da ferrugem asiática da soja (Phakopsora pachyrhizi) (Blum, 2016 - não publicado).

Na Austrália Kochman (1979) relatou que período latente foi de 14 dias numa faixa de temperatura variando de 7 a $17^{\circ} \mathrm{C}$, nove dias na faixa de 17 a $27^{\circ} \mathrm{C}$ e 11 dias na faixa de 22 a $32^{\circ}$ C. Já, no Brasil, Reis et al. (2006) relataram que $P$. pachyrhizi produz urédias 28 dias após a inoculação e que uma urédia individual pode produzir uredosporos durante 21 dias, paralisando o processo após 27 dias.

A formação de teliosporos por P. pachyrhizi é rara (Yeh et al., 1981), todavia, Dufresne et al. (1987) estudaram o efeito da temperatura e da intensidade de luz em dois isolados do fungo. Os autores encontraram que o isolado de Taiwan produziu telias aos 23 dias após a inoculação, enquanto que o isolado de Porto Rico produziu os teliosporos após 38 dias. As condições que induziram a formação de telias foram baixa intensidade de luz e temperatura de $10^{\circ} \mathrm{C}$. Sousa et al. (2006) relatam que a presença de telias se iniciou aos 15 dias a $15^{\circ} \mathrm{C}$.

Os sintomas da ferrugem podem surgir em qualquer momento do ciclo de desenvolvimento da cultura (AZEVEDO et al., 2004). Porém, a infecção que se inicia no estádio 
fenológico reprodutivo (R1/R2) da soja, é observado aumento significativo do dano, embora a ocorrência da doença em estádios mais avançados também possa acarretar danos muito elevados (AZEVEDO et al, 2004; YORINORI, 2004). Plantas severamente infectadas apresentam desfolha precoce, comprometendo a formação e o enchimento de vagens e o peso final do grão. Quanto mais cedo ocorrer a desfolha, menor será o tamanho do grão e, conseqüentemente, maior a perda de rendimento e de qualidade (YANG et al., 1991).

Para reduzir o risco de danos à cultura, as estratégias de manejo recomendadas no Brasil para essa doença são: a utilização de cultivares de ciclo precoce e semeaduras no início da época recomendada, a eliminação de plantas voluntárias de soja e a ausência de cultivo de soja na entressafra por meio do vazio sanitário, o monitoramento da lavoura desde o início do desenvolvimento da cultura, a utilização de fungicidas no aparecimento dos sintomas ou preventivamente e a utilização de cultivares resistentes, quando disponíveis (TECNOLOGIAS, 2011). A ferrugem asiática podem ser controlada pelo o uso de alguns fungicidas com diferentes modo de açõa (MILES et al., 2006). Os fungicidas dos grupos dos triazóis e estrobilurinas têm se mostrado mais eficientes para o controle da doença (GODOY et al, 2012). Porém, a aplicação em momento inadequado, assim como o uso indevido do produto, resulta em aumento do custo de produção ou controle deficiente (YORINORI, 2005). Os fungicidas representam uma das ferramentas para o controle da ferrugem, mas para que o controle seja eficiente, as demais estratégias devem ser adotadas (GODOY et al., 2012).

\subsection{Resistência genética}

A disponibilidade de cultivares parcialmente resisitentes, resistentes e tolerantes é importante no controle integrado da ferrugem asiática da soja. Resistência genética pode ser definida como a habilidade da planta para impedir ou superar, completamente ou em certo grau, o efeito de um patógeno ou outro fator danoso (AGRIOS, 1997). Enquanto a tolerância é 
capacidade apresentada por plantas que mesmo sofrendo o mesmo grau de intensidade de doença que outras plantas, apresenta menos danos quantitativos e qualitativos de produção (ROBINSON, 1969; SCHAFER, 1970).

As pesquisas têm-se empenhado na obtenção de cultivares resistentes. Seis genes dominantes, denominados Rppl (MCLEAN; BYTH, 1980), Rpp2 (BROMFIELD; HARTWIG, 1980), Rpp3 (HARTWIG; BROMFIELD, 1983), Rpp4 (HARTWIG, 1986) Rpp5 (GARCIA et al., 2008), e Rpp6 (LI et al., 2012), que condicionam a resistência vertical (qualitativa), já foram relatados na literatura, mas a estabilidade desse tipo de resistência pode não ser durável, quando testada em campo (HARTMAN et al., 2005). Deste modo, a busca por genótipos que possam ser utilizados como fontes para a resistência horizontal (quantitativa) certamente contribuirá para o aumento da longevidade das cultivares lançadas no mercado. Alguns autores mencionam a necessidade de busca de genótipos que possuam resistência horizontal ou taxa reduzida de progresso da doença (BERGAMIN FILHO; AMORIN, 1996; HARTMAN et al., 2005), em razão da alta capacidade de adaptação e presença de fatores múltiplos de virulência da $P$. pachyrhizi (BURDON; SPEER, 1984; TSCHANZ; WANG, 1985; YAMAOKA et al., 2002).

Todos os genes Rpp descritos já foram mapeados em cromossomos de soja (Chr), Rpp1 foi mapeado no cromossomo 18, Rpp2 no Chr 16, Rpp3 no Chr 6, Rpp4 no Chr 18 e Rpp5 no Chr 3 e em Rpp6 no Chr 18 ( (HYTEN et al. 2007, GARCIA et al. 2008, SILVA et al. 2008, HYTEN et al. 2009; LI et al., 2012).

O gene Rpp1 confere resposta imune da soja ao patógeno, pois, após a inoculação de certos isolados, as plantas não apresentaram sintomas visíveis (MILLES et al., 2006). Estas fontes de um único gene não foram durável quando utilizado em cultivares comerciais e não têm sido eficazes quando desafiados com amostras adicionais de P. pachyrhizi (BONDE et al., 2006, HARTMAN et al., 2005). A resistência conferida pelo gene Rpp2 a Rpp5 limita o crescimento e a esporulação do fungo, por meio de reação de hipersensibilidade que provoca 
lesão marrom-avermelhada visível, denominada "reddish-brown" (RB) (BONDE et al., 2006, GARCIA et al., 2008). Do ponto de vista do melhoramento genético, a planta hipersensível é altamente resistente, uma vez que o patógeno tem sua reprodução limitada, cessando o processo epidêmico no campo (CAMARGO, 1995). O chamado fenótipo "imune" é uma interação incompatível sem quaisquer sintomas visíveis da doença nas folhas do hospedeiro (BROMFIELD, 1984).

No Brasil a pesquisa para obtenção de cultivares resistentes à ferrugem da soja iniciouse em 2001, na Embrapa Soja, em Londrina-PR, quando, mediante testes em condições controladas de casa de vegetação, foram identificadas cultivares com resistência a essa doença, baseada na presença de lesões de hipersensibilidade do tipo RB, significando resistência parcial (GODOY; ARIAS, 2003; YORINORI et al., 2003).

As duas formas de resistência, a horizontal e a vertical são observadas entre os genótipos de soja, (BROMFIELD; HARTWIG, 1980). No caso da ferrugem, a maioria dos genes de resistência descritos é dominante, embora existam relatos de genes de resistência recessivos (PIEROZZI et al., 2008). Nenhuma das cultivares de soja na produção comercial atual é resistente a todos os isolados de $P$. pachyhrizi (HARTMAN et al., 2005).

Vários trabalhos relatam a existência de variabilidade genética em populações de $P$. pachyrhizi (SINCLAIR; HARTMAN,1999; YAMAOKA et al., 2002; BONDE et al., 2006). As fontes identificadas de resistência, no entanto, são todas específicas a determinados isolados do fungo (BONDE et al., 2006).

No Brasil foi constatada a existência de variabilidade genética em populações de $P$. pachyrhizi, devido à existência de tal variabilidade, a utilização de cultivares de soja com genes únicos de resistência vertical pode levar à rápida seleção de biótipos que quebrem a resistência dessas cultivares (TSCHURTSCHENTHALER et al., 2012). 
Quando a doença foi detectada pela primeira vez no Brasil, todos os genes de resistência descritos eram eficazes contra o fungo. Estudos realizados pela Embrapa Soja identificaram 11 cultivares com resistência à ferrugem (YORINORI et al., 2002), sendo essa resistência quebrada rapidamente com isolado do fungo proveniente do Mato Grosso. Das quatro fontes de resistência já descritas na literatura, apenas aquelas com os genes $R p p 2$ e $R p p 4$ permanecem resistentes à ferrugem no Brasil (ARIAS et al., 2004). Laperuta et al., 2008 verificaram a existência de 3 genótipos resistentes ao isolado do Mato Grosso com genes de resistência presente em Rpp2 e 23 genótipos com resistência ligada a novos genes.

Devido à variabilidade do patógeno, principalmente no cerrado brasileiro, a identificação de genótipos promissores em busca de fontes de resistência à ferrugem da soja deve ser realizada (YORINORI et al., 2004). A incorporação de genes de resistência em cultivares comerciais resultou no lançamento de cultivares como a soja Inox e BRSGO-7560 (SOUZA et al., 2009), na região centro-oeste do Brasil. As cultivares TMG 801, TMG 803 e TMG 7188 RR são resultados de pesquisas do Programa de Melhoramento Genético de Soja da Fundação de Apoio a Pesquisa Agropecuária de Mato Grosso (Fundação MT) e da Tropical Melhoramento Genético (TMG) (FUNDAÇÃO MT, 2012).

As cultivares TMG 801 E TMG 803 foram lançadas na safra 2009/2010 e na safra 2010/11, foi lançada a cultivar TMG 7188 RR, a Inox transgênica que trouxe embutido a tecnologia de herbicidas mais a resistência à ferrugem. A tecnologia Inox ${ }^{\circledR}$ torna mais fácil a detecção da doença na planta. Quando atacada, a planta apresenta uma reação de hipersensibilidade criando uma lesão escura que necrosa o tecido foliar ao redor do ponto de incidência, eliminando a fonte de alimento do fungo e evitando a multiplicação e esporulação. A lesão RB (Redish Brown) permite a detecção de ferrugem asiática na lavoura e facilita o manejo com aplicações de fungicidas (FUNDAÇÃO MT, 2012.). 
A cultivar de soja BRSGO-7560 indicada para os Estados de Goiás, Distrito Federal, Minas Gerais e Norte de São Paulo foi lançada em 2009 (SOUZA et al., 2009). Esta cultivar é portadora de um gene maior recessivo, que confere resistência vertical à ferrugem (EMBRAPA, 2009). Avaliada em estufas e em condições de campo, a cultivar apresentou reação de resistência à doença, resultando na formação de lesões escuras (RB). Essa cultivar apresenta reação de hipersensibilidade à infecção por $P$. pachyrhizi, resultando predominantemente na formação de lesões escuras do tipo RB com reduzida formação de esporos do patógeno, favorecendo o controle da ferrugem (EMBRAPA, 2009, FARIAS NETO et al., 2009). Os programas de melhoramento, além dos genes maiores, também buscam a resistência horizontal ou resistência de campo ou ainda a tolerância, a qual normalmente tem controle genético mais complexo baseado na ação de genes menores.

Devido a recorrente aplicação de fungicidas com o mesmo princípio ativo, a produção brasileira de soja, pode sofrer grandes danos, pois com o desenvolvimento de populações mais tolerantes do fungo aos fungicidas, consequentemente poderá ocorrer uma menor eficiência no controle da doença. Deste modo, o desenvolvimento de cultivares resistentes adaptadas às várias regiões brasileiras produtoras de soja é prioridade para os programas de melhoramento para auxiliar no manejo da doença.

\subsubsection{Resistência vertical}

Pode ser definida como resistência conferida por um ou mais genes (monogênica ou oligogênica), com expressão de genes maiores, apresentando resistência a raças específicas e normalmente revelando pouca estabilidade (VAN DER PLANK, 1982).

A obtenção de cultivares com resistência vertical à ferrugem asiática tem sido um grande desafio para pesquisa. Genes dominantes para resistência (Rpp1 -Rpp4), identificados em introduções de plantas (PI's) e cultivares, são relatados na literatura (BROMFIELD; 
HARTWIG, 1980). A recente incorporação de genes de resistência em cultivares comerciais resultou no lançamento de materiais como a soja Inox ${ }^{\circledR}$ e BRSGO-7560 (SOUZA et al., 2009), na região centro-oeste do Brasil. No entanto, a estabilidade dessa resistência é incerta, devido à grande variabilidade do patógeno.

Dessa forma, a busca por genótipos com resistência parcial à ferrugem asiática, representa uma importante estratégia no controle da doença, uma vez que a existência de raças dificulta o controle através da resistência vertical (ALMEIDA et al. 2005).

\subsubsection{Resistência horizontal}

A resistência horizontal é uniforme, condicionada por vários genes (poligênica) de pequeno efeito, raça não-específica, geralmente durável, não existindo interação diferencial entre as raças do patógeno e as variedades do hospedeiro (VAN DER PLANK, 1975).

Alguns autores mencionam a necessidade de busca de genótipos que possuam resistência horizontal ou taxa reduzida de progresso da doença (BERGAMIN FILHO; AMORIN, 1996; HARTMAN et al., 1997, HARTMAN et al 2005), em razão da alta capacidade de adaptação e presença de fatores múltiplos de virulência da P. pachyrhizi (BURDON; SPEER, 1984; TSCHANZ; WANG, 1985; YAMAOKA et al., 2002).A resistência parcial à $P$. pachyrhizi, também referido a taxa de redução da resistência, foi descrita em soja (BROMFIELD, 1980, WANG; HARTMAN, 1992. Estudos realizados por Santos et al. (2007) mostraram a presença de genes menores que conferem tolerância a ferrugem asiática da soja no germoplasma de soja brasileira. Esta informação pode ser útil para melhoristas e fitopatologistas a fim de agrupar estes genes em diferentes genótipos, com ou sem o uso de marcadores moleculares.

A busca pela resistência horizontal em plantas cultivadas é de fundamental interesse para o melhorista, pois à medida que se encontram genótipos com vários genes que 
condicionam a resistência, a probabilidade do patógeno vencer ou "quebrar" a resistência por seus mecanismos naturais de geração de variabilidade é muito pequena, por isso a resistência horizontal é caracterizada pela estabilidade e durabilidade, (MATIELLO et al., 1997).

A resistência parcial tem como característica a redução da taxa de progresso da doença, pela diminuição do número e tamanho das lesões, pela diminuição da produção de uredinosporos, e pelo aumento do período latente. Isso faz com que a população do patógeno seja reduzida, e que seja diminuída a quantidade de inoculo e, conseqüentemente, a intensidade da doença (WANG; HARTMAN, 1992). Este tipo de resistência torna-se visível após a resistência não durável ou monogênica ter sido superada por uma nova raça do patógeno (PARLEVLIET, 1997). O número médio de uredias por lesão e o diâmetro médio uredinial foram relatadas ser componentes de resistência parcial em ferrugem da soja e representam um reflexo do crescimento do fungo no tecido do hospedeiro (BONDE et al. 2006). A resistência parcial ou a resistência que reduz a taxa de infecção é também conhecida em soja para este patógeno (WANG; HARTMAN, 1992).

\subsection{Análise proteômica}

O termo proteômica foi introduzido em 1995 para descrever todas as proteínas que são expressas em um genoma (ANDERSON et al., 1996; WILLLKINS et al., 1996). A análise proteômica é uma ferramenta poderosa para a separação de um complexo de proteínas e também sua identificaçãoe, tornando-se uma parte importante da estratégia da genômica funcional subsequente (ZHEN et al., 2007).

Enquanto o termo genoma refere-se à sequência completa do DNA de um organismo, o

proteoma diz respeito ao conjunto de proteínas expressas pelo genoma ou, no caso de organismos multicelulares, como o complemento protéico expresso por um tecido ou por 
células diferenciadas (WILLKINS et al, 1997). Raciocínio análogo tem sido utilizado para definirem-se outros conjuntos moleculares como o transcriptoma e o metaboloma. Diferentemente do genoma, o proteoma varia entre os componentes (células, tecidos, fluidos) de um mesmo organismo multicelular e, considerando-se um único tipo celular, o proteoma pode variar de acordo com as condições às quais o sistema está submetido, refletindo alterações nos níveis de síntese e degradação de proteínas, e à regulação das modificações pós-traducionais das mesmas.

A partir de 1995, o estudo de proteomas, ou seja, a identificação sistemática de proteínas codificadas pelo genoma vem aumentando significativamente (LOPES, 1999). A proteômica possui inúmeras aplicações na pesquisa biológica. A recente explosão de trabalhos publicados na área proteômica ocorreu, em grande parte, graças aos avanços metodológicos relacionados à separação de proteínas por eletroforese bidimensional em géis de poliacrilamida (2D-PAGE) e, principalmente, à identificação de proteínas utilizando espectrometria de massa (AEBERSOLD; MANN, 2003). O conjunto de técnicas e estratégias proteômicas continua expandindo-se constantemente, o que tem permitido um aumento na velocidade da identificação de proteínas, do estudo de modificações pós-traducionais, e da determinação de interações moleculares que ocorrem nos sistemas biológicos. Assim, existe uma crescente aplicação da proteômica em problemas biológicos que envolvem sinalização celular e transdução de sinais moleculares como, por exemplo, a expressão de proteínas em plantas após condições de salinidade, seca, e contato com patógenos (YAN et al. 2005, SALEKDEH et al., 2002, KIM et al., 2004), indicando que a abordagem proteômica é útil para a análise de proteínas em função das alterações a que a planta é submetida.

Os dois passos clássicos principais da proteômica são a separação de proteínas por uma abordagem em gel de poliacrilamida, eletroforese bidimensional (2DPAGE) e a subsequente identificação dos spots por espectrometria de massa (MS) (XU et al., 
2006). A união destas duas técnicas pode permitir a detectar em mapas proteicos ou componentes isolados de amostras muito complexas, a presença ou ausência da expressão de proteínas específicas (MAMONE et al., 2009).

A aplicação da proteômica no melhoramento genético de plantas pode se iniciar com a detecção de proteínas responsivas aos efeitos bióticos ou abióticos. Estudos na área de estresses abióticos, como seca, temperatura (SULE et al., 2004) e salinidade (DANI et al., 2005), e estresses bióticos, como doenças (KONISHI et al., 2001) e pragas, podem empregar a análise de proteínas diferencialmente expressas, com o intuito principal de fornecer base à descoberta de novos marcadores moleculares. Muitas dessas proteínas podem revelar funções consistentes com a resposta ao estresse. O próximo passo é verificar se o comportamento das proteínas cosegrega com a característica de interesse ou com um QTL (locos de caracteres quantitativos), permitindo a integração de genes de interesse em programas de melhoramento genético assistido por marcadores moleculares ou ainda em programas que incluem a transformação genética (TOUZET et al., 1995; SALEKDEH; KOMATSU, 2007).

A proteômica surgiu no final de 1970 quando pesquisadores começaram a empregar a técnica de eletroforese bidimensional na separação de misturas complexas de proteínas (O'FARREL, 1975). Embora conhecida desde os anos 70, a eletroforese 2D só passou a ter grande notoriedade na década de 90, após uma revolução silenciosa da química de proteínas que levou à consolidação da proteômica (WILKINS et al., 1997).

A eletroforese bidimensional em gel de poliacrilamida é uma das ferramentas mais poderosas em proteômica para separação e quantificação de proteínas (NATARAJAN et al., 2005). Na eletroforese bidimensional, as proteínas são separadas na primeira dimensão de acordo com o ponto isoelétrico (pI) e e em função da massa molecular na segunda dimensão, esta é uma técnica de separação bastante empregada por pesquisadores na análise global e comparativa de proteínas (XU et al., 2006). 
A primeira separação (primeira dimensão) é a focalização isoelétrica (IEF), e a segunda dimensão (2DE) é a eletroforese em gel de poliacrilamida, chamada de SDS-PAGE. Na IEF as proteínas são separadas, através de uma alta tensão, em um gradiente de pH imobilizado em um gel de poliacrilamida até alcançarem uma posição estacionária onde a carga é zero. $\mathrm{O}$ pH no qual a proteína tem carga líquida zero é chamado de ponto isoelétrico (pI). Na 2DE, as proteínas são separadas pelo peso molecular, através de uma tensão, também em gel de poliacrilamida na presença do detergente dodecil sulfato de sódio (SDS) a fim de homogenizar as cargas dos Spots. A mobilidade eletroforética se dá de acordo com a massa molecular da proteína, sendo restringida pelo tamanho do poro da matriz de poliacrilamida empregada, de forma que as proteínas migrem em uma velocidade proporcional à sua massa molecular (O'FARREL, 1975).

A eletroforese bidimensional é um método de separação eficiente porque todas as proteínas em uma amostra são separadas simultaneamente fornecendo informações úteis sobre ponto isoelétrico (PI), massa molecular (MM), expressão, abundância relativa e modificações pós-traducionais, verificadas pela alteração da mobilidade eletroforética (PANDEY; MANN, 2000).

Para intensificar a resolução da eletroforese 2DE, a extração das proteínas pode ser realizada com ácido tricloroacético e acetona, que são úteis para minimizar a degradação protéica devido à presença de proteases e também ajudam na remoção de compostos interferentes como lipídios, pigmentos, polifenóis, entre outros (ZARKADAS et al., 2007; GÖRG et al., 2004).

O resultado da eletroforese bidimensional é um perfil de distribuição de Spots constituídos por proteínas únicas ou misturas simples de proteínas (PENNINGTON; DUNN, 2001).

A análise de imagens dos géis bidimensionais é um passo fundamental no trabalho com proteômica e tem impacto direto sobre a obtenção de dados qualitativos e quantitativos. Como 
a análise é um processo complexo e gera grandes quantidades de dados, é necessária a utilização de um software (STESSL et al., 2009). A partir da análise das imagens é possível obter os resultados relativos à comparação entre os géis. Essa etapa consiste em um trabalho minucioso para possibilitar a detecção de alterações inerentes à técnica, diferenças de colorações, concentração relativa de cada spot, dentre outros.

As principais limitações associadas à eletroforese bidimensional são a sua baixa reprodutibilidade e o pequeno poder de automação. A reprodutibilidade pode ser aumentada definindo-se as melhores condições para a eletroforese, mas a automação do processo só é possível com relação à análise de géis. Os softwares de análise de géis determinam os spots, identificam aqueles diferencialmente expressos e seus volumes, inferindo uma quantificação relativa da expressão daquela proteína em comparação ao mesmo spot de outro gel (LÓPEZ et al., 2002).

Como a automação completa é o principal alvo dos métodos para análises em larga escala, foram desenvolvidos métodos de separação livres de gel por cromatografia líquida de fase reversa acoplada à espectrometria de massas em tandem (LC/MS/MS).

A espectrometria de massas é uma técnica utilizada no estudo das massas de átomos, moléculas ou fragmentos de moléculas. De uma forma geral, a espectrometria de massas baseia-se em propriedades físicas do analito de forma a determinar a relação entre a massa e a carga (m/z) de espécies ionizadas em fase gasosa (AEBERSOLD; MANN, 2003).

A proteômica baseada em espectrometria de massa é considerada uma tecnologia indispensável para interpretar a informação codificada no genoma (AEBERSOLD; MANN, 2003). A identificação de proteínas por meio da espectrometria de massas depende da digestão proteolítica que produz uma coleção de peptídeos que são ionizados por eletronebulização ou por dessorção a laser auxiliada por matriz (PENNINGTON \& DUNN, 2001). 
A finalização do processo consiste na interpretação dos espectros gerados pelos espectrômetros de massas que é realizado por consultas a bancos de dados (XU et al., 2006) como SEQUEST e MASCOT. No MASCOT, software de identificação das proteínas e peptídeos, a proteína ao ser identificada, recebe uma pontuação (score), além de informações como o número de acesso no banco de dados (NCBI), massa molecular, ponto isoelétrico e cobertura de sequência dos espectros de massas.

\subsubsection{Análise proteômica em tecido vegetal}

Os estudos proteômicos em plantas foram iniciados com milho (Zea mays) (TOUZET et al., 1996) e Arabidopsis thaliana (SAHNOUN et al., 2000). De fato, estudos em larga escala sobre proteômica em soja começaram apenas em 2002 (HERMAN et al., 2003).

A etapa mais crítica em um estudo de proteômica é a extração das proteínas, atenção especial deve ser dada ao preparo inicial da amostra (ROSE et al., 2004). Normalmente tecidos de plantas apresentam baixas concentrações de proteínas e são ricos em compostos que podem interagir com as proteínas durante a extração (como proteases, compostos fenólicos, pigmentos e carboidratos), interferindo e reduzindo a reprodutibilidade durante a análise (CARPENTIER et al., 2005).

O processo de preparo das amostras também deve garantir o rompimento com interações macromoleculares, a manutenção das proteínas em solução durante o processo de eletroforese, como também prevenir modificações na proteína (HEBERT, 1999; RABILLOUD et al., 1997). O preparo consiste nas seguintes etapas: extração protéica da amostra utilizando tampões específicos para cada tipo de amostra; precipitação para concentrar as proteínas ali contidas e eliminação de contaminação por outras substâncias e solubilização das proteínas precipitadas (WILKINS et al., 2008). 
Os métodos mais utilizados para extração de proteínas totais em células e tecidos vegetais utilizam soluções, geralmente a base de uréia e tiouréia, ou utilizam diretamente o ácido tricloroacético (TCA)/acetona, seguido de um método de precipitação para concentrar as proteínas e eliminar os interferentes (CARPENTIER et al., 2005; NATARAJAN et al., 2005; SARAVANAN; ROSE, 2004).

Devido a grande variedade de metabolitos secundários e hidratos de carbono (por exemplo, polissacarídeos e pectinas) presentes em tecidos de soja, este é um dos principais desafios para se obter extratos de alta qualidade para análises proteômica em soja (KOMATSU; AHSAN, 2009). Embora haja uma certa dificuldades na extração de proteínas a partir de tecidos de soja, tem ocorrido substancial progresso na caracterização de proteomas de diversos tecidos de plantas de soja, tais como sementes madura, sementes em desenvolvimento, raízes, células em suspensão e folhas (HERMAN et al., 2003., HAJDUCH et al., 2005., WAN et al., 2005.,NATARAJAN et al., 2006., XU et al., 2008., SARMA et al., 2008).

A maior parte dos protocolos utilizados na extração de proteínas a partir de tecidos de soja são baseado na precipitação com fenol ou TCA/acetona (KOMATSU; AHSAN, 2009). O uso de TCA/acetona tem sido usado com sucesso em tecidos a partir de plantas jovens, no entanto, verificou-se não ser a melhor escolha para tecidos de plantas mais velhos (SARAVANAN; ROSE, 2004., CARPENTIER et al., 2005., WANG et al., 2003). Técnicas para o isolamento de proteínas e a solubilização de vários tecidos de soja já foram otimizados e indicam que existem grandes limitações e desafios na análise proteômica de tecidos de plantas de soja. 


\subsubsection{Proteômica na interação soja e fungos}

\subsubsection{Ferrugem asiática da soja (Phakopsora pachyrhizi)}

Como relatado anteriormente, a ferrugem da soja é uma doença que causa graves impactos na produção da cultura da soja. Logo, o conhecimento na interação planta-patógeno se torna essencial a fim se de buscar medidas de controle para esta importante doença. Diante disso, serão descritas algumas contribuições de trabalhos realizados na interação soja-ferrugem.

Em estudos realizados por Wang et al (2012) com folhas de cultivar de soja resistente à ferrugem (SX6907) inoculadas e não inoculadas foi possível verificar proteínas diferencialmente expressas 12 e 24 horas após a inoculação, onde 12 horas após a inoculação encontrou-se vinte proteínas super expressas e quatro sub expressas, enquanto 24 horas após foi possível verificar dezoito proteínas expressas e oito sub expressa. Estas proteínas foram identificadas pela técnica de eletroforese bidimensional (2DE) e por espectometria de massas (MALDI-TOF/TOF). As proteínas encontradas neste estudo foram classificadas em sete categorias funcionais usando os critérios descritos por Bevan et al. (1998). A maioria das proteínas foram associadas com o metabolismo dos carboidratos, fotossíntese, resposta de defesa à doença, proteínas de dobramento e montagem, vias de energia, biossíntese, bem como à proteínas desconhecidas. Com base na alteração em abundância destas proteínas, juntamente com as suas funções bioquímicas, possíveis respostas em folhas de soja resistentes à $P$. pachyrhizi foram propostas: a) eliminação de ROS, gerando o estresse oxidativo através da expressão aumentada de enzimas antioxidantes;b) facilitar a montagem e a ativação de transdução de sinal via proteínas de defesa sobre-regulada de choque térmico, bem como as chaperonas moleculares homólogas; c) fornecimento de energia suficiente para a defesa contra a infecção pelo fungo, através do reforço do catabolismo (via glicolítica e geração de ATP) e enfraquecendo o anabolismo (fotossíntese). 
Recentemente em estudos realizados por Tra et al (2015), por uma abordagem proteômica com folhas da cultivar de soja DT2000 (resistente à P. pachyrhizi). As folhas foram coletadas 9 dias após a inoculação com $P$. pachyrhizi, e as proteínas foram separadas por eletroforese bidimensional (2DE). Os spots diferencialmente expressos foram analisados por cromatografia líquida (LC) acoplada a espectrometria de massa (ESI Q TRAP MS/MS). Neste estudo 35 proteínas foram caraterizadas, e estas proteínas foram classificadas em nove grupos funcionais pelo Gene Ontology, os quais são: relacionados a fotossíntese (29\%), energia (17\%), glicólise (11\%), armazenamento $(9 \%)$, metabolismo $(8 \%)$, transporte $(8 \%)$, transcrição $(8 \%)$, defesa/doença $(8 \%)$ e desconhecidas $(6 \%)$. Entre as proteínas analisadas, três estavam relacionadas a defesa e resistência à doença: ascorbate peroxidase 2, catalase and stressinduced protein SAM22.

Da mesma forma, Pereira et al (2013) empregou análise proteômica no estudo da interação soja-ferrugem. Para tal estudo, foram empregadas 2 cultivares de soja (PI561356, resistente à ferrugem asiática e Embrapa 48, suscetível), as quais foram avaliadas 72 e 192 horas após inoculadas com P. pachyrhizi. Os perfis de proteínas nas folhas das plantas foram comparados por 2DE associada a espectrometria de massas (MALDI-TOF/TOF). No genótipo resistente PI561356, 72 horas após a inoculação, nove spots foram identificados utilizando espectros de MS de alta qualidade: proteína tumoral em translação controlada (TCTP), gama-glutamil hidrolase, subunidade pequena da proteína ribossomal S1, fator alfa 1 de alongamento, três proteínas obrigatórias da subunidade beta da Rubisco, glutamina sintetase e frutose-bisfosfatoaldolase. Para o genótipo Embrapa 48, cinco spots exibiram variação significativa em \% de volume, três dos quais foram identificados: subunidade A da gliceraldeído-3-fosfato desidrogenase (GAPDHa), 1-desoxi-D' xylulose-5-fosfato reductoisomerase (DXR) e anidrase carbônica. O nível reduzido de TCTP encontrado nas folhas do genótipo PI561356 após 72 horas da inoculação com o patógeno, evidencia a ocorrência de $\mathrm{HR}$ (reação de 
hipersensibilidade), por morte cellular programada (PCD-programmed cell death) levando-se em consideração as funções proliferativa e anti-apoptótica do TCTP. Neste trabalho os autores sugerem que um nível mais baixo de TCTP como resposta à inoculação pode ser uma resposta fisiológica e celular para induzir a apoptose em locais próximos ao local infectado pelo patógeno. Foi observado neste trabalho aumento da enzima frutose-bisfosfato-aldolase em plantas de genótipo PI561356 após 72 horas. E no caso da subunidade beta da Rubisco observou-se uma redução na sua abundância. Já na cultivar sucetível (Embrapa 48) a enzima anidrase carbônica foi altamente acumulada após 192 horas da inoculação. E estes autores citam que existem várias evidências que demonstram que a anidrase carbônica está envolvida com mecanismos de defesa moleculares das plantas contra agentes patogênicos, (PEREIRA et al., 2013).

Cooper et al (2011) analisaram as cultivares de sojaWilliams 82 (suscetível) e Williams 82 (resistente-Rpp1) 24 horas após a inoculação com $P$. pachyrhizi por um método de espectrometria de massas acoplada à cromatografia de líquida e detectaram aproximadamente 4.975 proteínas. Muitas destas proteínas identificadas apresentaram sinais de localização nuclear, homologia com fatores de transcrição e outras proteínas reguladoras nucleares, que são fosforiladas. Mudanças no acúmulo das proteínas identificadas foram comparadas com as mudanças de expressão de genes previamente relatados e muito pouca sobreposição foi encontrada. Nesse estudo, verificou-se que numerosas proteínas nucleares são afetadas após a tradução em resposta à infecção. Também observaram que os níveis da lipoxigenase e da acetilCoA sintetase diminuíram na cultivar resistente (Rpp1) comparada com a cultivar susceptível. Na cultivar suscetível Williams 82, foi verificada diminuição na quantidade de S-glicosil relacionadas a hidrolases. Por outro lado, a quantidade desta enzima teve aumento de expressão na cultivar resistente. 


\subsubsection{Phytophthora sojae}

Trabalhos proteômicos também tem sido realizado com Phythophthora sojae, importante patógeno que também ataca a cultura da soja. Zhang et al (2011) analisaram hastes de soja das cultivares Yudou 25 resistente a Phytophthora sojae e NG6255 cultivar suscetível, utilizando a técnica de eletroforese bidimensiondal (2DE) em diferentes tempos de avaliação (12, 24 e 48 horas após a inoculação). Das 51 proteínas analisadas, 46 foram identificadas, com uma taxa de sucesso na identificação de aproximadamente $84 \%$. No presente estudo, estas 46 proteínas diferencialmente expressas foram identificadas em hipocótilos de soja infectadas com P. sojae, utilizando MALDI-TOF-TOF. Os níveis de expressão de 26 proteínas foram significativamente afetados nos diferentes tempos avaliados na cultivar de soja resistente Yudou 25, onde 12 tiveram abundância relativa aumentada e 14 diminuída. Em contraste, na cultivar suscetível (NG6255), apenas 20 proteínas tiveram abundância relativa afetadas, onde 11 apresentaram aumento, e 9 foram reduzidas. Entre estas proteínas, 26\% foram relacionadas à regulação de energia, 15\% como proteínas de armazenamento, $11 \%$ de defesa contra doenças e metabolismo, $9 \%$ de proteínas de síntese, 4\% envolvidas em metabolismo secundário, e também $24 \%$ de proteínas com funções desconhecidas. Tal como nos estudos anteriores com Phakopsora pachyrhizi, as proteínas foram classificadas em 7 categorias funcionais utilizando os métodos de Bevan et al. (1998): metabolismo, energia, síntese de proteínas, proteínas de armazenamento, defesa contra doenças, metabolismo secundário, ou proteínas de função desconhecida. Na cultivar resistente, Yudou 25, as proteínas relacionadas com energia representaram 22\%, seguida por proteínas de destino/aramazenamento $15 \%$ e $11 \%$, respectivamente. Em contraste, nenhuma categoria predominou na linhagem suscetível (NG6255). As proteínas envolvidas no metabolismo, na defesa contra doenças e com função desconhecida, corresponderam a 9\% do total para cada categoria, proteínas relacionadas com a 
produção de energia a $7 \%$, proteínas de armazenamento $4 \%$ e proteínas relacionadas com metabolismo secundário com $2 \%$.

Hong-Mei et al. (2009) realizaram estudos com folhas de soja da cultivar Suinong 10 (resistente) em resposta à inoculação com o patógeno $P$. sojae em diferentes tempos de avaliação (12, 24, 36 e 48 horas após a inoculação) empregando a técnica 2DE e de espectrometria de massas MALDI-TOF-MS. Neste estudo foram detectadas 19 proteínas com expressão diferencial, nas quais 12 delas apresentaram abundância relativa aumentada e 6 reduzidas. Dentre as proteínas avaliadas, estas estavam envolvidos em 8 proteínas funcionais que foram categorizadas em 4 grupos, onde entre estas, foi observada possíveis proteínas relacionadas a defesa desta cultivar à $P$. sojae, como por exemplo, $F$-box protein envolvida em resistência mediada por ácido jasmônico. 


\section{OBJETIVO GERAL}

- Correlacionar os proteomas de plantas de soja (Glycine max) suscetíveis e resistentes à ferrugem asiática nas condições não inoculada e inoculada com o fungo Phakopsora pachyrhizi, visando à identificação de proteínas com abundância relativa significativas entre os diferentes mapas bidimensionais obtidos, a fim de identificar proteínas de defesa expressas nas plantas de soja avaliadas nas diferentes condições.

\subsection{OBJETIVOS ESPECÍFICOS}

- Obter mapas proteômicos bidimensionais de folhas de plantas suscetíveis e resistentes não inoculadas e inoculadas com o fungo causador da ferrugem asiática (Phakopsora pachyrhizi);

- Obter um padrão bidimensional de consenso para proteínas expressas por folhas de plantas de soja suscetíveis e resistentes não inoculadas e inoculadas com P. pachyrhizi;

- Identificar proteínas por meio de espectrometria de massas. 


\section{MATERIAL E MÉTODOS}

\subsection{Delineamento experimental}

O fluxograma das etapas realizadas durante a fase experimental da análise proteômica das folhas de soja das cultivares BRSGO-7560 (resistente à Phakopsora pachyrhizi) e MSOY-8001 (cultivar suscetível ao fungo), nas condições não inoculada (NI) e inoculada (I) com $P$. pachyrhizi é ilustrado abaixo (Figura 2):

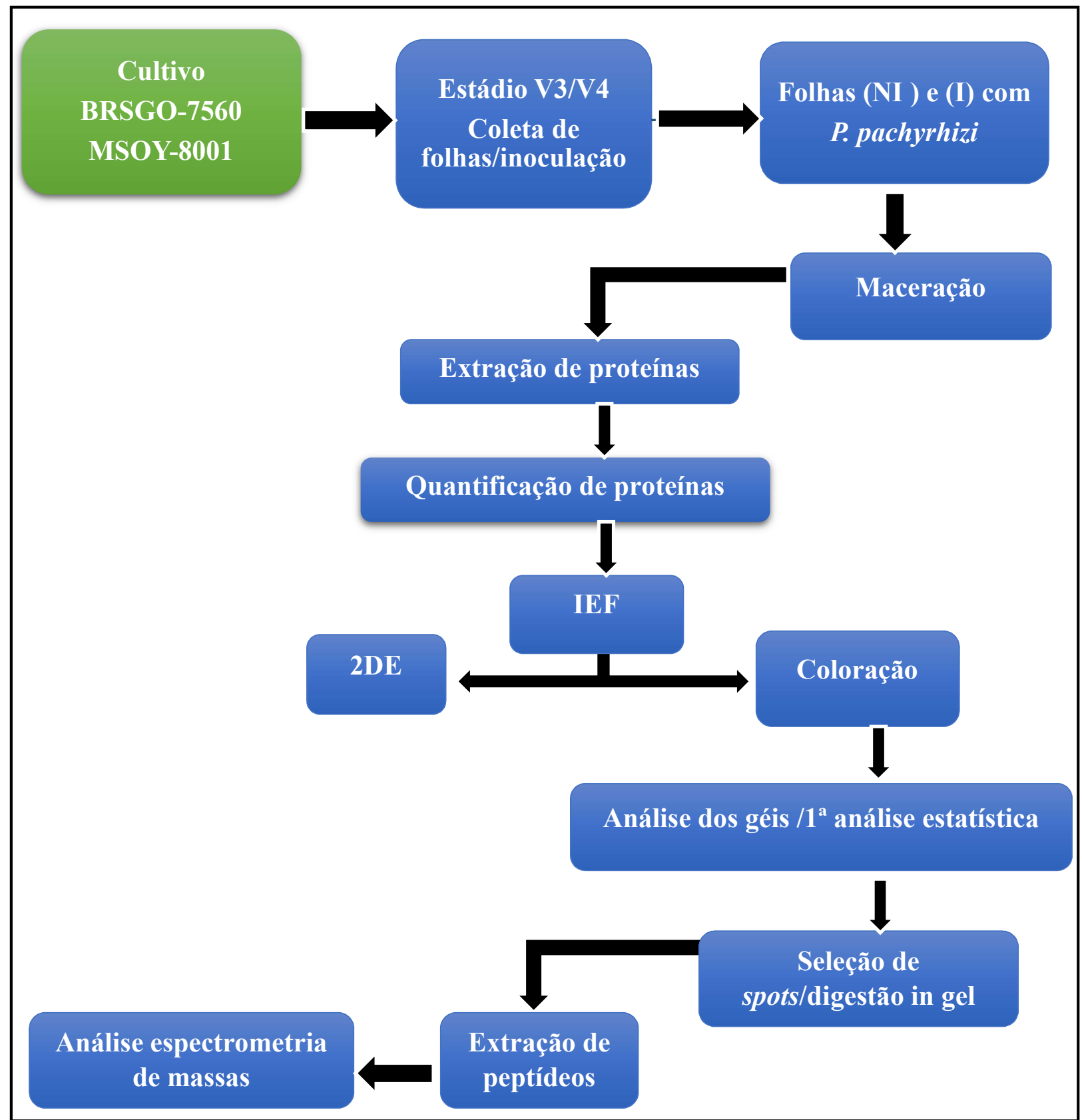

Figura 2. Fluxograma das etapas experimentais adotadas durante o estudo proteômico realizado com folhas de duas cultivares de soja não inoculada (NI) e inoculada com o fungo Phakopsora pachyrhizi. 


\subsection{Cultivo de plantas de soja}

Cultivares de soja MSOY-8001 (suscetível à P. pachyrhizi) e BRSGO-7560 (resistente à $P$. pachyrhizi) foram semeadas em vasos com capacidade para $2 \mathrm{~L}$ e cultivadas em casa de vegetação na Estação Experimental de Biologia. Solo de barranco (latossolo vermelho) sem matéria orgânica foi utilizado para preenchimento dos vasos, sendo esses acrescidos com adubo N-P-K (04-14-08) (figura 3). Foram semeadas 5 sementes por vaso, onde após o processo germinativo foi realizado o desbaste e apenas 3 plântulas de soja permaneceram em cada vaso, as quais foram irrigadas conforme necessidade até atingirem o estádio fenológico ideal para o estudo (V3/V4). Para o presente estudo foram utilizados 4 vasos para cada cultivar.

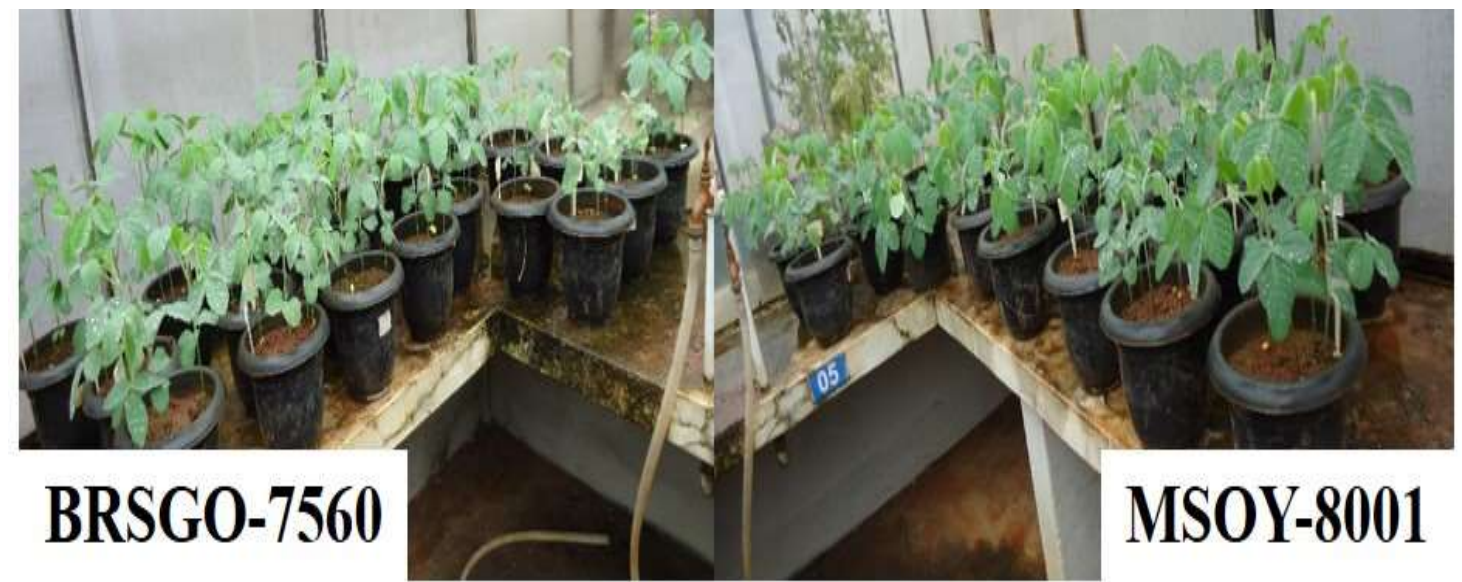

Figura 3. Plantas das cultivares de soja BRSGO-7560 e MSOY-8001 cultivadas (V3/V4) em casa de vegetação.

\subsection{Coleta de folhas e inoculação das cultivares de soja com $P$. pachyrhizi}

Ao atingir o estádio fenológico vegetativo (V3/V4), folhas de plantas de ambas as cultivares, correspondente ao trifolio V3/V4 foram coletadas, sendo coletados 6 trifólios por vaso, correspondendo a folhas coletadas em 4 vasos. As demais plantas neste mesmo estádio fenológico, foram inoculadas com suspensão de $1 \times 10^{5}$ esporos $/ \mathrm{mL}$ do patógeno $(P$. pachyrhizi), calculado com base na câmara de Neubauer. Apenas a primeira folha cotiledonar e a primeira folha trifoliolada foram inoculadas com auxílio de um pincel de cerdas macias. E 
após 7 dias da inoculação, as folhas foram coletadas na posição do trifólio V3/V4 quando as plantas já apresentavam sintomas.

Os esporos de P. pachyrhizi utilizado para inoculação foram obtidos a partir de plantas infectadas de área produtora de soja na região do núcleo de produção agrícola do Distrito Federal, próximo a Unaí-MG.

As folhas em ambas as coletas foram lavadas com água Milli-Q, enxugadas com papel absorvente, pesadas, acondicionadas em N2 líquido e, posteriormente armazenadas à $80^{\circ} \mathrm{C}$

\subsection{Maceração das folhas coletadas}

As folhas de ambas as cultivares (BRSGO-7560 e MSOY 8001) armazenadas à $-80^{\circ} \mathrm{C}$ foram maceradas em N2 líquido com auxílio de pistilo e almofariz e posteriormente acondicionadas em microtubos de polipropileno, os quais foram armazenados $\mathrm{a}-80^{\circ} \mathrm{C}$ para posterior extração das proteínas.

\subsection{Extração de proteínas de folhas de soja}

Todo o processo de extração foi baseado em metodologia adaptada de ZHANG et al (2011). A extração de proteínas foi realizada em triplicatas técnicas para cada condição e armazenadas para posterior elaboração dos géis $2 \mathrm{DE}$.

Alíquotas de $1 \mathrm{~g} / \mathrm{mL}$ de folhas maceradas de cada tratamento foram submetidas ao processo de extração em solução de TCA $10 \%$ (v/v)/ $/$-mercaptoetanol 1\% (v/v) em acetona. Os tubos foram incubados por 5 min no gelo. Em seguida, cada amostra foi submetida a três ciclos de centrifugação a $10.000 \mathrm{~g}, 4^{\circ} \mathrm{C}$ por $5 \mathrm{~min}$, até conseguir um sobrenadante límpido. O sedimento foi lavado com acetona gelada duas vezes e, em seguida, o tubo invertido foi colocado sobre 
papel absorvente até a acetona ser completamente drenada. Após a secagem da acetona, adicionou-se fenol tamponado contendo DTT $0,5 \%(\mathrm{p} / \mathrm{v})$. Os tubos foram submetidos à agitação por 10 min e, em seguida, submetidos três ciclos de centrifugação (10.000 g, $4^{\circ} \mathrm{C}$ por 5 min). Os sobrenadantes resultantes de cada centrifugação foram transferidos para novos tubos e as proteínas presentes nos sobrenadantes foram precipitadas por adição de $5 \mathrm{x}$ o volume do sobrenadante coletado de uma solução de acetato de amônio 0,1 M em metanol gelado e armazenadas a $-20^{\circ} \mathrm{C}$ por $10 \mathrm{~min}$. Posteriormente, cada amostra foi centrifugada $\left(10.000 \mathrm{~g}, 4^{\circ}\right.$ C, 5 min) e o sedimento obtido lavado em metanol gelado (3x) para remover resíduos de acetato de amônio e fenol. Este sedimento foi ressuspenso em cloridrato de guanidina $8 \mathrm{M}$ contendo DTT 10 mM para redução e alquilação com 4-vinilpiridina $100 \mathrm{mM}$, sendo mantido no escuro em mesa agitadora por $90 \mathrm{~min}$. Posteriormente a amostra foi centrifugada (10.000 g, $4^{\circ} \mathrm{C}, 5$ min) e o sobrenadante transferido para um novo tubo. Ao sobrenadante foram adicionados 5 volumes de acetona/etanol gelado (1:1) eos tubos foram incubados a $-20^{\circ} \mathrm{C}$ por 10 min para precipitação das proteínas. Em seguida, a amostra foi submetida à centrifugação $\left(10.000 \mathrm{~g}, 4^{\circ}\right.$ C, $5 \mathrm{~min}$ ), e o sobrenadante cuidadosamente descartado. O sedimento obtido foi lavado com etanol gelado (3x), para remover os resíduos de cloridrato de guanidina e armazenado a $-80{ }^{\circ} \mathrm{C}$. Este sedimento $(2 \mathrm{~g} / \mathrm{mL})$ foi ressuspenso em tampão de lise (Uréia $7 \mathrm{M}$, Tiouréia $2 \mathrm{M}$, Triton X$1001 \% \mathrm{v} / \mathrm{v}$, Pharmalyte $0,5 \% \mathrm{v} / \mathrm{v}$ e DTT $10 \%$ ) e posteriormente armazenado para utilização nas etapas subsequentes para confecção dos géis.

\subsection{Quantificação de proteínas extraídas de folhas de soja}

A quantificação de proteínas foi determinada de acordo com o método de Bradford (1976), utilizando-se BSA como padrão. Para a leitura das amostras, $300 \mu \mathrm{L}$ de cada ensaio foram adicionados em poços de microplaca. A leitura das amostras foi realizada em espectrômetro a 480nm usando água como branco. 
Uma curva de calibração foi gerada a partir dos dados obtidos na leitura das amostras, onde a equação foi empregada para estimar a concentração de proteínas em cada amostra. A quantidade de amostra padronizada após cálculos a partir da curva de calibração para os extratos de soja, foi de $450 \mu \mathrm{g}$.

\subsection{Focalização isoelétrica (IEF)}

A eletroforese em primeira dimensão (IEF) foi conduzida usando strip (IPG) de $18 \mathrm{~cm}$ com $\mathrm{pH} 4,0-7,0$. A amostra contendo $450 \mu \mathrm{g}$ de proteína foi preparada com isopropanol e tampão de lise (Uréia 7M, Tiouréia 2M, Triton 1\% v/v, Pharmalyte 0,5\% v/v e DTT 10\%), correspondendo a um volume final de $350 \mu \mathrm{L}$, posteriormente deixada sob agitação por 1 hora. Após este período, a amostra foi adicionada no sarcófago, e em seguida o strip (IPG), onde permaneceu por 1 hora para hidratação do strip no IPGPhor. Ao concluir a hidratação, foram adicionados $350 \mu \mathrm{L}$ de óleo mineral ao longo de todo o sarcófago, e em seguida, iniciou-se a IEF, onde o strip foi reidratado por $6 \mathrm{~h}$ à $20^{\circ} \mathrm{C}$, seguido da seguinte programação: $30 \mathrm{~V}$ por 4 h, $120 \mathrm{~V}$ por $2 \mathrm{~h}, 500 \mathrm{~V}$ por $1 \mathrm{~h}, 1000 \mathrm{~V}$ por $1 \mathrm{~h}, 8000 \mathrm{~V}$ por $4 \mathrm{~h}$ e $8000 \mathrm{~V}$ por $5: 30 \mathrm{~h}$, sendo utilizado $75 \mu \mathrm{A}$ por strip (ZHANG et al, 2011). Ao concluir a focalização isoelétrica, o strip foi imediatamente imerso em $6 \mathrm{~mL}$ de tampão de equilíbrio (Tris $50 \mathrm{mM} \mathrm{pH} \mathrm{8,8,} \mathrm{Uréia} 6 \mathrm{M}$, glicerol 30\% e SDS 10\%) por 30 minutos.

\subsection{Eletroforese bidimensional (2DE)}

Após a primeira dimensão, as amostras foram submetidas à eletroforese em gel de poliacrilamida $12 \%$ desnaturante. O gel de poliacrilamida é composto por duas fases, uma representada pelo chamado gel concentrador que permite a concentração das proteínas durante 
a sua entrada no gel possibilitando uma corrida eletroforética mais uniforme, e o gel separador, no qual ocorre efetivamente a separação das proteínas presentes no strip.

Um marcador de massa molecular foi aplicado em região específica (canto esquerdo do gel) e vedado com agarose $(0,3 \%$ p/v em tampão de corrida $1 \mathrm{x}$ com traços de azul de bromofenol).

Após a etapa de equilíbrio, o strip foi colocado sobre o gel concentrador e vedado com agarose. Em seguida, as placas foram colocadas na cuba contendo 2 L de tampão corrida 1x. Na parte superior do sistema, acima das placas, foram acrescentados $500 \mathrm{~mL}$ de tampão corrida 1x novo. A corrida eletroforética foi realizada utlizando-se $30 \mathrm{~mA}$ por gel e $500 \mathrm{~V}$. A evolução do processo foi acompanhado pela frente de corrida indicada pelo azul de bromofenol presente no gel de agarose. Para cada condição foram confeccionados nove géis, com um total de 36 géis.

\subsection{Coloração dos géis bidimensionais}

Após cada corrida eletroforética, os géis foram submetidos ao processo de coloração. Incialmente foram acondicionados em solução de fixação (etanol comercial $50 \% \mathrm{v} / \mathrm{v}, \mathrm{H}_{3} \mathrm{PO}_{4}$ 3\% v/v) por, no mínimo, 3 h. Em seguida, lavados com água Milli-Q (3x, por 20 minutos) e pré-incubados por $1 \mathrm{~h}$ em $150 \mathrm{~mL}$ de uma solução contendo metanol 34\% (v/v), $\mathrm{H}_{3} \mathrm{PO}_{4} 3 \%$ (v/v) e sulfato de amônio $17 \%$ (p/v). Ao concluir o tempo de pré-incubação, $50 \mathrm{~mL}$ da solução de pré-incubação contendo Comassie Brilliant Blue Coloidal (CBB coloidal) (NEWSHOLME et al., 2000) foi adicionada a cada gel. Os géis foram armazenados sob agitação por, pelo menos $24 \mathrm{~h}$, até serem visíveis os spots. 


\subsection{Análise computacional dos géis}

Os géis que apresentaram uma boa distribuição de spots por inspeção visual foram digitalizados em scanner modelo 53 Image Scan UMAX (GE Healthcare), padronizando-se o modo de captura da imagem em 300 dpi, colorida, com alta nitidez e tamanho aproximado de 7 x 7 polegadas. As imagens foram gravadas em 2 formatos (TIFF e JPG) possibilitando sua utlização em outros programas.

Para análises computacionais das imagens digitalizadas foi utilizado o software Image Master Platinum versão 5 e versão 6 (GE Heathcare). Esses programas reconhecem as imagens no formato TIFF que, em seguida, são convertidas ao formato MEL, para que a análise no Image Master Platinum versão 5 possa ser realizada (HEALTHCARE, 2004).

Para possibilitar uma posterior análise estatística confiável, as imagens foram submetidas ao seguinte procedimento: em uma primeira etapa, foi empregada a versão 5 do programa para a detecção automática dos spots por meio da qual se dá a delimitação dos spots de acordo com o programa, seguida de um refinamento manual. Como a detecção realizada pelo programa não é precisa, essa etapa serve somente para ajuste dos parâmetros iniciais, sendo realmente necessária uma revisão manual (BIRON, 2006; HEALTHCARE, 2004), por meio da qual possíveis erros resultantes da detecção automática podem ser corrigidos utilizando ferramentas disponíveis no software como, por exemplo, a visualização individual dos spots em 3D, o que facilita a separação de spots que o programa tenha detectado erroneamente.

Em uma segunda etapa foi utilizada a versão 6 do programa para fazer os pareamentos e obter parte dos dados estatísticos. Dois tipos de pareamento foram realizados: intra-classe e inter-classe, sendo as classes correspondentes às condições folhas não inoculadas e inoculadas com P. pachyrhizi de ambas as cultivares de soja e cujo objetivo foi detectar a variação da porcentagem do volume de cada spot (abundância relativa). 
Um gel referência, também chamado de gel master de cada condição (não inoculada e inoculada) de ambas as cultivares, foi escolhido adotando-se dois critérios: gel com maior quantidade de proteínas e com melhor resolução dos spots. Depois de escolhido, o pareamento do gel referência com os demais géis dentro de uma mesma classe foi realizado, conforme apresentado na tabela 1 . O segundo pareamento foi realizado entre os géis master tanto intra quanto inter-cultivares em cada condição avaliada: não inoculada e inoculada, como descrito na tabela 2.

Tabela 1. Pareamento dos géis obtidos das cultivares BRSGO-7560 e MSOY-8001 nas condições não inoculada (NI) e inoculada (I) com $P$. pachyrhizi com o gel de referência (master) no Image Master 5.

\begin{tabular}{|c|c|}
\hline \multicolumn{2}{|c|}{ Primeiro pareamento } \\
\hline Cultivares & Condição \\
\hline Gel master BRSGO-7560 & (NI) \\
\hline (Pareado com demais géis da mesma classe-8) & (I) \\
\hline Gel master BRSGO-7560 & (NI) \\
\hline (Pareado com demais géis da mesma classe-8) & (I) \\
\hline (Pareado com demaister MSOY-8001 & Géis da mesma classe-8) \\
\hline
\end{tabular}


Tabela 2. Pareamento dos géis obtidos da análise intra e inter cultivares nas condições não inoculada (NI) e inoculada (I) com $P$. pachyrhizi.

\begin{tabular}{|c|c|c|}
\hline \multicolumn{3}{|c|}{ Segundo pareamento } \\
\hline Cultivares & \multicolumn{2}{|c|}{ Condição } \\
\hline BRSGO-7560 & $(\mathrm{NI}) \times(\mathrm{I})$ & $(\mathrm{I}) \times(\mathrm{NI})$ \\
\hline MSOY-8001 & $(\mathrm{NI}) \times(\mathrm{I})$ & $(\mathrm{I}) \mathrm{x}(\mathrm{NI})$ \\
\hline $\begin{array}{l}\text { BRSGO-7560 x MSOY-8001 } \\
\text { MSOY } 8001 \text { x BRSGO-7560 }\end{array}$ & \multicolumn{2}{|c|}{$(\mathrm{NI}) \times(\mathrm{NI})$} \\
\hline $\begin{array}{l}\text { BRSGO-7560 x MSOY-8001 } \\
\text { MSOY } 8001 \text { x BRSGO-7560 }\end{array}$ & \multicolumn{2}{|c|}{ (I) $\mathrm{x}(\mathrm{I})$} \\
\hline
\end{tabular}

\subsection{Primeira análise estatística}

O programa Image Master 6 forneceu dados, por meio de tabelas, da porcentagem de volume de cada spot, de todos os géis. Esses dados foram transformados em tabelas compatíveis com o programa SPSS 13.0, sendo possível a realização dos cálculos estatísticos para avaliação da presença de proteínas em quantidades significativamente diferentes entre as duas classes. Considerando a porcentagem de volume dos spots dos géis produzidos ( 9 géis de cada condição, um deles representado pelo gel master: BRSGO-7560 não inoculada, BRSGO-7560 inoculada, MSOY-8001 não inoculada e MSOY-8001 inoculada.

Nos casos em que a distribuição foi caracterizada como normal, utilizou-se o teste t-pareado. A partir dele foi possível comparar duas variáveis, calculando primeiramente a diferença dos valores das médias entre as condições estudadas (inoculada e não inoculada), seguido do cálculo das médias das diferenças e do desvio padrão. Só depois foi possível obter a significância de cada cálculo realizado aplicando o teste de Mann-Whitney com significância estatística $\mathrm{p} \leq$ 0,05\% (SPSS, 2004), conforme anexos (1, 2, 3, 4, 5, 6, 7 e 8). Para ser significativo quanto ao 
aumento da abundância relatica, foi estabelecido a presença do mesmo spot em pelo menos 6 géis de cada condição avaliada. Os spots exclusivos também foram obtidos tanto na comparação intra cultivar quanto inter cultivares em ambas as condições avaliadas conforme critérios de Biron (2006), onde o spot deve ser considerado exclusivo quando aparecer em mais de 5 géis em uma condição, porém não pode aparecer em nenhum gel da outra condição.

\subsection{Seleção de spots}

Após a análise de imagens e teste estatístico, os spots significativos (com abundância relativa aumentada) e os exclusivos foram selecionados e cortados do gel master de cada condição com auxílio de uma pinça de ponta bem fina e armazenados em microtubos de $0,5 \mathrm{~mL}$ para posterior digestão tríptica.

\subsection{Digestão in gel dos spots}

Os spots retirados dos géis foram submetidos ao processo de digestão. Esse processo tem início com a exposição dos spots a três ciclos alternados de lavagem com água milli-Q e acetonitrila $50 \%$ com vortex entre as trocas. Posteriormte os spots foram incubados em solução descolorante contendo $15 \mathrm{mM}$ de ferricianeto de potássio e $50 \mathrm{mM}$ de tiossulfato de sódio $(50 \mu \mathrm{L})$ por cerca de dez minutos até que o gel ficasse transparente. Após o tempo de incubação o gel correspondente a cada spot foi lavado em água $(50 \mu \mathrm{L}),(2-4$ lavagens) até que o gel ficasse transparente (límpido), e em seguida foram realizados três ciclos alternados de embebição com $50 \mu \mathrm{L}$ de bicarbonato de amônia 50mmol/L (composto volátil com pH8 ótimo para atuação da tripsina, retira o SDS) e $50 \mu \mathrm{L}$ de acetonitrila $100 \%$ (desidrata o spot, retira resíduos de SDS). Na última lavagem o spot foi macerado com $60 \mu \mathrm{L}$ de acetonitrila, composto esse que facilita o processo pelo aumento da área de superfície do spot. Depois de 
macerado, o microtubo contendo o spot, foi para a centrífuga a vácuo por aproximadamente $20 \mathrm{~min}$, para que a amostra ficasse totalmente seca (CASTRO et al 2006).

$\mathrm{Na}$ etapa seguinte o gel foi hidratado em solução tampão de tripsina (50 $\mu 1 \mathrm{NH}_{4} \mathrm{HCO}_{3}$ 50mM, 2,5 $\mu \mathrm{l} \mathrm{CaCl}_{2} 200 \mathrm{mM}, 6,25 \mu \mathrm{l}$ tripsina e 41,25 $\mu 1 \mathrm{H}_{2} 0$ ) durante 45 minutos no gelo. Posteriormente, adicionou-se $10 \mu \mathrm{l}$ de tampão de digestão $\left(50 \mu 1 \mathrm{NH}_{4} \mathrm{HCO}_{3} 50 \mathrm{mM}, 2,5 \mu 1\right.$ $\mathrm{CaCl}_{2} 200 \mathrm{mM}, 47,5 \mu 1 \mathrm{H}_{2} 0$ ), e o gel foi incubado a $37^{\circ} \mathrm{C}$ overninght entre por 12 horas. Após a digestão, as amostras foram secas na centrífuga a vácuo.

\subsection{Extração de peptídeos}

A extração de peptídeos foi iniciada com a ressuspensão das amostras em $40 \mu \mathrm{L}$ de TFA 0,1\% (v/v), agitação em vórtex e centrifugação a $14.000 \mathrm{rpm}$ por $10 \mathrm{~min}$. O sobrenadante obtido para cada amostra foi filtrado em micro-coluna (feita com ponteira com plug de $\mathrm{C}_{8}$ ), eluindo todo o volume em uma placa de 96 poços. A micro-coluna foi lavada com TFA 0,1\% (v/v) em acetonitrila $70 \%$ (v/v), coletando o material eluído no mesmo poço. A placa com as amostras foi seca em Speed-Vac. Em seguida, as amostras foram ressuspendidas em $1 \mu \mathrm{L}$ de TFA 5\% (v/v) em DMSO 50\% (v/v) com acréscimo de $4 \mu \mathrm{L}$ de água Milli Q. A placa foi transferida para o amostrador automático acoplado ao HPLC concetado ao espectrômetro de massas tipo LTQ Orbitrap Velos. (Thermo Scientific).

\subsection{Análise dos peptídeos por espectrometria de massas}

Os peptídeos foram identificados por cromatografia líquida acoplada à espectrometria de massas (LC-MS/MS), sendo o procedimento repetido de forma automatizada para os peptídeos extraídos do sistema de digestão obtidos de cada Spot selecionado. Alíquotas de $1 \mu \mathrm{g}$ de peptídeos diluídos em $5 \mu \mathrm{L}$ de TFA 1\% (v/v) em DMSO 10\% (v/v) foram aplicadas ao sistema 
de cromatografia constituído por uma coluna concentradora (trap column) de $3 \mathrm{~cm}$ x $100 \mu \mathrm{m}$ contendo partículas de $\mathrm{C}_{18}$ de $5 \mu \mathrm{m}$, conectada por um sistema ventilado a uma coluna analítica de $25 \mathrm{~cm} \times 75 \mu \mathrm{m}$ contendo partículas de $\mathrm{C}_{18}$ de $3 \mu \mathrm{m}$ e com ponta afilada utilizada como emissor não metalizado de íons. A eluição foi feita em sistema de gradiente entre os solventes A: ácido fórmico $0,1 \%(\mathrm{v} / \mathrm{v})$ e B: ácido fórmico $0,1 \%(\mathrm{v} / \mathrm{v})$ em acetonitrila $98 \%(\mathrm{v} / \mathrm{v}) . \mathrm{O}$ gradiente utilizado progrediu de 5 a $35 \%$ de solvente B em 55 minutos, utilizando um fluxo de $200 \mathrm{~nL} / \mathrm{min}$. Os componentes eluídos foram ionizados diretamente a partir da extremidade da coluna em um espectrômetro de massas Orbitrap Velos programado em modo DDA (aquisição dependente de dados) de forma que os componentes ionizados foram primeiramente analisados em alta resolução (30.000) na faixa de m/z de 350 a 1650 e, a seguir, os 10 componentes mais intensos foram fragmentados e os fragmentos analisados no ion trap. Foi aplicada exclusão dinâmica com duração de 90 s e resolução de 10 ppm. Ao final desta etapa foi obtido um arquivo no formato RAW contendo os diversos espectros para cada spot.

\subsection{Segunda análise estatística após espectrometria de massas}

Os arquivos RAW foram tratados empregando os programas Peaks 6.0 (ZHANG, 2012) e Maxquant 1.4.1.2 (COX; MANN, 2008) a fim de se identificar a proteína responsável pela detecção (por coloração com coomassie brilhant blue) de cada spot. As buscas foram feitas utilizando-se o banco de dados do Uniprot (UNIPROT, 2014)), filtrados por espécie (Glycine max) e como critérios foram empregados: número máximo de modificações por peptídeo igual a 5, uso de tripsina, máximo de duas clivagens perdidas, tolerância de erros em MS1 de 6 ppm e em MS2 de 0.5 Da carga máxima de 7, S-piridiletilação de cisteínas como modificação fixa, oxidação de metioninas como modificação variável. Em ambos os programas foi definida a busca em um banco reverso (decoy) para avaliação estatística da taxa de FDR (false discovery rate), bem como a exclusão de contaminantes conhecidos. 
Os dados analisados no programa MaxQuant foram tomados como base em função do acesso às informações quantitativas e os resultados de identificação, bem como as modificações pós-traducionais, foram validadas pelo programa Peaks. Com a finalidade de se evitar identificações falso-positivas, foram estabelecidos critérios de filtragem sucessivos no programa MaxQuant: o primeiro critério de filtragem foi relativo à significância estatística da identificação. Apenas proteínas identificadas com $\mathrm{FDR}<1 \%$ foram consideradas significativas. Caso houvesse apenas uma proteína identificada atendendo a esse critério, o conteúdo do spot era atribuído a essa proteína. Caso houvesse mais que uma proteína que atendesse ao critério de significância, avaliava-se a abundância relativa entre as proteínas, por meio da comparação das razões entre as intensidades reportadas pelo MaxQuant. Caso a razão entre as intensidades fosse superior a 5 (fold change $>5$ ), a detecção do spot foi atribuída à proteína mais abundante. Caso fosse menor, considerou-se inviável determinar a proteína a ser atribuída ao spot e excluiu-se o spot da análise. Também foi considerado como critério a proteínas com menor valor PEP (provável erro posterior de indentificação $\leq$ que 0,01 ).

Também foram realizadas buscas do mesmo conjunto de dados contra os bancos de dados do gênero Phakopsora com a finalidade de se avaliar a presença de proteínas do fungo no extrato vegetal. Após a determinação da lista de proteínas de soja foram buscados dados funcionais e de localização celular de cada proteína utilizando-se o software Blast2GO (CONESA; GOTZ, 2008), obtendo-se informações dos termos GO (Gene Ontology) e posteriormente elaborados os gráficos de acordo com a função molecular, processos biológicos e compartimentos celulares, conforme figura 4. 


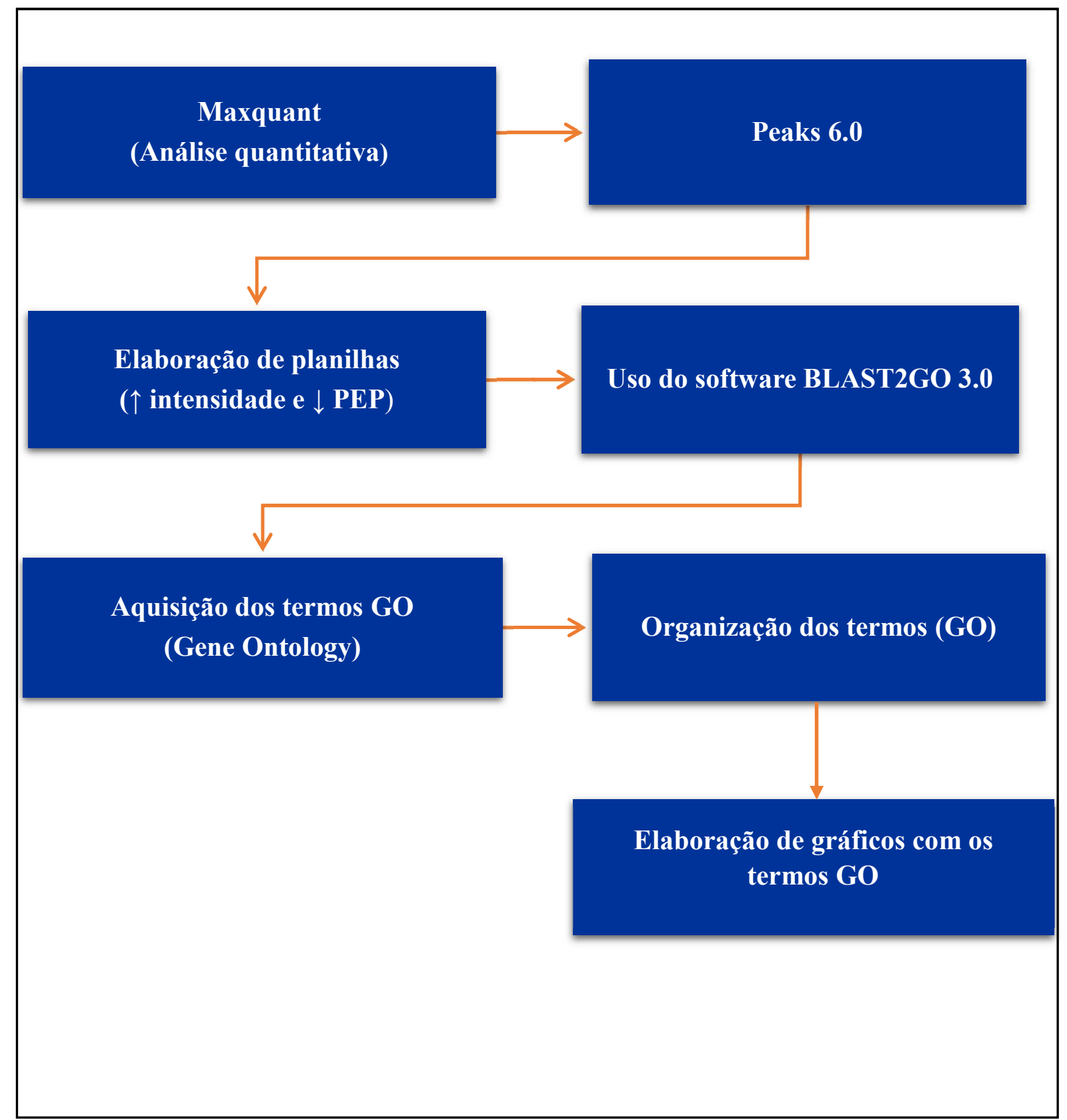

Figura 4. Fluxograma das análises após espectrometria de massas. 


\section{RESULTADOS}

\subsection{Análise intra cultivares}

A seguir estão representados o total de spots significativos com abundância relatativa aumentada na análise intra cultivar observados em BRSGO-7560 e MSOY-8001 nas condições não inoculada (NI) e inoculada (I), bem como o total de spots exclusivos para esta mesma condição (Tabela 3). Na cultivar BRSGO-7560 foram observadas 21 spots com abundância relativa aumentada na condição não inoculada e 8 spots exclusivos, enquanto na condição inoculada um total de 20 spots e 2 spots exclusivos (Figuras 5 e 6). Em MSOY-8001 observouse 4 spots com aumento em sua abundância relativa na condição não inoculada e apenas 1 spot exclusivo, enquanto na condição inoculada foram observados 20 spots e nenhum spot exclusivo, os quais estão ilustrados nas figuras 7 e 8.

Tabela 3.Total de spots com abundância relativa aumentada ( $\uparrow$ ) e spots exclusivos resultantes da análise intra cultivares para BRSGO-7560 (resistente) e MSOY-8001 (suscetível) nas condições não inoculada (NI) e inoculada (I) com P. pachyrhizi.

\begin{tabular}{|c|c|c|c|c|}
\hline \multirow{2}{*}{ Cultivar } & Reação & Condição & Total de spots & Spots exclusivos \\
\hline \multirow{2}{*}{ BRSGO-7560 } & Resistente & (NI) x (I) & $21 \uparrow(\mathrm{NI})$ & $8(\mathrm{NI})$ \\
\cline { 4 - 5 } & & & $20 \uparrow(\mathrm{I})$ & $2(\mathrm{I})$ \\
\hline \multirow{2}{*}{ MSOY-8001 } & Suscetível & (NI) $x(\mathrm{I})$ & $4 \uparrow(\mathrm{NI})$ & $1(\mathrm{NI})$ \\
\cline { 4 - 5 } & & & $20 \uparrow(\mathrm{I})$ & $0(\mathrm{I})$ \\
& & & & \\
\hline
\end{tabular}




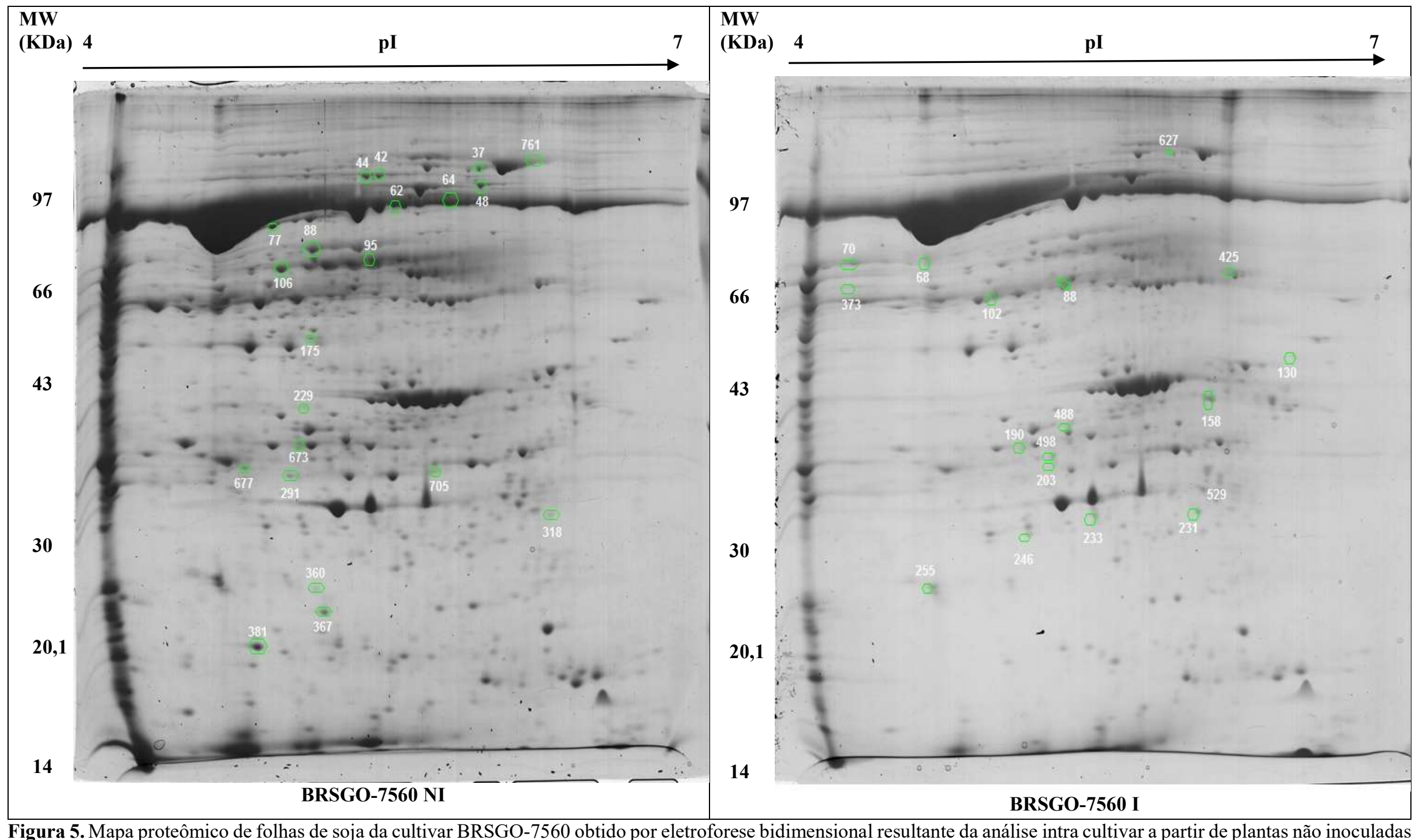

Figura 5. Mapa proteômico de folhas de soja da cultivar BRSGO-7560 obtido por eletroforese bidimensional resultante da análise intra cultivar a partir de plantas não inoculadas (NI) e inoculadas com P. pachyrhizi. Os spots com abundância relativa aumentada significativos estão identificados pelo número Match ID e circundados em verde. 


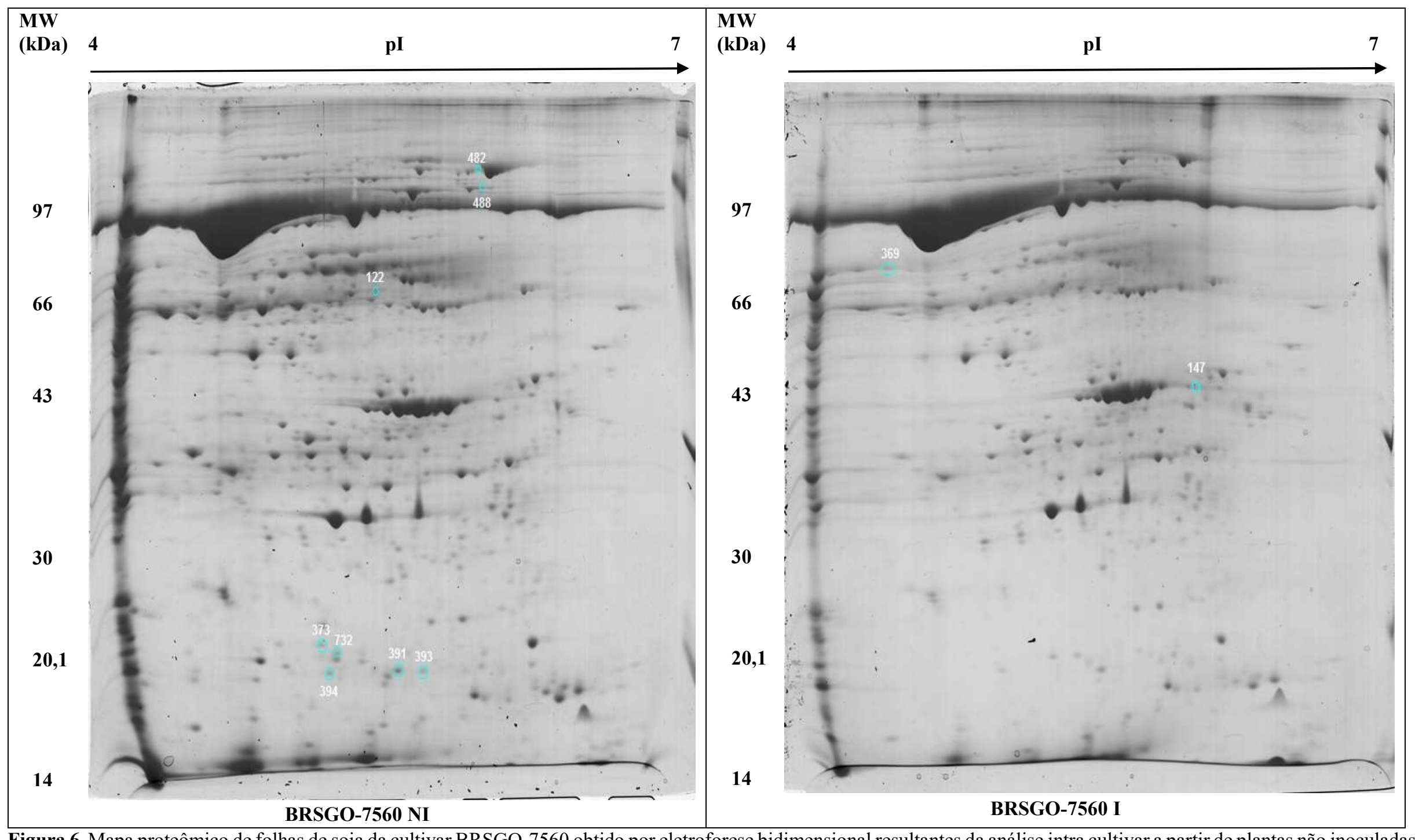

Figura 6. Mapa proteômico de folhas de soja da cultivar BRSGO-7560 obtido por eletroforese bidimensional resultantes da análise intra cultivar a partir de plantas não inoculadas (NI) e inoculadas (I) com P. pachyrhizi. Os spots exclusivos estão identificados pelo número Match ID e circundados em azul. 


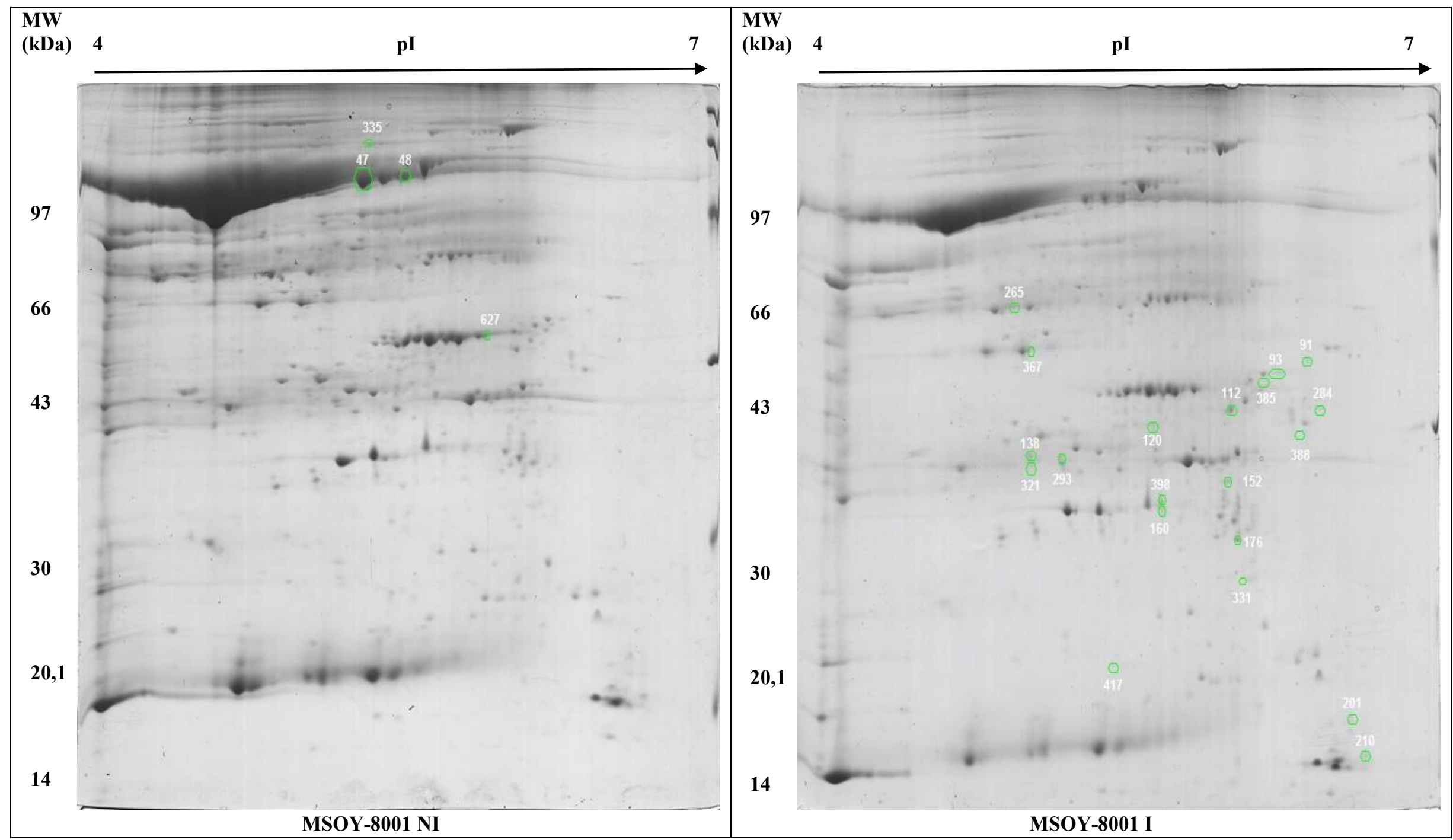

Figura 7. Mapa proteômico de folhas de soja da cultivar MSOY-8001 obtido por eletroforese bidimensional resultantes da análise intra cultivar de plantas não inoculadas (NI) e inoculadas (I) com P. pachyrhizi. Os spots exclusivos (presente em pelo menos 5 geis de uma condição e ausente na outra) estão identificados pelo número Match ID e circundados em verde. 


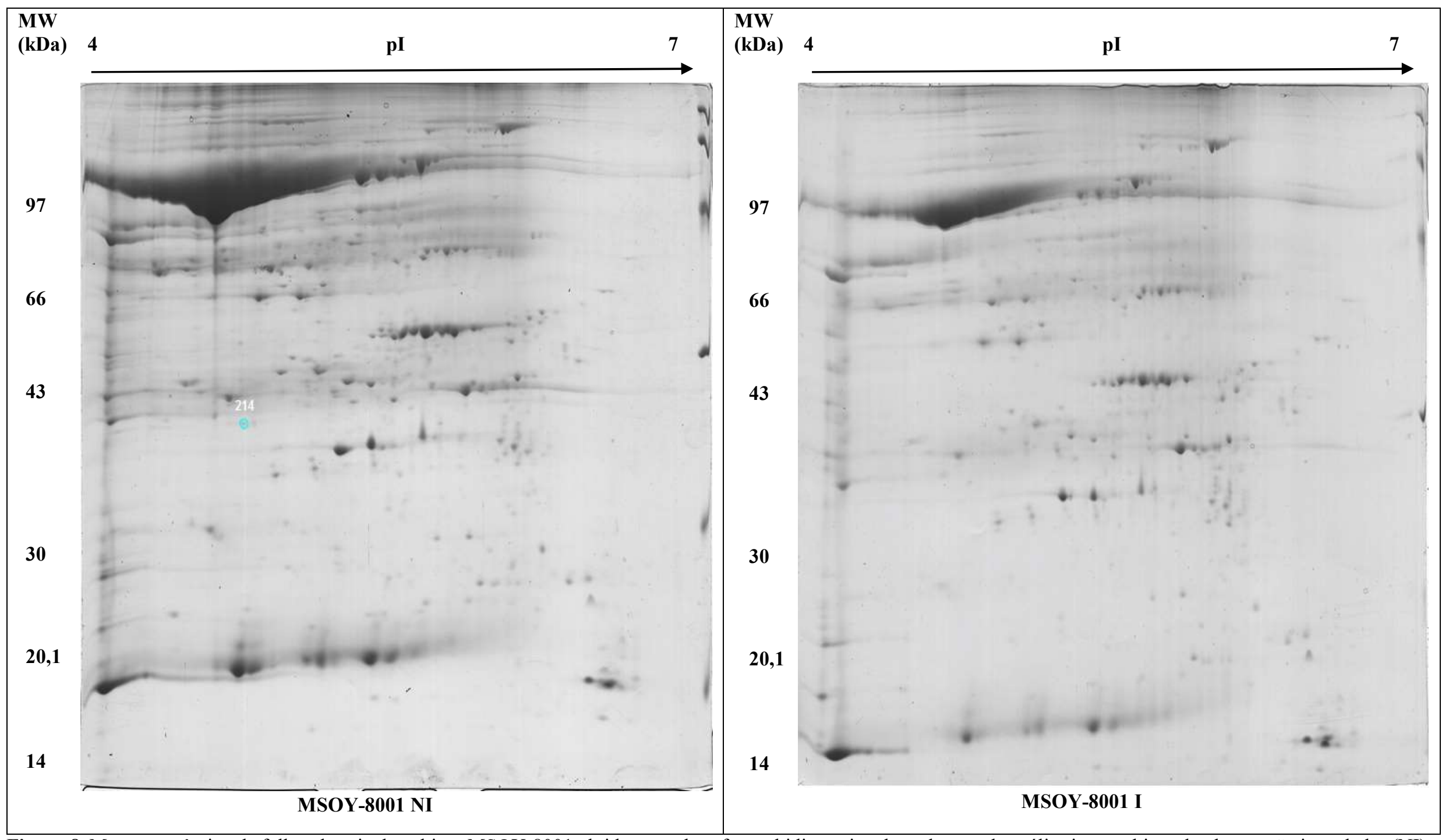

Figura 8. Mapa proteômico de folhas de soja da cultivar MSOY-8001 obtidos por eletroforese bidimensional resultantes da análise intra cultivar de plantas não inoculadas (NI) e inoculadas (I) com P. pachyrhizi. O spot exclusivo (presente em pelo menos 5 geis de uma condição e ausente na outra) está identificado pelo número Match ID e circundado em azul. 
Dos 21 spots evidenciados na análise intra cultivar para BRSGO-7560 nas condições não inoculada (NI) x inoculada (I), 9 foram descritos de acordo com o Uniprot e 12 de acordo com o Blast2Go (Tabela 4). Com relação aos spots exclusivos para esta condição, 7 foram descritos de acordo com o Blast2Go e 1 pelo Uniprot, (Tabela 5). 
Tabela 4. Spots com abundância relativa aumentada obtidos em BRSGO-7560 na condição não inoculada (NI) resultantes da análise comparativa intra cultivar com a condição inoculada (I) com Phakopsora pachyrhizi.

\begin{tabular}{|c|c|c|c|c|c|c|c|}
\hline \multicolumn{3}{|c|}{$\begin{array}{l}\text { BRSGO-7560 (NI) } \\
\quad x \\
\text { BRSGO-7560 (I) }\end{array}$} & \multirow[b]{2}{*}{ *Descrição } & \multirow{2}{*}{ Espécie } & \multirow{2}{*}{$\begin{array}{c}\text { Massa } \\
(\text { kDa) }\end{array}$} & \multirow{2}{*}{$\begin{array}{l}\text { Cobertura } \\
\quad(\%)\end{array}$} & \multirow{2}{*}{ *PEP } \\
\hline Spot & $\begin{array}{c}* \mathrm{~N}^{\circ} \text { de acesso } \\
\text { (Uniprot) } \\
\end{array}$ & $\begin{array}{c}\text { e-Value } \\
\text { (Blast2GO) }\end{array}$ & & & & & \\
\hline $\begin{array}{c}37 \\
761\end{array}$ & I1MJU7 & $0,0 \mathrm{E} 0$ & Stromal 70 kda heat shock-related chloroplastic - (Blast2GO) & Glycine max & $\begin{array}{l}73.754 \\
73.754\end{array}$ & $\begin{array}{l}30,6 \\
42,7\end{array}$ & $\begin{array}{c}4,92 \mathrm{E}-70 \\
2,70 \mathrm{E}-112\end{array}$ \\
\hline $\begin{array}{l}42 \\
44\end{array}$ & $\mathrm{I} 1 \mathrm{MJ} 28$ & $0,0 \mathrm{E} 0$ & $\begin{array}{l}\text { Rubisco large subunit-binding protein- (Blast2GO) } \\
60 \mathrm{kda} \text { chaperonin subunit beta - (Blast2GO) }\end{array}$ & Glycine max & $\begin{array}{l}62.843 \\
62.843\end{array}$ & $\begin{array}{l}46,2 \\
46,7\end{array}$ & $\begin{array}{l}8,71 \mathrm{E}-141 \\
3,42 \mathrm{E}-109\end{array}$ \\
\hline 48 & I1LR60 & $0,0 \mathrm{E} 0$ & $\begin{array}{l}\text { Rubisco large subunit-binding protein-(Blast2GO) } \\
60 \mathrm{kda} \text { chaperonin subunit alpha - (Blast2GO) }\end{array}$ & Glycine max & 61.704 & 47,6 & $1,55 \mathrm{E}-124$ \\
\hline 62 & Q2PMV0 & $0,0 \mathrm{E} 0$ & $\begin{array}{l}\text { ATP synthase subunit beta, chloroplastic- (Uniprot) } \\
\text { (ATP synthase F1 sector subunit beta) (F-ATPase subunit beta) - } \\
\text { (Uniprot) }\end{array}$ & Glycine max & 53.754 & 63,5 & $5,28 \mathrm{E}-112$ \\
\hline 64 & P27066 & $0,0 \mathrm{E} 0$ & $\begin{array}{l}\text { Ribulose bisphosphate carboxylase large chain (RuBisCO large } \\
\text { subunit) - (Uniprot) }\end{array}$ & Glycine max & 52.609 & 22,5 & $2,33 \mathrm{E}-33$ \\
\hline 77 & A8IKE5 & $0,0 \mathrm{E} 0$ & Alanine aminotransferase 2 - (Uniprot) & Glycine $\max$ & 53.523 & 37,2 & $4,85 \mathrm{E}-86$ \\
\hline 88 & F4ZZ27 & $0,0 \mathrm{E} 0$ & 1-deoxy-D-xylulose 5-phosphate reductoisomerase - (Uniprot) & Glycine max & 50.509 & 39,1 & $1,75 \mathrm{E}-72$ \\
\hline $\begin{array}{c}95 \\
106\end{array}$ & C6TNM8 & $0,0 \mathrm{E} 0$ & Glutamine synthetase - (Uniprot) & Glycine max & $\begin{array}{l}47.664 \\
47.664\end{array}$ & $\begin{array}{l}25,7 \\
25,7\end{array}$ & $\begin{array}{l}2,16 \mathrm{E}-41 \\
2,26 \mathrm{E}-84\end{array}$ \\
\hline 175 & C6TCM2 & $1,7 \mathrm{E}-36$ & $\begin{array}{l}\text { Glucose-6-phosphate 1-epimerase } \\
\text { d-hexose-6-phosphate mutarotase } \\
\text { Apospory-associated protein c - (Blast2Go) }\end{array}$ & Glycine max & 33.721 & 11,9 & $6,99 \mathrm{E}-07$ \\
\hline
\end{tabular}




\begin{tabular}{|c|c|c|c|c|c|c|c|}
\hline 229 & I1JFJ9 & $1,1 \mathrm{E}-117$ & $\begin{array}{l}\text { Lectin db58 - (Blast2Go) } \\
\text { Lectin db58 subunit alpha } \\
\text { Lectin db58 subunit beta }\end{array}$ & Glycine $\max$ & 31.882 & 29 & $4,60 \mathrm{E}-35$ \\
\hline 291 & I1NJ59 & $1,6 \mathrm{E}-117$ & DHAR class glutathione s-transferase - (Blast2Go) & Glycine max & 23.472 & 39,9 & $4,06 \mathrm{E}-20$ \\
\hline 318 & C6TGM9 & $3,3 \mathrm{E}-90$ & $\begin{array}{l}\text { 2-cys peroxiredoxin bas1-chloroplastic - (Blast2Go) } \\
2 \text {-cys peroxiredoxin b thiol-specific antioxidant protein b flags: } \\
\text { precursor-(Blast } 2 \mathrm{Go})\end{array}$ & Glycine max & 22.331 & 19,7 & $9,19 \mathrm{E}-14$ \\
\hline 360 & A8Y7Z9 & $3,8 \mathrm{E}-118$ & Cytochrome b6-f complex iron-sulfur subunit- (Uniprot) & Glycine max & 24.119 & 14,5 & $1,89 \mathrm{E}-45$ \\
\hline 367 & C6SVX0 & $1,2 \mathrm{E}-99$ & Hsp16_soybn ame: full= kda class i heat shock protein- (Blast2Go) & Glycine max & & 48.4 & $1,62 \mathrm{E}-41$ \\
\hline 381 & I1KRC3 & $0,0 \mathrm{E} 0$ & n-acetylglucosaminyl-phosphatidylinositol de-n-acetylase - (Blast2Go) & Glycine max & 29.839 & 11,9 & $1,30 \mathrm{E}-02$ \\
\hline 673 & I1N783 & $1,1 \mathrm{E}-158$ & Proteasome subunit alpha type - (Uniprot) & Glycine max & 27.335 & 60,2 & $2,23 \mathrm{E}-64$ \\
\hline 677 & I1LY84 & $8.5 \mathrm{E}-112$ & $\begin{array}{l}20 \text { kDa Chloroplastic- (Blast2Go) } \\
\text { Chaperonin 10- (Blast2Go) } \\
\text { Chaperonin 20- (Blast2Go) } \\
\text { Protein cpn21- (Blast2Go) }\end{array}$ & Glycine max & 26.469 & 62,5 & $1,17 \mathrm{E}-63$ \\
\hline 705 & C6TJG0 & $5.0 \mathrm{E}-127$ & $\begin{array}{l}20 \mathrm{kDa} \text { Chloroplastic- (Blast2Go) } \\
\text { Chaperonin } 10 \\
\text { Chaperonin } 20 \\
\text { Protein cpn } 21\end{array}$ & Glycine max & 26.656 & 50,6 & $2,49 \mathrm{E}-45$ \\
\hline
\end{tabular}

* $\mathrm{N}^{\mathrm{o}}$ de acesso de acordo com banco de dados do Uniprot.

* Descrição: realizada de acordo com o Uniprot ou pelo Blast2Go para as proteínas que não apresentavam anotações no Uniprot.

*PEP: Posterior Error Probability of the identification. 
Tabela 5. Spots exclusivos obtidos em BRSGO-7560 na condição não inoculada (NI) resultantes da análise comparativa intra cultivar com a condição inoculada (I) com Phakopsora pachyrhizi.

\begin{tabular}{|c|c|c|c|c|c|c|c|}
\hline \multicolumn{2}{|c|}{$\begin{array}{l}\text { BRSGO-7560 (NI) } \\
\mathbf{x} \\
\text { BRSGO (I) }\end{array}$} & \multirow[b]{2}{*}{$\begin{array}{l}\text { e-Value } \\
\text { (Blast 2GO) }\end{array}$} & \multirow{2}{*}{ *Descrição } & \multirow{2}{*}{ Espécie } & \multirow{2}{*}{$\begin{array}{c}\text { Massa } \\
\text { (kDa) }\end{array}$} & \multirow{2}{*}{$\begin{array}{l}\text { Cobertura } \\
(\%)\end{array}$} & \multirow{2}{*}{ *PEP } \\
\hline Spot & $\begin{array}{c}* \mathrm{~N}^{0} \text { de acesso } \\
\text { (Uniprot) }\end{array}$ & & & & & & \\
\hline 122 & I1N1G8 & $5,1 \mathrm{E}-162$ & $\begin{array}{l}\text { 2-Methylene-furan-3-one reductase - (Blast2Go) } \\
\text { Enone oxidoreductase- (Blast2Go) - (Blast2Go) }\end{array}$ & Glycine $\max$ & 41.969 & 44,8 & $2,83 \mathrm{E}-64$ \\
\hline 373 & I1JBB1 & $0,0 \mathrm{E} 0$ & $\begin{array}{l}\text { abc Transporter b family member } 21-(\text { Blast2Go) } \\
\text { Multidrug resistance protein } 17 \text { - (Blast2Go) } \\
\text { p-Glycoprotein 21- (Blast2Go) }\end{array}$ & Glycine $\max$ & 138,28 & 2,5 & $2,11 \mathrm{E}-02$ \\
\hline 391 & C6T5M6 & $6,2 \mathrm{E}-100$ & Hsp11 kDa class i heat shock protein - (Blast2Go) & Glycine $\max$ & 17.437 & 66 & $2,08 \mathrm{E}-43$ \\
\hline 393 & P04793 & $1,6 \mathrm{E}-94$ & 17.5 kDa class I heat shock protein- (Uniprot) & Glycine $\max$ & 17.546 & 60,8 & $1,01 \mathrm{E}-74$ \\
\hline 394 & C6T5U3 & $1.7 \mathrm{E}-103$ & Hsp11 kDa Class i heat shock protein - (Blast2Go) & Glycine max & 17.485 & 68,6 & $5,69 \mathrm{E}-42$ \\
\hline 482 & C6T2L4 & $2,1 \mathrm{E}-106$ & Hsp11 kDa Class i heat shock protein (Blast2Go) & Glycine $\max$ & 17.346 & 41,8 & $3,52 \mathrm{E}-29$ \\
\hline 488 & C6SVX0 & $1,2 \mathrm{E}-99$ & Hsp16 kDa Class i heat shock protein- (Blast2Go) & Glycine $\max$ & 18.503 & 24,2 & $1,42 \mathrm{E}-10$ \\
\hline 732 & C6T2N6 & $6,8 \mathrm{E}-85$ & Hsp13 kDa Class i heat shock protein - (Blast2Go) & Glycine $\max$ & 17.514 & 40,5 & $1,45 E-33$ \\
\hline
\end{tabular}

* $\mathrm{N}^{\mathrm{o}}$ de acesso de acordo com banco de dados do Uniprot.

* Descrição: realizada de acordo com o Uniprot ou pelo Blast2Go para as proteínas que não apresentavam anotações no Uniprot

*PEP:Posterior Error Probability of the Identification 
A seguir encontra-se o resultado dos spots com abundância relativa aumentada na análise intra cultivar entre BRSGO-7560 inoculada (I) x não inoculada (NI), bem como a descrição das proteínas encontradas, (Tabela 6). Dos 20 spots resultantes da análise intra cultivar para a cultivar BRSGO-7560 inoculada (I) x não inoculada (NI), 13 foram descritos de acordo com Uniprot e 7 pelo Blast2Go . Com relação ao spots exclusivos para esta condição, 1 foi descrito de acordo com Uniprot e outro pelo Blast2Go. Entre as proteínas encontradas temos Ribulose bisphosphate carboxylase large chain (spot 369) e também 1 proteína envolvidas no aumento da oxigenação nos cloroplastos (spot 147), (Tabela 7). 
Tabela 6. Spots com abundância relativa aumentada em BRSGO-7560 na condição inoculada (I) com P. pachyrhizi resultantes da análise comparativa intra cultivar com a condição não inoculada (NI).

\begin{tabular}{|c|c|c|c|c|c|c|c|}
\hline \multicolumn{3}{|c|}{$\begin{array}{l}\text { BRSGO-7560 (I) } \\
\qquad x \\
\text { BRSGO (NI) }\end{array}$} & \multirow{2}{*}{ *Descrição } & \multirow{2}{*}{ Espécie } & \multirow{2}{*}{$\begin{array}{c}\text { Massa } \\
(\mathbf{k D a})\end{array}$} & \multirow{2}{*}{$\begin{array}{l}\text { Cobertura } \\
\quad(\%)\end{array}$} & \multirow{2}{*}{ *PEP } \\
\hline Spot & $\begin{array}{c}{ }^{*} \mathbf{N}^{0} \text { de } \\
\text { acesso } \\
\text { (Uniprot) }\end{array}$ & $\begin{array}{c}\text { e-Value } \\
\text { (Blast 2GO) }\end{array}$ & & & & & \\
\hline 130 & I1LTB6 & $8,6 \mathrm{E}-152$ & Stromal 70 kda heat shock-related chloroplastic flags precursor (Blast2Go) & Glycine max & 45.806 & 29,6 & $1,17 \mathrm{E}-51$ \\
\hline 148 & I1KZW8 & $4,4 \mathrm{E}-134$ & Plastid-lipid-associated chloroplastic (Blast2Go) & Glycine $\max$ & 33.659 & 29,5 & $1,38 \mathrm{E}-44$ \\
\hline $\begin{array}{l}158 \\
231 \\
237\end{array}$ & Q2PMV0 & $0,0 \mathrm{E} 0$ & $\begin{array}{l}\text { ATP synthase subunit beta, chloroplastic - (Uniprot) } \\
\text { ATP synthase F1 sector subunit beta) (F-ATPase subunit beta) - (Uniprot) }\end{array}$ & Glycine max & $\begin{array}{l}53.754 \\
53.754 \\
53.754\end{array}$ & $\begin{array}{l}21,9 \\
17,3 \\
10,4\end{array}$ & $\begin{array}{l}7,38 \mathrm{E}-43 \\
4,46 \mathrm{E}-40 \\
3,34 \mathrm{E}-13\end{array}$ \\
\hline $\begin{array}{l}203 \\
498 \\
\end{array}$ & I1LCI3 & $\begin{array}{l}3,6 \mathrm{E}-174 \\
8,8 \mathrm{E}-152 \\
\end{array}$ & Superoxide dismutase (Uniprot) & Glycine $\max$ & $\begin{array}{l}27.515 \\
27.515\end{array}$ & $\begin{array}{c}30,3 \\
34\end{array}$ & $\begin{array}{l}6,06 \mathrm{E}-20 \\
2,72 \mathrm{E}-50\end{array}$ \\
\hline 233 & I1KXW9 & $8,2 \mathrm{E}-162$ & $\begin{array}{l}\text { Oxygen-evolving enhancer protein chloroplastic }- \text { (Blast2Go) } \\
\text { Subunit of oxygen evolving system of photosystem ii thylakoid membrane } \\
\text { protein - (Blast2Go) }\end{array}$ & Glycine max & 28.229 & 24,4 & $1,42 \mathrm{E}-19$ \\
\hline 246 & C6T8W8 & $4,6 \mathrm{E}-157$ & $\begin{array}{l}\text { Oxygen-evolving enhancer protein chloroplastic - (Blast2Go) } \\
33 \mathrm{kDa} \text { subunit of oxygen evolving system of photosystem ii - (Blast2Go) } \\
33 \mathrm{kDa} \text { thylakoid membrane protein - (Blast2Go) }\end{array}$ & Glycine max & 28.447 & 20,8 & $9,57 \mathrm{E}-29$ \\
\hline 255 & C6TFS5 & $1,1 \mathrm{E}-113$ & Cytochrome b6-f complex iron-sulfur subunit - (Uniprot) & Glycine $\max$ & 28.426 & 15,3 & $3,08 \mathrm{E}-13$ \\
\hline $\begin{array}{l}70 \\
68\end{array}$ & $\mathrm{P} 27066$ & $0,0 \mathrm{E} 0$ & $\begin{array}{l}\text { Ribulose bisphosphate carboxylase large chain (RuBisCO large subunit) - } \\
\text { (Uniprot) }\end{array}$ & Glycine max & $\begin{array}{l}52.609 \\
52.609\end{array}$ & $\begin{array}{l}17,1 \\
21,1 \\
\end{array}$ & $\begin{array}{l}2,44 \mathrm{E}-29 \\
1,82 \mathrm{E}-26\end{array}$ \\
\hline 373 & I1M6D5 & $0,0 \mathrm{E} 0$ & Fructose-bisphosphate aldolase (Uniprot) & Glycine $\max$ & 38,42 & 41,5 & $9,87 \mathrm{E}-52$ \\
\hline 425 & I1N5T2 & $0,0 \mathrm{E} 0$ & Peptidyl-prolyl cis-trans isomerase chloroplastic (Blast2Go) & Glycine max & 48.731 & 42,9 & $6,91 \mathrm{E}-78$ \\
\hline $\begin{array}{c}88 \\
102\end{array}$ & I1LPX6 & $0,0 \mathrm{E} 0$ & Fructose-bisphosphate aldolase (Uniprot) & Glycine $\max$ & $\begin{array}{l}42.869 \\
42.869\end{array}$ & $\begin{array}{l}28,6 \\
33,2\end{array}$ & $\begin{array}{l}5,83 \mathrm{E}-56 \\
3,72 \mathrm{E}-64\end{array}$ \\
\hline
\end{tabular}




\begin{tabular}{|c|c|c|c|c|c|c|c|}
\hline 488 & P28759 & $0,0 \mathrm{E} 0$ & Superoxide dismutase [Fe], chloroplastic (Uniprot) & Glycine $\max$ & 27.841 & 30,2 & $1,39 \mathrm{E}-76$ \\
\hline 190 & Q76LA8 & $3,3 \mathrm{E}-90$ & Cytosolic ascorbate peroxidase 1- (Uniprot) & Glycine max & 27.868 & 11,7 & $1,02 \mathrm{E}-04$ \\
\hline 529 & C6TGM9 & $3,7 \mathrm{E}-7$ & $\begin{array}{l}\text { 2-Cys peroxiredoxin bas1-chloroplastic- (Blast2Go) } \\
\text { 2-Cys peroxiredoxin b - (Blast2Go) } \\
\text { Thiol-specific antioxidant protein } b \text { - (Blast2Go) }\end{array}$ & Glycine $\max$ & 22.331 & 12,3 & $2,09 \mathrm{E}-06$ \\
\hline 627 & I1M1Z5 & $8,6 \mathrm{E}-152$ & Homeobox protein partial - (Blast2Go) & Glycine max & 198,16 & 0,6 & $4,73 \mathrm{E}-03$ \\
\hline
\end{tabular}

* $\mathrm{N}^{\mathrm{o}}$ de acesso de acordo com banco de dados do Uniprot.

* Descrição: realizada de acordo com o Uniprot ou pelo Blast2Go para as proteínas que não apresentavam anotações no Uniprot.

*PEP: Posterior Error Probability of the identification 
Tabela 7. Spots exclusivos obtidos em BRSGO-7560 (cultivar resistente) na condição inoculada (I) resultantes da análise comparativa intra cultivar com a condição não inoculada (NI).

\begin{tabular}{|c|c|c|c|c|c|c|c|}
\hline \multicolumn{2}{|c|}{$\begin{array}{l}\text { BRSGO-7560 (I) } \\
x \\
\text { BRSGO-7560 (NI) }\end{array}$} & & \multirow[t]{2}{*}{ *Descrição } & \multirow{2}{*}{ Espécie } & \multirow{2}{*}{$\begin{array}{l}\text { Massa } \\
(\text { kDa) }\end{array}$} & \multirow{2}{*}{$\begin{array}{l}\text { Cobertura } \\
\quad(\%)\end{array}$} & \multirow{2}{*}{ *PEP } \\
\hline Spot & $\begin{array}{c}\text { * }^{\mathbf{0}} \text { de acesso } \\
\text { (Uniprot) }\end{array}$ & $\begin{array}{c}\text { e-Value } \\
\text { (Blast 2GO) }\end{array}$ & & & & & \\
\hline 147 & I1MNK0 & $0,0 \mathrm{E} 0$ & $\begin{array}{l}\text { Oxygen-evolving enhancer protein chloroplastic- (Blast 2Go) } \\
33 \text { kDa Subunit of oxygen evolving system of photosystem ii- (Blast 2Go) } \\
33 \text { kDa Thylakoid membrane protein- (Blast 2Go) }\end{array}$ & Glycine max & 35.058 & 43,8 & $3,10 \mathrm{E}-57$ \\
\hline 369 & P27066 & $0,0 \mathrm{E} 0$ & $\begin{array}{l}\text { Ribulose bisphosphate carboxylase large chain (RuBisCO large subunit)- } \\
\text { (Uniprot) }\end{array}$ & Glycine max & 52.609 & 25,5 & $9,36 \mathrm{E}-39$ \\
\hline
\end{tabular}

* $\mathrm{N}^{\circ}$ de acesso de acordo com banco de dados do Uniprot.

* Descrição: realizada de acordo com o Uniprot ou pelo Blast2Go para as proteínas que não apresentavam anotações no Uniprot.

*PEP: Posterior Error Probability of the identification 
Ao analisar as proteínas com abundância relativa aumentada presentes na análise intra cultivar para BRSGO-7560 nas condições não inoculada e inoculada, foi possível observar a presença de 3 proteínas em comum (provenientes de spots distintos) entre as condições avaliadas (Q2PMV0, P27066, C6TGM9), conforme diagrama de Venn (Figura 9).

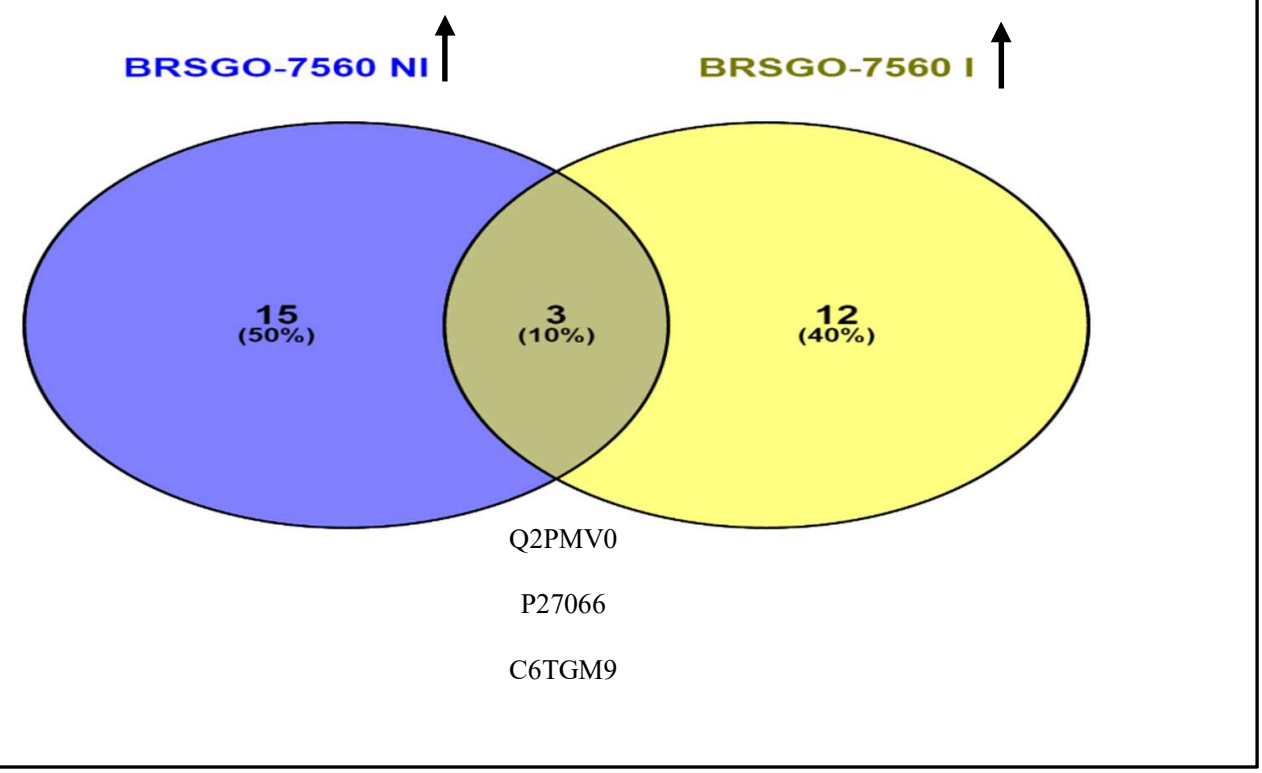

Figura 9. Diagrama de Venn de proteínas com abundância relativa aumentada ( $\uparrow$ ) resultantes da análise intra cultivar para BRSGO-7560 nas condições não inoculada (NI) e inoculada (I).

As proteínas com abundância relativa aumentada na análise intra cultivar para BRSGO7560 nas condições não inoculada e inoculada, foram classificadas de acordo com os termos GO (Gene ontology) por função molecular, processos biológicos e componentee celulares na análise intra cultivar conforme figuras 10, 11, e 12, respectivamente.

De acordo com os resultados obtidos para função molecular na condição não inoculada observamos uma maior concentração de proteínas que possuem ligações a nucleotídeos (46\%), seguidos por proteínas de ligação (16\%) e de atividade hidrolase (16\%), conforme figura 10. Na condição inoculada a análise por função molecular resultou na maior parte a proteínas com 
atividade catalítica (40\%), seguido por proteínas de ligação (32\%) e também as que se ligam a RNA (12\%), coforme ilustrado na figura 10.

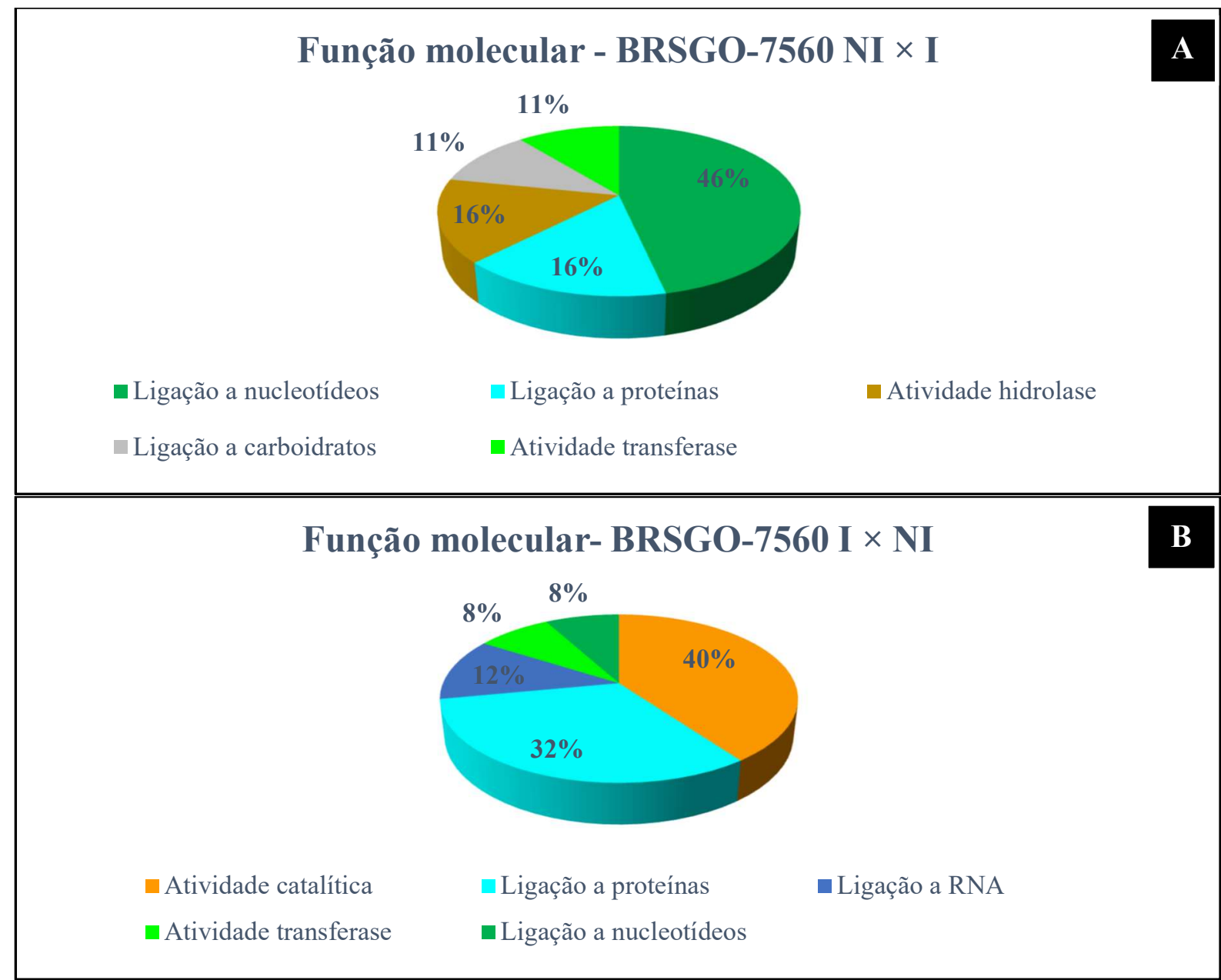

Figura 10. Distribuição das proteínas com abundância relativa aumentada em função de suas propriedades moleculares resultantes da análise intra cultivar de BRSGO-7560 nas condições não inoculada (NI) e inoculada (I). A-condição não inoculada; B- condição inoculada.

Quanto aos termos GO relacionados aos processos biológicos tivemos a seguinte distribuição: proteínas envolvidas em processos biosintéticos (26\%), seguidos de demais processos entre estes, (resposta ao estresse, processos metabólicos de carboidratoas, fotossíntese, organização de componente celular, todos com $11 \%$, conforme figura $11 . \mathrm{Na}$ condição inoculada da mesma forma houve maior resposta para processos biossintéticos $(9 \%)$, resposta a estímulos abióticos $(9 \%)$, resposta ao estresse $(9 \%)$, seguido por organização de componente celular $(8 \%)$, processos metabólicos contendo nucletídeos, além de demais 
processos, tais como resposta a estímulo biótico (5\%), morte celular (4\%) e transdução de sinais (4\%), (Figura 11).

\section{Processos biológicos BRSGO-7560 NI × I}

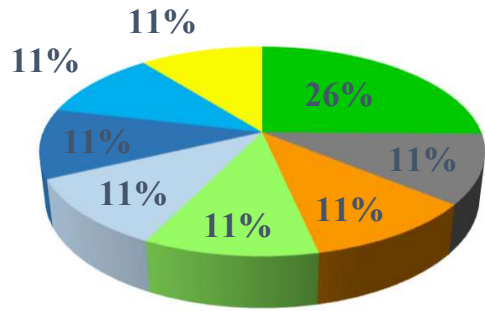

— Processos biosintéticos

- Resposta a estresse

- Organização de componente celular

- Desenvolvimento pos-embrionário
- Processos metabólicos de carboidratos

Fotossíntese

- Desenvolvimento embrionário

Reprodução

Processos biológicos BRSGO-7560 I × NI

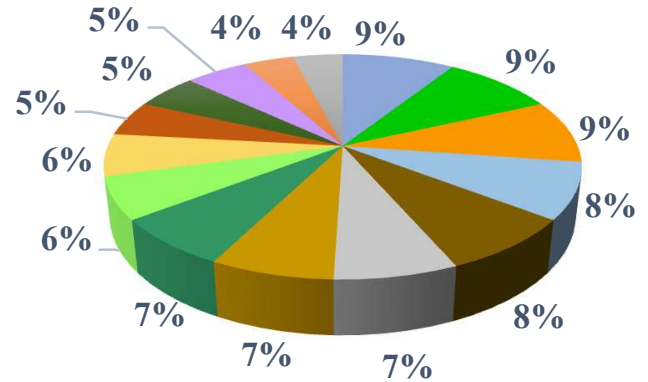

- Resposta a estímulo abiótico

- Processos biosintéticos

- Resposta a estresse

- Organização de componente celular

- Processos metabólicos contendo compostos de nucleobase

Desenvolvimento de organismo multicelular

- Geração de precursores de metabolismo e energia

- Resposta a estímulo endógeno

Fotossíntese

- Processos de modificação de proteína celular

- Resposta a estímulo biótico

- Transporte

- Resposta a estímulo externo

- Morte celular

- Transdução de sinal

Figura 11. Distribuição das proteínas com abundância relativa aumentada em função dos processos bilógicos resultantes da análise intra cultivar de BRSGO-7560 nas condições não inoculada (NI) e inoculada (I). A-condição não inoculada; B- condição inoculada. 
Em relação à distribuição das proteínas nos diferentes compartimentos celulares observou-se na condição não inoculada que as proteínas ocorreram principalmente nos plastídeos $(25 \%)$, seguido por membrana (23\%) e tilacóides (16\%), (Figura 12). Da mesma forma na cultivar BRSGO-7560 inoculada, a distribuição das proteínas ocorreu principalmente nos plastídeos (26\%) e nos tilacóides (22\%), (Figura 12).

\section{Compartimentos celulares BRSGO-7560 (NI) $\times($ I)}

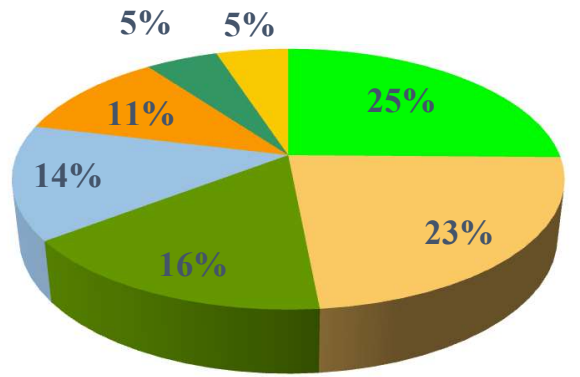

- Plastídeo $\square$ Membrana $\square$ Tilacóide $\square$ Região extracelular $\square$ Mitocôndria $\square$ Citosol $\square$ Ribossomo

\section{Compartimentos celulalares BRSGO-7560 (I) $\times(\mathrm{NI})$}

- Plastídeo

- Região extracelular

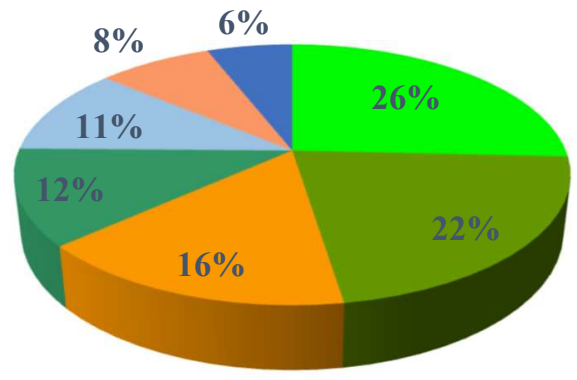

- Tilacóide

- Mitocôndria

- Membrana plasmática

- Núcleo

- Citosol

Figura 12. Distribuição das proteínas com abundância relativa aumentada em função dos compartimentos celulares resultantes da análise intra cultivar para BRSGO-7560 nas condições não inoculada (NI) e inoculada (I). A- condição não inoculada; B- condição inoculada. 
Quanto às proteínas identificadas correspondentes aos spots exclusivos, foi observado na função molecular na análise intra cultivar para BRSGO-7560 (NI) × (I) a predominância de proteínas que se ligam a nucleotídeos (33\%), seguidas por proteínas que se ligam a outras proteínas, atividade de hidrolases e atividade transporte (17\%), (Figura 13). Na condição inoculada foi observado maior percentual de proteínas com atividade catalítica (40\%), seguido por proteínas com atividade de ligação, proteínas que se ligam a outras proteínas e por proteínas que se ligam a RNA, todas correspondendo a 20\%, (Figura 13)

\section{Função molecular BRSGO-7560 (NI) $\times($ I) spots exclusivos}

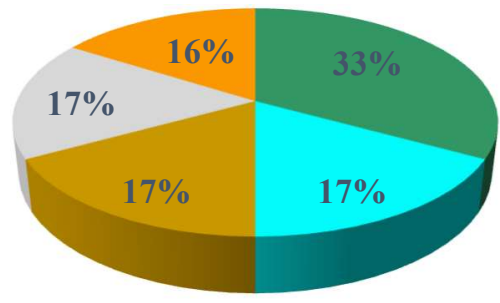

- Ligação a nucleotídeos

Função molecular BRSGO-7560 (I) $\times(\mathrm{NI})$ spots exclusivos

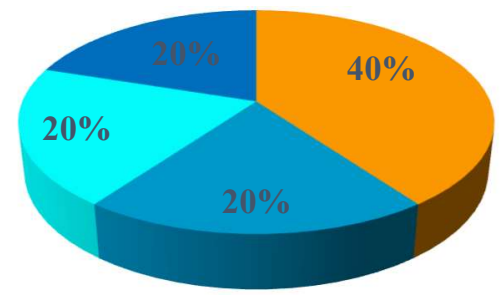

- Atividade catalítica

- Ligação

- Ligação a proteínas

Ligação a RNA

Figura 13. Distribuição das proteínas provenientes dos spots exclusivos em função de suas propriedades moleculares resultantes da análise intra cultivar para BRSGO-7560 nas condições não inoculada (NI) e inoculada (I). A- condição não inoculada; B- condição inoculada. 
Quanto aos processos biológicos na condição não inoculada para BRSGO-7560 houve maior atividade de proteínas responsáveis por estresse (21\%), resposta a estímulos abióticos (21\%), seguidos por proteínas de processos metabólicos (18\%) e organização de componente celular (18\%), (Figura 14). Na análise para condição inoculada houve maior relação com a fotossintese $(9 \%)$ e processos biossintéticos (9\%). Para os demais processos podemos citar: resposta a estímulo biótico (5\%), processo de morte celular (4\%), bem como transdução de sinais (4\%), (Figura 14).

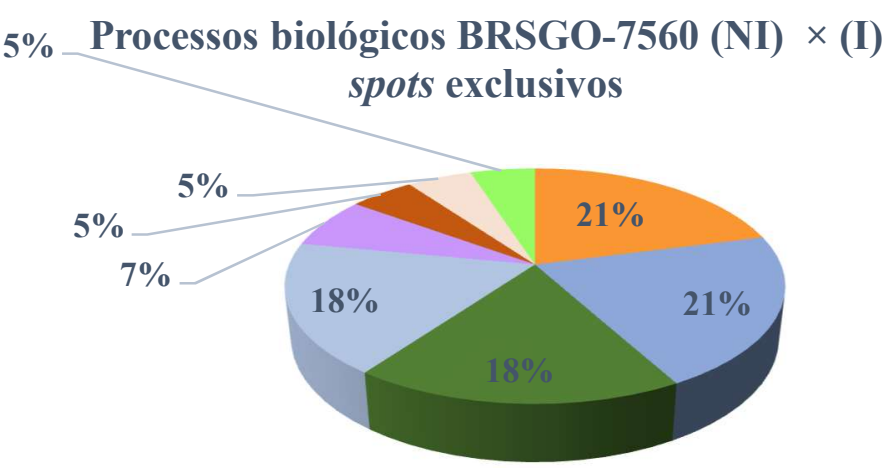

- Resposta a estresse

- Organização de componente celular

Processos catabólicos
- Resposta a estímulo abiótico

- Resposta a estímulo externo

- Processos metabólicos secundários
- Proteínas de processos metabólicos

- Resposta a estímulo biótico

\section{Processos biológicos BRSG0-7560 I × NI spots exclusivos}

- Resposta a estímulo abiótico

- Resposta a estresse

- Processos metabólicos contendo compostos de nucleobase

- Geração de precursores de metabolismo e energia

Fotossíntese

- Resposta a estímulo biótico

- Resposta a estímulo externo

- Transdução de sinal

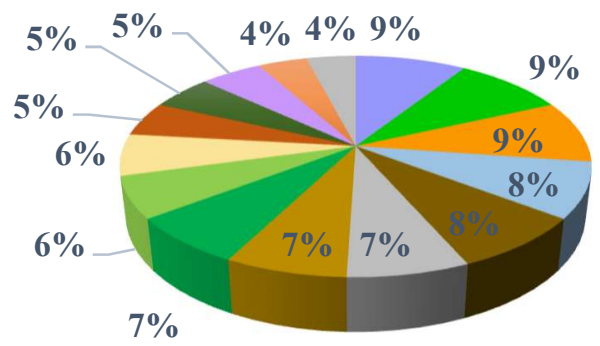

- Processos biosintéticos

- Organização de componente celular

- Desenvolvimento de organismo multicelular

- Resposta a estímulo endógeno

Processos de modificação de proteína celular

- Transporte

Morte celular

Figura 14. Distribuição das proteínas provenientes dos spots exclusivos em função dos processos biológicos resultantes da análise intra cultivar para BRSGO-7560 nas condições não inoculada (NI) e inoculada (I). Acondição não inoculada; B- condição inoculada. 
Nos resultados para distribuição pelos compartimentos celulares nesta mesma condição, observou-se uma maior concentração de proteínas ligadas ao citoplasma (38\%), seguido por região extra celular e núcleo (13\%). Para as os demais compartimentos ocorreu uma concentração de apenas $6 \%$, conforme figura 15. Na condição inoculada as proteínas tiveram maior distribuição nos plastídeos (29\%), (Figura 15).

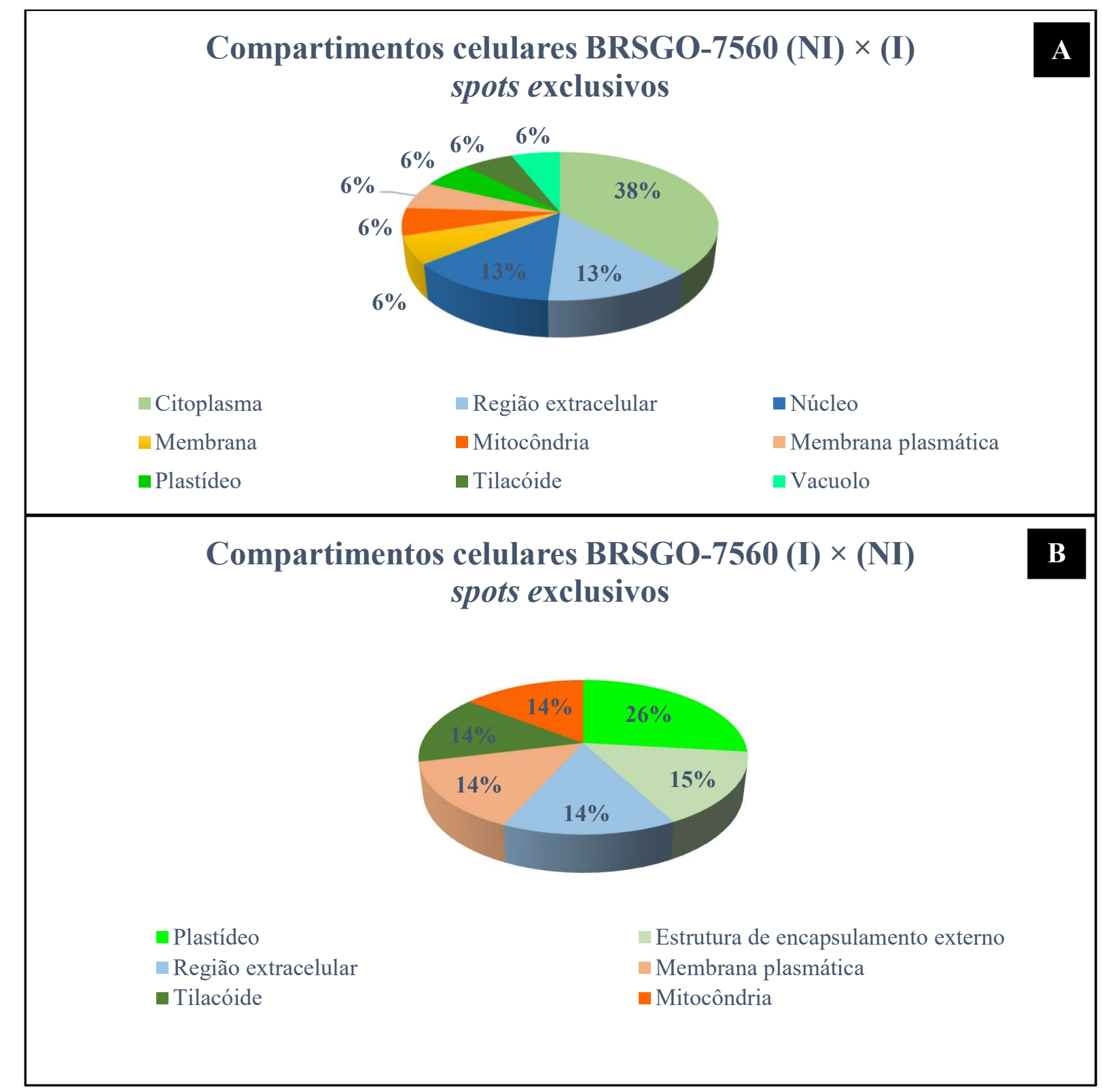

Figura 15. Distribuição das proteíns provenientes dos spots exclusivos em função dos compartimentos celulares resultantes da análise intra cultivar para BRSGO-7560 nas condições não inoculada (NI) e inoculada (I). Acondição não inoculada; B- condição inoculada. 
Na análise intra cultivar para MOSY-8001 (NI) $\times(\mathrm{I})$, foram observados 4 spots com abundância relativa aumentada, 2 foram descritos de acordo com Uniprot (spot 47 e 48) e 2 pelo Blast2Go (spots 627 e 335), (Tabela 8). A descrição da proteína correspondente ao único spot exclusivo encontrado para esta condição (spot 214) está apresentada na tabela 9. 
Tabela 8. Spots com abundância relativa aumentada obtidos em MSOY-8001 na condição não inoculada (NI) resultantes da análise comparativa intra cultivar com a condição inoculada (I) com Phakopsora pachyrhizi

\begin{tabular}{|c|c|c|c|c|c|c|c|}
\hline \multicolumn{3}{|c|}{$\begin{array}{l}\text { M-SOY-8001 (NI) } \\
\quad x \\
\text { MSOY-8001 (I) }\end{array}$} & \multirow{2}{*}{ *Descrição } & \multirow{2}{*}{ Espécie } & \multirow{2}{*}{$\begin{array}{c}\text { Massa } \\
(\mathbf{k D a})\end{array}$} & \multirow{2}{*}{$\begin{array}{l}\text { Cobertura } \\
\quad(\%)\end{array}$} & \multirow{2}{*}{ *PEP } \\
\hline Spot & $\begin{array}{c}{ }^{*} \mathbf{N}^{0} \mathrm{de} \\
\text { acesso } \\
\text { (Uniprot) }\end{array}$ & $\begin{array}{c}\text { e-Value } \\
\text { (Blast 2GO) }\end{array}$ & & & & & \\
\hline $\begin{array}{l}47 \\
48\end{array}$ & Q2PMV0 & $0,0 \mathrm{E} 0$ & $\begin{array}{l}\text { ATP synthase subunit beta, chloroplastic- (Uniprot) } \\
\text { (ATP synthase F1 sector subunit beta) (F-ATPase subunit beta) - (Uniprot) }\end{array}$ & Glycine max & $\begin{array}{l}53.754 \\
53.754\end{array}$ & $\begin{array}{l}64,7 \\
51,6\end{array}$ & $\begin{array}{l}8,91 \mathrm{E}-107 \\
3,23 \mathrm{E}-158\end{array}$ \\
\hline 627 & C6TKL8 & $0,0 \mathrm{E} 0$ & $\begin{array}{l}\text { Oxygen-evolving enhancer protein chloroplastic - (Blast2Go) } \\
33 \text { kda subunit of oxygen evolving system of photosystem ii - (Blast2Go) } \\
33 \text { kda thylakoid membrane protein }\end{array}$ & Glycine $\max$ & 34.784 & 38,0 & $6,24 \mathrm{E}-80$ \\
\hline 335 & I1MJ28 & $0,0 \mathrm{E} 0$ & $\begin{array}{l}\text { Rubisco large subunit-binding protein subunit chloroplastic- (Blast2Go) } \\
60 \mathrm{kda} \text { chaperonin subunit beta - (Blast2Go) }\end{array}$ & Glycine max & 62.843 & 47,9 & $3,10 \mathrm{E}-115$ \\
\hline
\end{tabular}

* $\mathrm{N}^{\mathrm{o}}$ de acesso de acordo com banco de dados do Uniprot.

* Descrição: realizada de acordo com o Uniprot ou pelo Blast2Go para as proteínas que não apresentavam anotações no Uniprot

*PEP: Posterior Error Probability of the identification. 
Tabela 9. Spots exclusivos obtidos em MSOY-8001 na condição não inoculada (NI) resultantes da análise comparativa intra cultivar com a condição inoculada (I) com Phakopsora pachyrhizi.

\begin{tabular}{|c|c|c|c|c|c|c|c|}
\hline \multicolumn{3}{|c|}{$\begin{array}{l}\text { MSOY-8001 (NI) } \\
\mathbf{x} \\
\text { MSOY-8001 (I) }\end{array}$} & \multirow{2}{*}{ *Descrição } & \multirow{2}{*}{ Espécie } & \multirow{2}{*}{$\begin{array}{c}\text { Massa } \\
(\mathbf{k D a})\end{array}$} & \multirow{2}{*}{$\begin{array}{c}\text { Cobertura } \\
(\%)\end{array}$} & \multirow{2}{*}{ *PEP } \\
\hline Spot & $\begin{array}{c}{ }^{*} \mathrm{~N}^{0} \text { de acesso } \\
\text { (Uniprot) }\end{array}$ & $\begin{array}{c}\text { e-Value } \\
\text { (Blast 2GO) }\end{array}$ & & & & & \\
\hline 214 & C6SV84 & $3,1 \mathrm{E}-116$ & $\begin{array}{l}\text { NADH dehydrogenase - (Blast 2Go) } \\
\text { Flavodoxin-like quinone reductase 1- (Blast 2Go) }\end{array}$ & Glycine max & 21.806 & 33,7 & $8,10 \mathrm{E}-25$ \\
\hline
\end{tabular}

* $\mathrm{N}^{0}$ de acesso de acordo com banco de dados do Uniprot.

* Descrição: realizada de acordo com o Uniprot ou pelo Blast2Go para as proteínas que não apresentavam anotações no Uniprot.

*PEP: Posterior Error Probability of the identification.

Na condição inoculada para a cultivar MSOY-8001, dos 2 spots que puderam ser analisados, 1 foi descrito de acordo com o Uniprot (spot

293) e o outro (spot 284) pelo Blast2Go (Tabela 10). 
Tabela 10. Spots com abundância relativa aumentada obtidos em MSOY-8001 na condição inoculada (I) com $P$. pachyrhizi resultantes da análise comparativa intra cultivar com a condição nã inoculada (NI).

\begin{tabular}{|c|c|c|c|c|c|c|c|}
\hline \multicolumn{3}{|c|}{$\begin{array}{l}\text { M-SOY-8001 (I) } \\
\text { x } \\
\text { M-SOY } 8011 \text { (NI) }\end{array}$} & \multirow{2}{*}{ *Descrição } & \multirow{2}{*}{ Espécie } & \multirow{2}{*}{$\begin{array}{l}\text { Massa } \\
\text { (kDa) }\end{array}$} & \multirow{2}{*}{$\begin{array}{c}\text { Cobertura } \\
(\%)\end{array}$} & \multirow{2}{*}{ *PEP } \\
\hline Spot & $\begin{array}{c}{ }^{*} \mathrm{~N}^{0} \text { de acesso } \\
\text { (Uniprot) }\end{array}$ & $\begin{array}{c}\text { e-Value } \\
\text { (Blast 2Go) }\end{array}$ & & & & & \\
\hline 284 & C6SXP1 & $1,6 \mathrm{E}-76$ & $\begin{array}{l}\text { Elongation factor 1-delta- (Blast2Go) } \\
\text { Elongation factor 1b-beta - (Blast2Go) }\end{array}$ & Glycine max & 25.087 & 47,4 & 6,97E-32 \\
\hline 293 & I1N5Q1 & $0,0 \mathrm{E} 0$ & Carbonic anhydrase - (Uniprot) & Glycine $\max$ & 36.749 & 9,7 & $6,47 \mathrm{E}-07$ \\
\hline
\end{tabular}

* $\mathrm{N}^{\circ}$ de acesso de acordo com banco de dados do Uniprot.

* Descrição: realizada de acordo com o Uniprot ou pelo Blast2Go para as proteínas que não apresentavam anotações no Uniprot.

*PEP: Posterior Error Probability of the identification.

Na figura 16 pode-se observar que de acordo com o diagrama, as proteínas encontradas com abundância relativa aumentada na análise intra cultivar para MSOY-8001 nas condições não inoculada e inoculada não possuem proteínas em comum estre as condições avaliadas.

Ao compararar todas as proteínas encontradas tanto na cultivar BRSGO-7560 quanto em MSOY-8001 nas condições não inoculada e inoculada, foi possível observar 1 protéina em comum entre BRSGO-7560 (NI) e MSOY-8001 (NI) proveniente de spots distintos, resultantes da análise intra cultivar (Figura 17). 


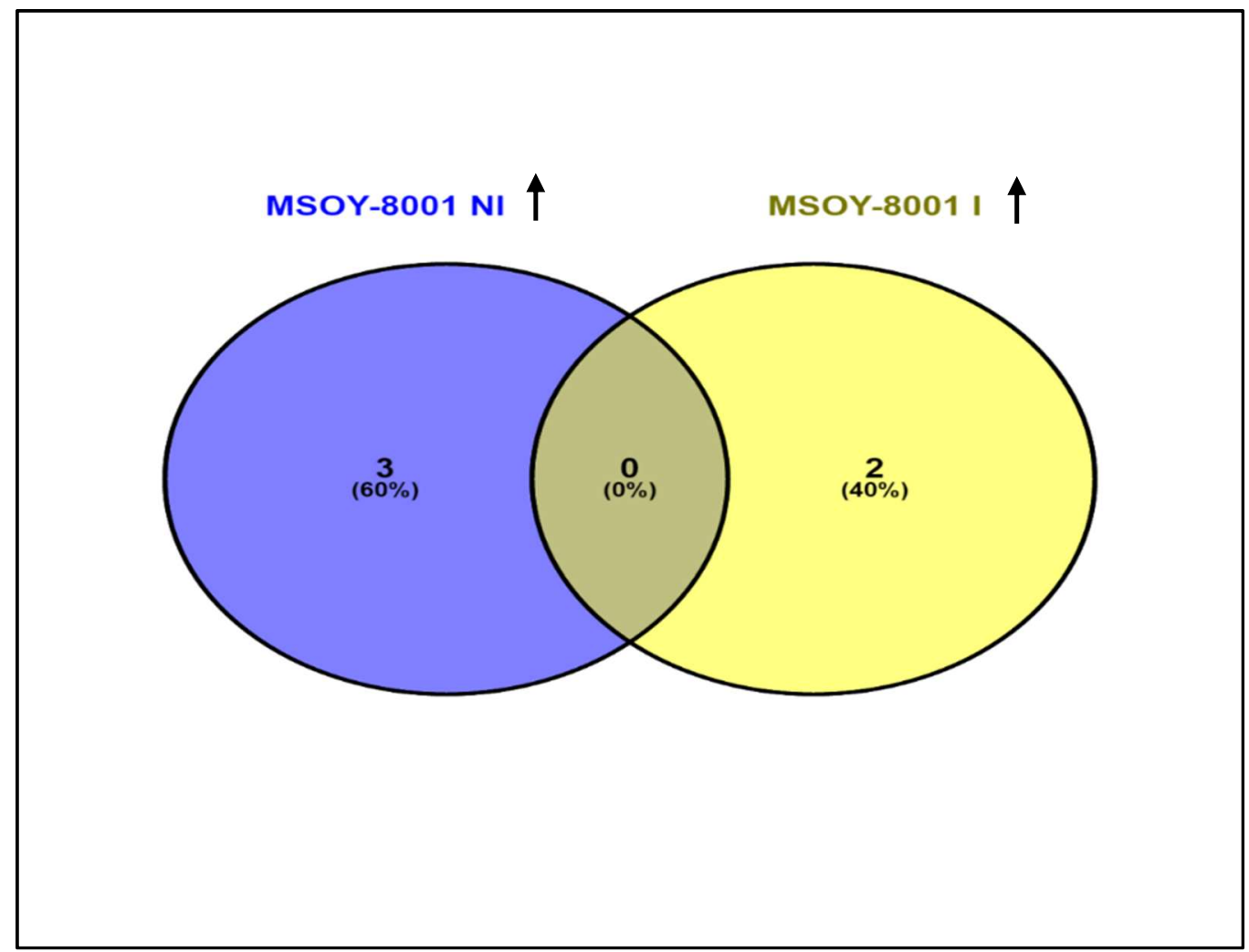

Figura 16. Diagrama de Venn de proteínas com abundância relativa aumentada ( $\uparrow$ ) resultantes da análise intra cultivar para MSOY-8001 nas condições não inoculada (NI) e inoculada (I).

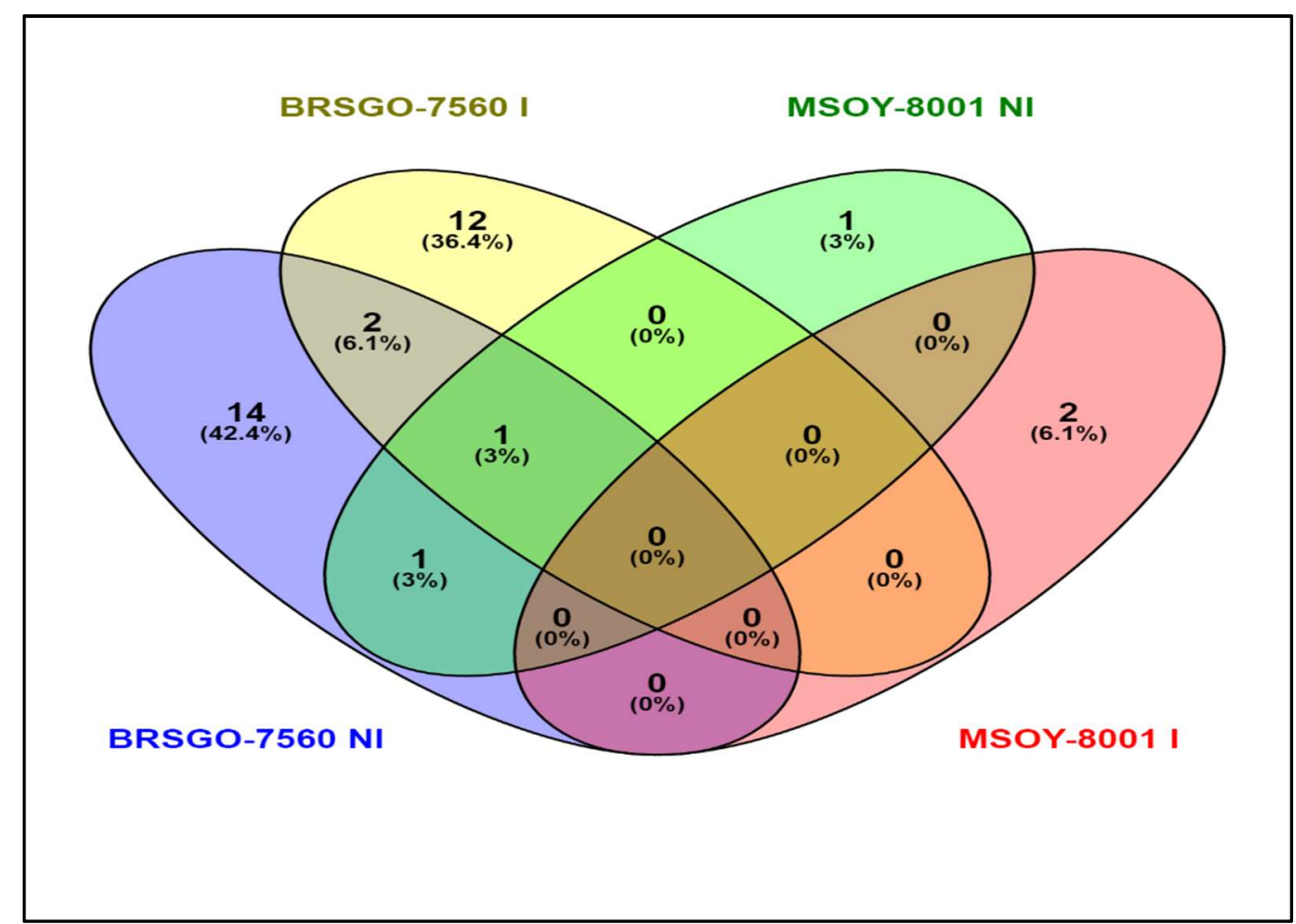

Figura 17. Diagrama de Venn de proteínas com abundância relativa aumentada resultantes da análise intra cultivar para BRSGO-7560 e MSOY-8001 nas condições não inoculada (NI) e inoculada (I). 
As proteínas identificadas na cultivar MSOY-8001 também foram agrupadas de acordo com os termos GO por função molecular, processos biológicos e compartimento celular figuras 18,19 e 20 , respectivamente.

Considerando a distribuição das proteínas de acordo com a função molecular, observouse na cultivar MSOY-8001 não inoculada uma maior porcentagem para proteínas de ligação a $\operatorname{ATP}(25 \%)$ e proteínas de ligação a outras proteínas (25\%), seguidas por proteínas ligadas à cauda polyU de RNA (12\%) e por proteínas envolvidas com atividades de síntese de ATP (12\%), além de proteínas que se ligam a íons de cálcio bem como proteínas envolvidas em atividade de oxigenação (12\%), (Figura 18). Na condição inoculada foi encontrado proteínas relacionadas à atividade catalítica $(50 \%)$ e protéinas com fator de atividade de tradução/ligação a RNA (50\%), (Figura 18). 


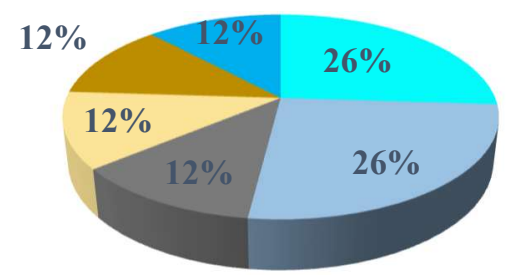

- Ligação a outras proteínas

- Ligação a ATP

- Ligação a cauda PolyU de RNA

Atividade relacionada a mecanismo de transporte de proton ATP

- Ligação a íons de cálcio

- Atividade envolvendo oxigenação

Função molecular MSOY-8001 (I) $\times($ NI)

- Atividade catalítica

- Atividade de tradução/ligação a RNA

Figura 18. Distribuição das proteínas com abundância relativa aumentada em função de suas propriedades moleculares resultantes da análise intra cultivar de MSOY-8001 nas condições não inoculada (NI) e inoculada (I). A- condição não inoculada; B- condição inoculada.

Com relação aos processos biológicos em MSOY-8001 na condição não inoculada foi observado uma maior concentração de proteínas relacionadas a processos celulares únicos (39\%), (Figura 19). 


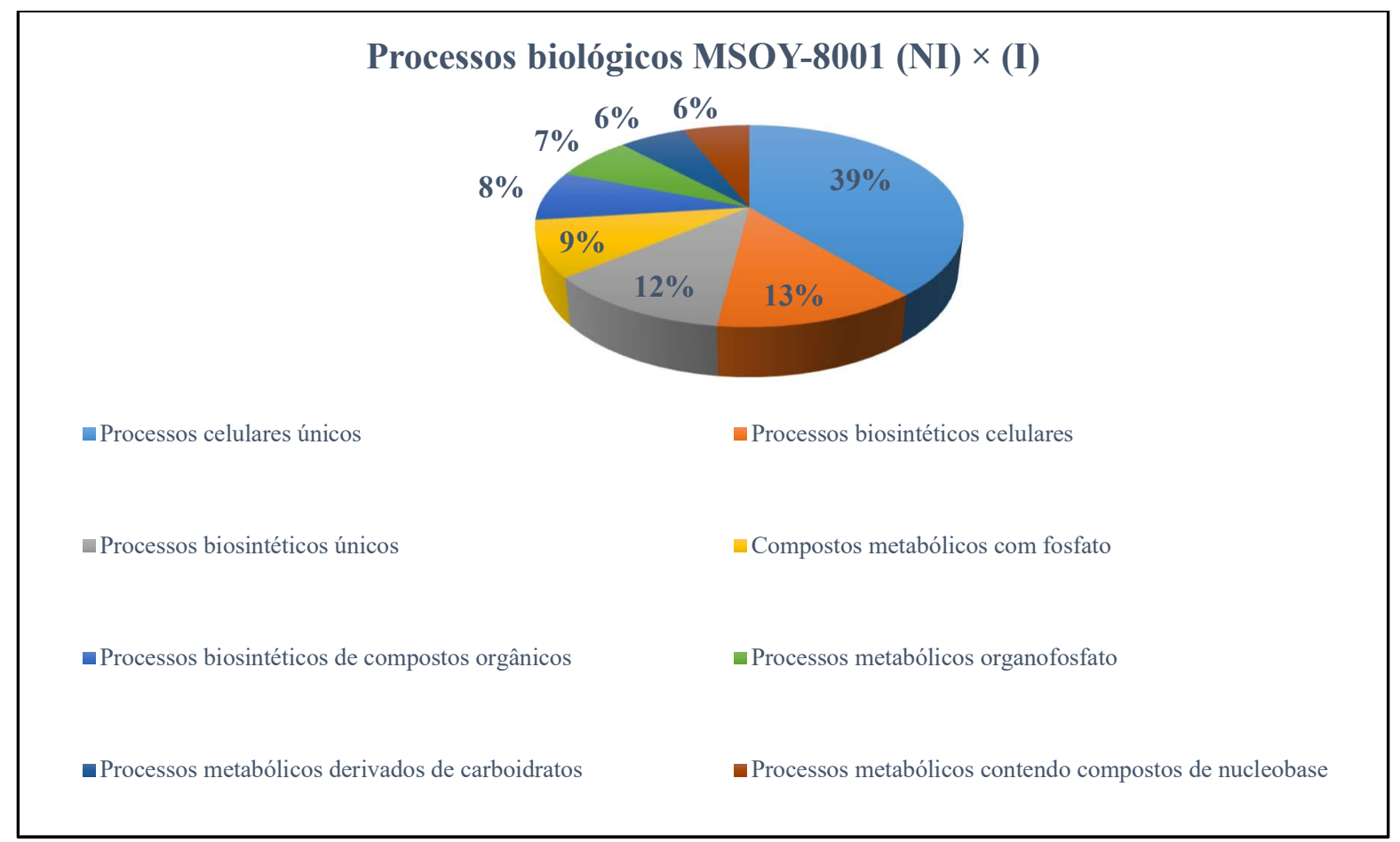

Figura 19 - Distribuição das proteínas com abundância relativa aumentada em função dos processos biológicos resultantes da análise intra cultivar para MSOY-8001 na condição não inoculada (NI).

Na distribuição em função dos compartimentos celulares para a condição não inoculada, houve predominância de proteínas associadas ao estroma do cloroplasto (21\%), membrana plasmática (19\%), apoplasto (16\%), membrana cloroplástica do tilacóide (16\%), e demais compartimentos em menor proporção (11\% e 6\%), (Figura 20).

\section{Compartimentos celulares MSOY-8001 (NI) $\times($ I)}

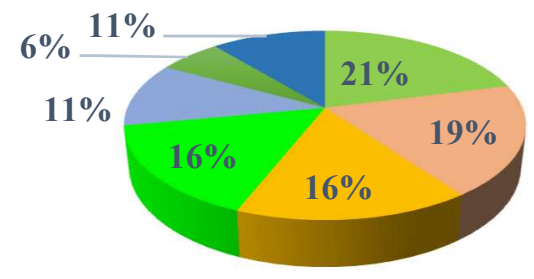

Estroma do cloroplasto

Membrana plasmática

Apoplasto

- Membrana cloroplástica do tilacóide

- Complexo proteina de membrana

Envelope

• Proteína de membrana intracelular não delimitada

Figura 20. Distribuição das proteínas em função dos compartimentos celulares resultantes da análise intra cultivar para MSOY-8001 na condição não inoculada (NI). 
A proteína correspondente ao único spot exclusivo observado na cultivar MSOY-8001 na condição não inoculadam, também foi classificada de acordo com os termos GO, conforme figuras 21,22 e 23 , respectivamente.

Nos resultados para função molecular, de acordo com os termos GO, observou-se para esta proteína 50\% de atividade relacionada à ligação a flavina-mononucleotídeo e 50\% com atividade NAD (P)H desidrogenase (Figura 21).

\section{Função molecular MSOY-8001 (NI) × (I) spot exclusivo}

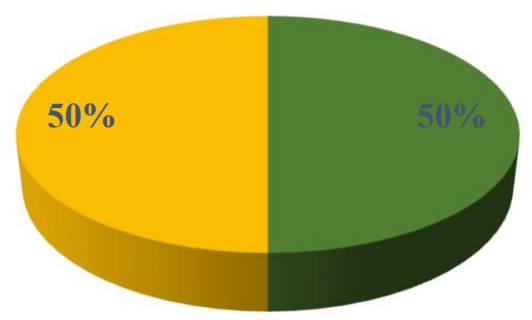

Figura 21. Distribuição da proteína proveniente do spot exclusivo em função de suas propriedades moleculares- análise intra cultivar para M-SOY-8001 na condição não inoculada (NI), resultante da análise comparatativa com a condição inoculada (I).

Com relação aos processos biológicos observa-se a presença de processos relacionados com resposta celular ao estímulo de auxinas, processos de oxi-redução, resposta ao íon cádmio, resposta ao estresse osmótico e regulação negativa de transcrição, todas na mesma proporção (20\%), conforme figura 22. 


\section{Processos biológicos MSOY-8001 (NI) $\times$ (I) spot exclusivo}

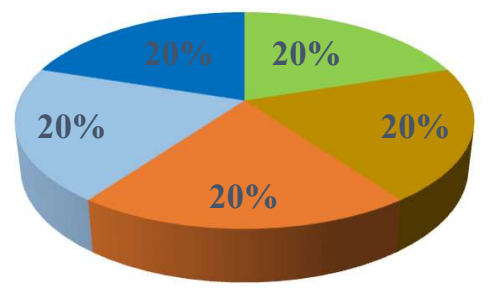

$$
\begin{aligned}
& \square \text { Resposta celular ao estímulo de auxinas } \quad \square \text { Processos de oxi-redução } \\
& \square \text { Resposta ao íon cádmio } \\
& \square \text { Resposta ao estresse osmótico } \\
& \text { - Regulação negativa de transcrição }
\end{aligned}
$$

Figura 22. Distribuição da proteína proveniente do spot exclusivo em função dos processos biológicos- análise intra cultivar para M-SOY-8001 na condição não inoculada (NI), resultante da análise comparatativa com a condição inoculada (I).

Ao se analisar a distribuição nos diferentes compartimentos celulares, constatou-se uma distribuição ampla: citosol, plasmodesma, região extracelular, membrana vacuolar e membrana plasmática, todos representado por $20 \%$ em cada compartimento (figura 23).

\section{Compartimentos celulares MSOY-8001 (NI) $\times($ I) spot exclusivo}

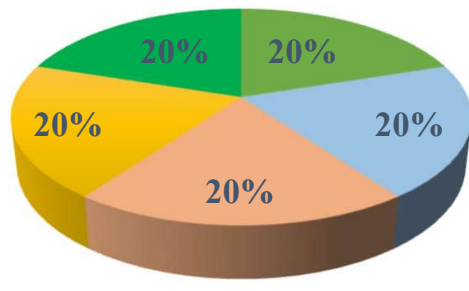

ロ Citosol $\square$ Região extra celular $\square$ Membrana plasmática $\square$ Plasmodesma $\square$ Membrana vacuolar

Figura 23. Distribuição da proteína proveniente do spot exclusivo em função dos compartimentos celularesanálise intra cultivar para MSOY-8001 na condição não inoculada (NI), resultante da análise comparatativa com a condição inoculada (I). 


\subsection{Análise inter cultivares}

A seguir estão representados os resultados para as cultivares BRSGO-7560 e para MSOY-8001 de acordo com a abundância relativa na análise inter cultivares nas condições não inoculada (NI) e inoculada (I), (Tabela 11). A cultivar BRSGO-7560 apresentou na condição não inoculada um total de 23 spots com abundância relativa aumentada, enquanto MSOY-8001 nesta mesma condição apresentou um total de 14 spots com aumento em sua abundância relativa (Tabela 11 e Figura 24). Com relação aos spots exclusivos, na cultivar BRSGO-7560 foram observados 11 spots na condição não inoculada, enquanto em MSOY-8001 nesta mesma condição não foi observado nenhum spot exclusivo, (Tabela 11 e Figura 25). Ao avaliar a condição inoculada, em BRSGO-7560 foram observados 32 spots com abundância relativa aumentada, já a cultivar MSOY-8001 nesta mesma condição, apresentou 13 spots (Tabela 11 e Figura 26). Quanto aos spots exclusivos na condição inoculada, para a cultivar BRSGO-7560 foram encontrados 2 spots exclusivos, e em MSOY-8001 apenas 1, conforme tabela 11 e figura 27.

Tabela 11. Total de spots com abundância relativa aumentatada $(\uparrow)$ e spots exclusivos resultantes da análise inter cultivares para as cultivares BRSGO-7560 (resistente) e MSOY8001 (suscetível) nas condições não inoculada (NI) e inoculada (I) com P. pachyrhizi.

\begin{tabular}{|c|c|c|c|c|}
\hline Cultivar & Reação & Condição & Total de spots & Spots exclusivos \\
\hline $\begin{array}{c}\text { BRSGO-7560 } \\
\times \\
\text { MSOY-8001 }\end{array}$ & Resistente & \multirow[t]{2}{*}{$(\mathrm{NI})$} & $23 \uparrow(\mathrm{NI})$ & $11(\mathrm{NI})$ \\
\hline $\begin{array}{c}\text { MSOY-8001 } \\
\times \\
\text { BRSGO-7560 } \\
\end{array}$ & Suscetível & & $14 \uparrow(\mathrm{NI})$ & $0(\mathrm{NI})$ \\
\hline $\begin{array}{c}\text { BRSGO-7560 } \\
\times \\
\text { MSOY-8001 }\end{array}$ & Resistente & \multirow[t]{2}{*}{ (I) } & $32 \uparrow(\mathrm{I})$ & $2(\mathrm{I})$ \\
\hline $\begin{array}{c}\text { MSOY-8001 } \\
\times \\
\text { BRSGO-7560 }\end{array}$ & Suscetível & & $13 \uparrow(\mathrm{I})$ & $1(\mathrm{I})$ \\
\hline
\end{tabular}




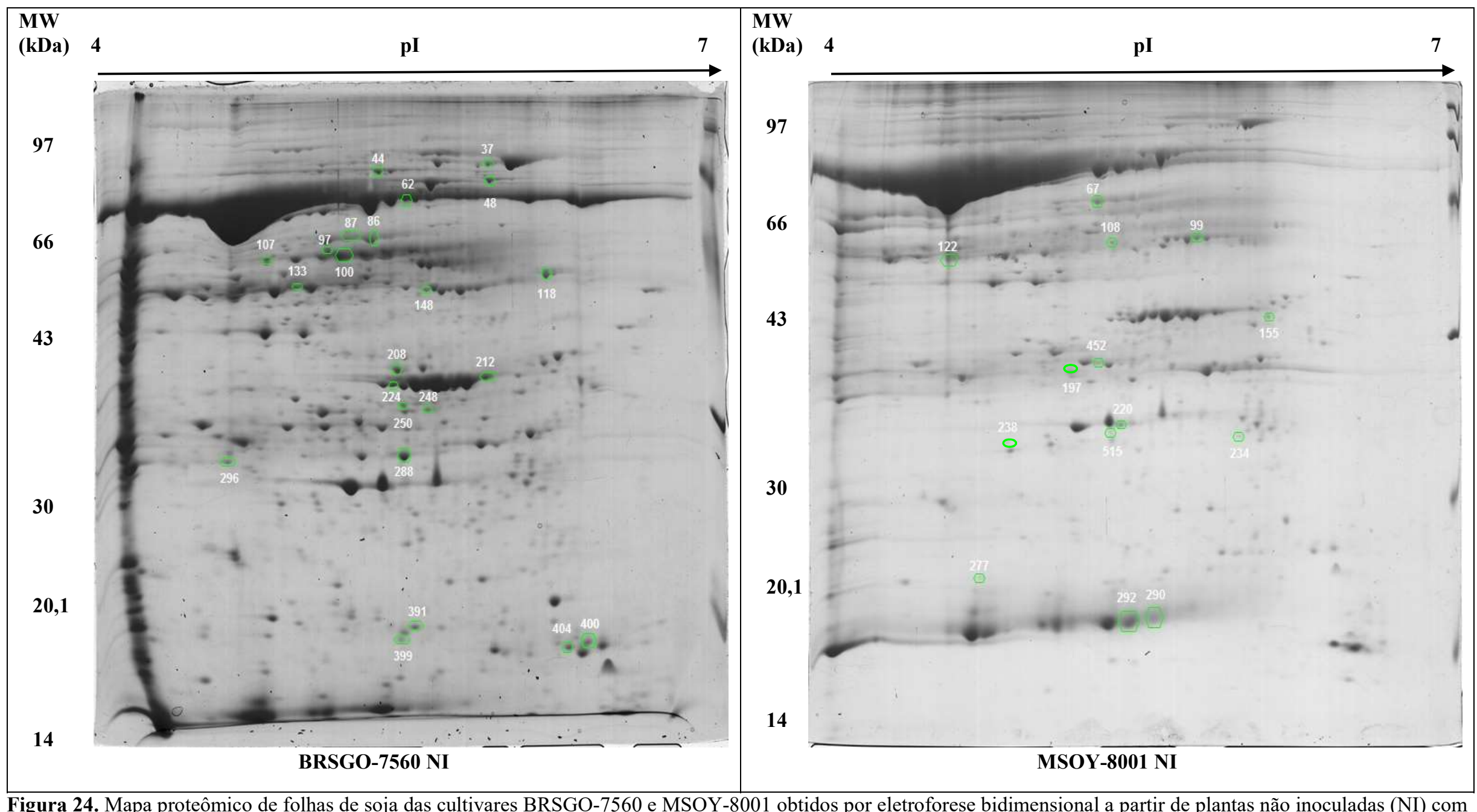

Figura 24. Mapa proteômico de folhas de soja das cultivares BRSGO-7560 e MSOY-8001 obtidos por eletroforese bidimensional a partir de plantas não inoculadas (NI) com P. pachyrhizi. Os spots com abundância relativa aumentada estão identificados pelo número Match ID e circundados em verde. 


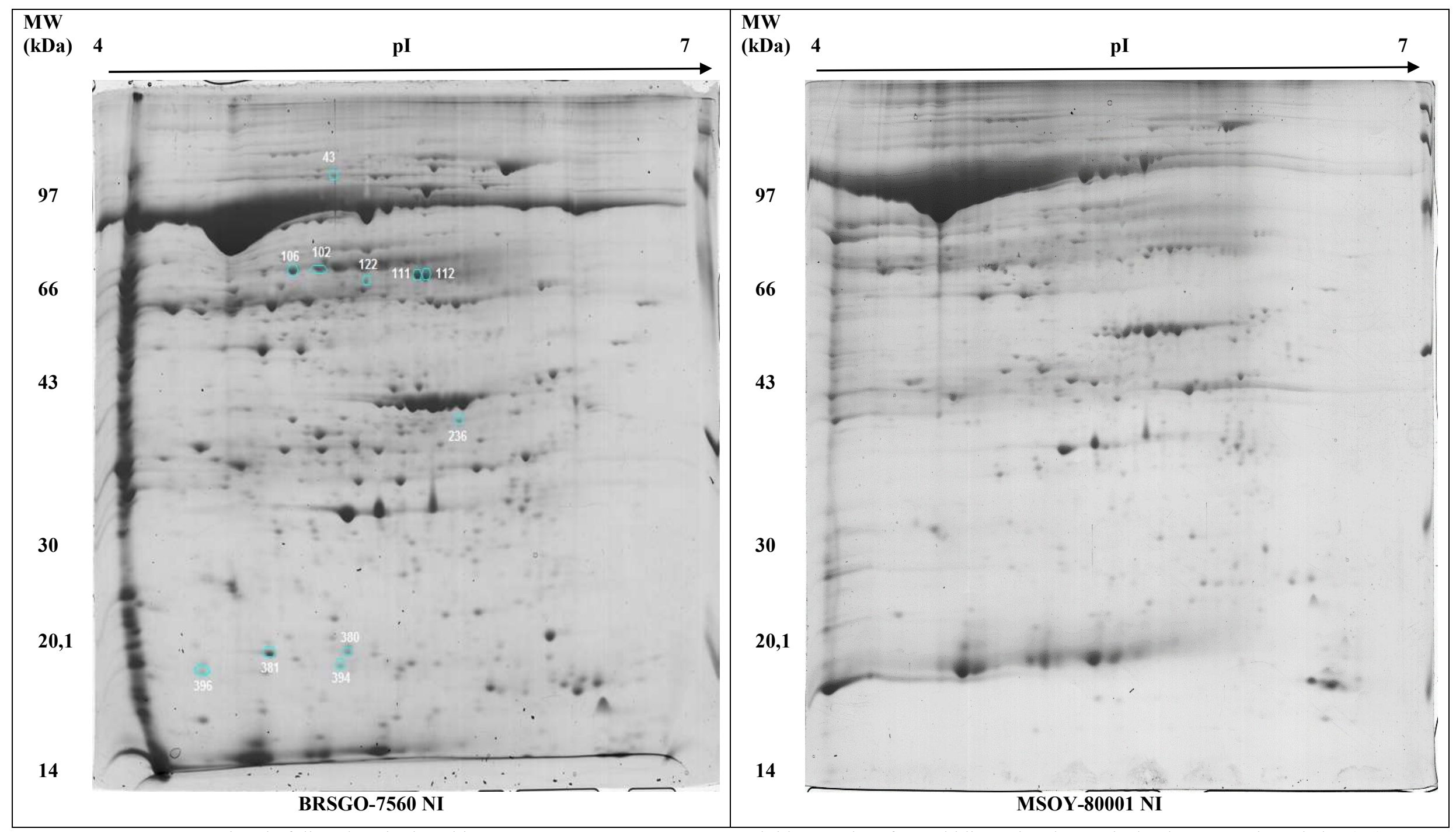

Figura 25. Mapa proteômico de folhas de soja da cultivar BRSGO-7560 e MSOY-8001 obtido por eletroforese bidimensional a partir de plantas não inoculadas (NI) com $P$. pachyrhizi. Os spots exclusivos estão identificados pelo número Match ID e circundados em azul. 


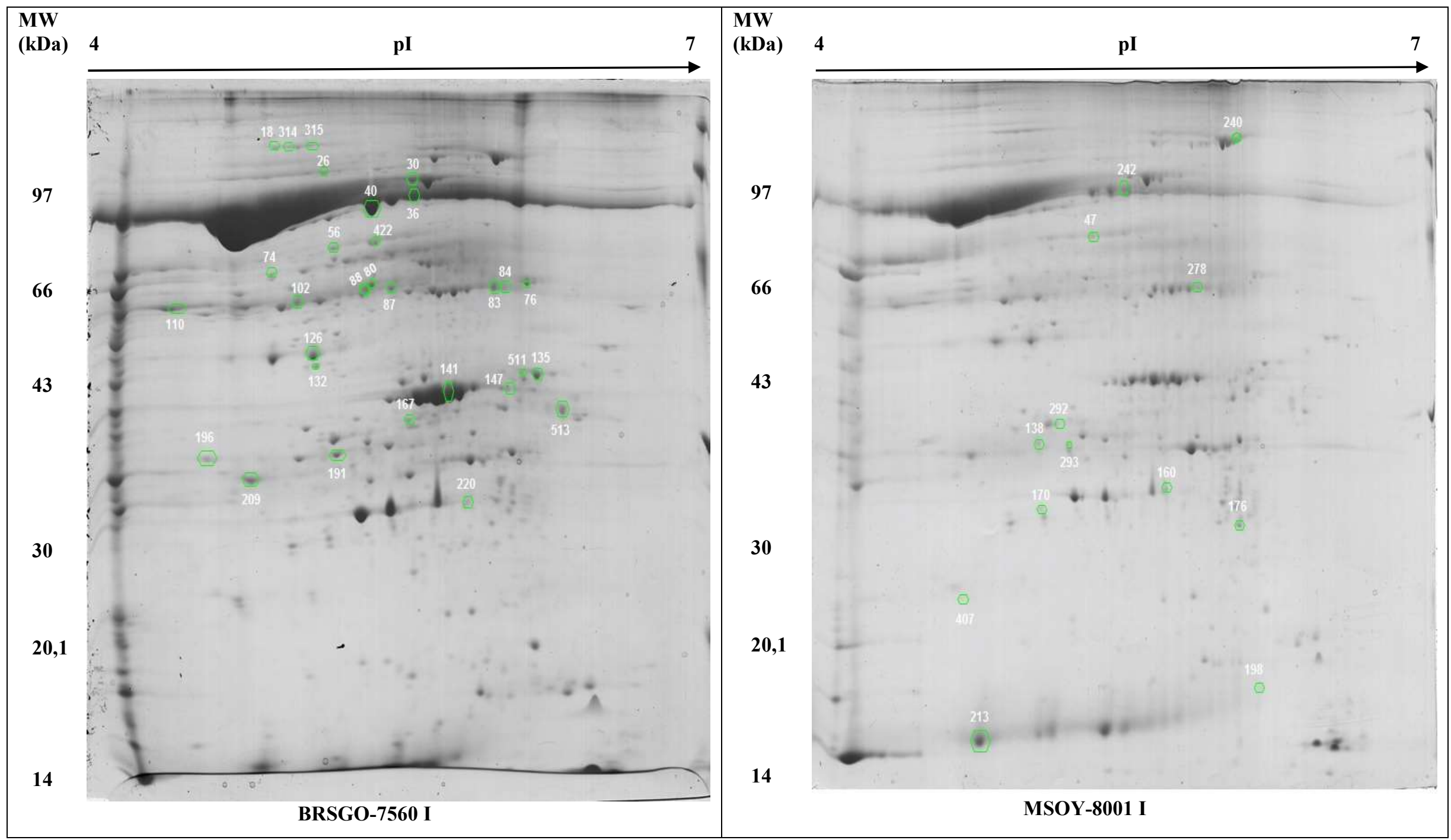

Figura 26. Mapa proteômico de folhas de soja das cultivares BRSGO-7560 e MSOY-8001 obtidos por eletroforese bidimensional a partir de plantas inoculadas (I) com $P$. pachyrhizi. Os spots com abundância relativa aumentada estão identificados pelo número Match ID e circundados em verde. 


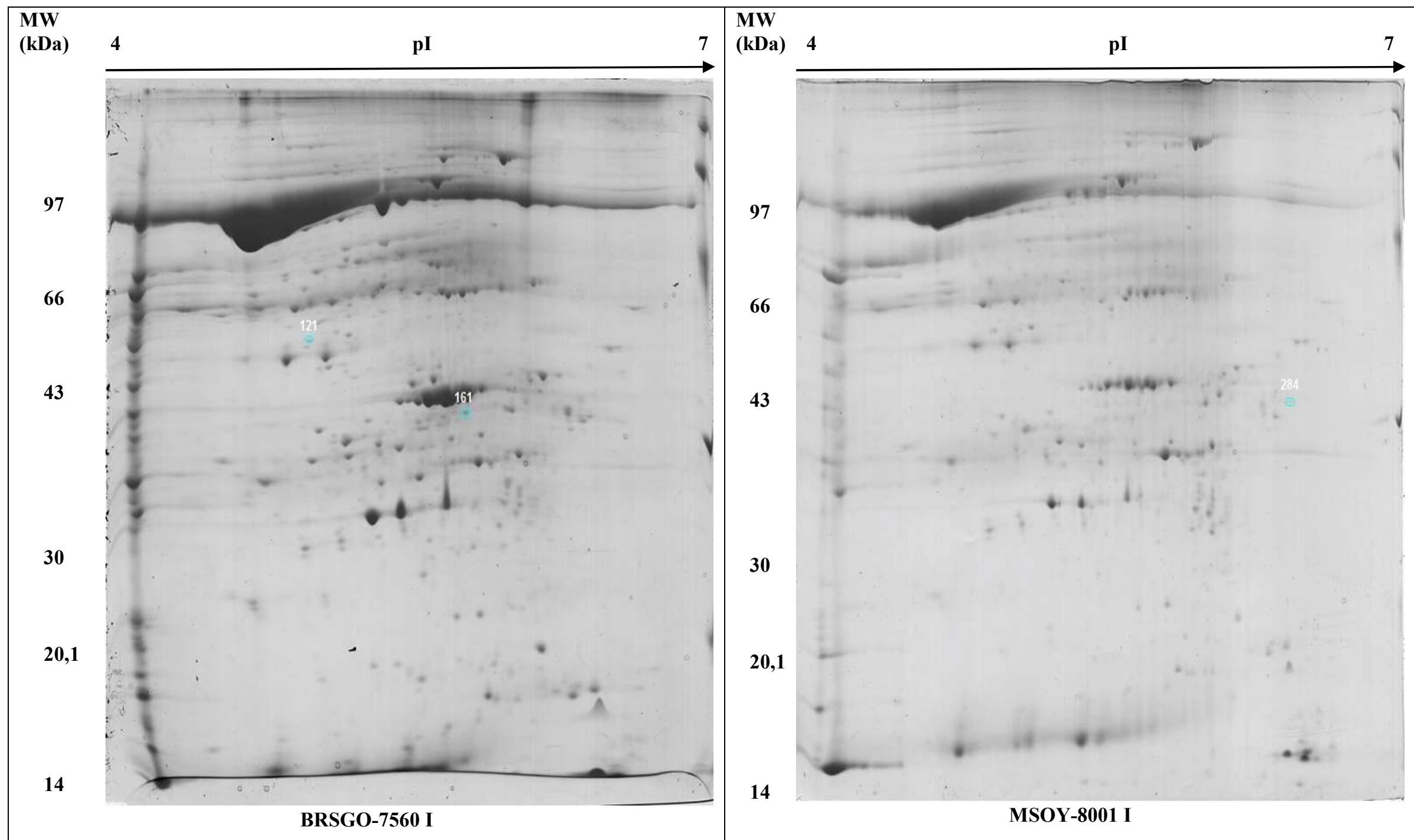

Figura 27. Mapa proteômico de folhas de soja das cultivares BRSGO-7560 e MSOY-8001 obtidos por eletroforese bidimensional a partir de plantas inoculadas com $P$. pachyrhizi. Os spots exclusivos estão identificados pelo número Match ID e circundados em azul. 
Entre os 23 spots observados na análise comparativa entre BRSGO-7560 e MSOY-8001 na condição não inoculada, 19 foram analisados. Destes, 6 foram descritos de acordo com o banco de dados do Uniprot e os demais pelo Blast2Go, (Tabela 12). Dos 11 spots exclusivos observados na interação entre BRSGO-7560 e MSOY-8001 na condição não inoculada, 4 foram descritos pelo Uniprot e os demais pelo Blast2Go, (Tabela 13).

Dos 14 spots observados na análise inter cultivares entre MSOY-8001 e BRSGO-7560 na condição não inoculada, 11 foram descritos de acordo com o banco de dados do Uniprot e os demais pelo Blast2Go, (Tabela 14). 
Tabela 12. Spots com abundância relativa aumentada obtidos em BRSGO-7560 na condição não inoculada (NI) resultantes da análise comparativa inter cultivares com MSOY-8001 na condição não inoculada (NI).

\begin{tabular}{|c|c|c|c|c|c|c|c|}
\hline \multicolumn{3}{|c|}{$\begin{array}{l}\text { BRSGO-7560 (NI) } \\
\quad x \\
\text { MSOY-8001 (NI) }\end{array}$} & \multirow{2}{*}{ *Descrição } & \multirow{2}{*}{ Espécie } & \multirow{2}{*}{$\begin{array}{l}\text { Massa } \\
\text { (kDa) }\end{array}$} & \multirow{2}{*}{$\begin{array}{l}\text { Cobertura } \\
\quad(\%)\end{array}$} & \multirow{2}{*}{ *PEP } \\
\hline Spot & $\begin{array}{c}* \mathrm{~N}^{0} \text { de acesso } \\
\text { (Uniprot) }\end{array}$ & $\begin{array}{c}\text { e-Value } \\
\text { (Blast 2GO) }\end{array}$ & & & & & \\
\hline 37 & I1MJU7 & $0,0 \mathrm{E} 0$ & Stromal $70 \mathrm{kda}$ heat shock-related chloroplastic- (Blast 2Go) & Glycine $\max$ & 73.754 & 30,6 & $4,92 \mathrm{E}-70$ \\
\hline 44 & $\mathrm{I} 1 \mathrm{MJ} 28$ & $0,0 \mathrm{E} 0$ & $\begin{array}{l}\text { Rubisco large subunit-binding protein subunit chloroplastic- (Blast 2Go) } \\
60 \mathrm{kDa} \text { Chaperonin subunit beta- (Blast 2Go) }\end{array}$ & Glycine $\max$ & 62.843 & 46,7 & $\begin{array}{l}3,42 \mathrm{E}- \\
109\end{array}$ \\
\hline 48 & I1LR60 & $0,0 \mathrm{E} 0$ & $\begin{array}{l}\text { Rubisco large subunit-binding protein subunit chloroplastic- (Blast 2Go) } \\
60 \mathrm{kDa} \text { Chaperonin subunit alpha- (Blast 2Go) }\end{array}$ & Glycine max & 61.704 & 47,6 & $\begin{array}{l}1,55 \mathrm{E}- \\
124\end{array}$ \\
\hline 62 & Q2PMV0 & $0,0 \mathrm{E} 0$ & $\begin{array}{l}\text { ATP synthase subunit beta, chloroplastic- (Uniprot) } \\
\text { (ATP synthase F1 sector subunit beta) (F-ATPase subunit beta)- (Uniprot) }\end{array}$ & Glycine $\max$ & 53.754 & 63,5 & $\begin{array}{l}5,28 \mathrm{E}- \\
112\end{array}$ \\
\hline $\mathbf{8 6}+\mathbf{8 7}+\mathbf{1 0 7}$ & F4ZZ27 & $0,0 \mathrm{E} 0$ & 1-Deoxy-D-xylulose 5-phosphate reductoisomerase- (Uniprot) & Glycine $\max$ & 50.509 & 29,7 & $1,71 \mathrm{E}-62$ \\
\hline 118 & I1MJC6 & $8,3 \mathrm{E}-111$ & Phosphoglycerate kinase- (Uniprot) & Glycine $\max$ & 39.047 & 9,8 & $3,95 \mathrm{E}-09$ \\
\hline 133 & I1JSJ3 & $0,0 \mathrm{E} 0$ & Fructose-bisphosphate aldolase- (Uniprot) & Glycine $\max$ & 42.568 & 36,2 & $1,82 \mathrm{E}-68$ \\
\hline 148 & I1KE04 & $0,0 \mathrm{E} 0$ & $\begin{array}{l}\text { Peptidyl-prolyl cis-trans isomerase chloroplastic- (Blast2Go) } \\
\text { Rotamase cyp37- (Blast2Go) } \\
\text { Thylakoid lumen ppiase of } 38 \mathrm{kDa} \text { - (Blast2Go) }\end{array}$ & Glycine $\max$ & 47,32 & 36,9 & $5,59 \mathrm{E}-39$ \\
\hline
\end{tabular}




\begin{tabular}{|c|c|c|c|c|c|c|c|}
\hline 208 & K7MUH9 & $0,0 \mathrm{E} 0$ & Phosphoglycolate phosphatase chloroplastic- (Blast2Go) & Glycine max & 40.725 & 36,7 & $8,94 \mathrm{E}-44$ \\
\hline 212 & C6TKL8 & $0,0 \mathrm{E} 0$ & $\begin{array}{l}\text { Oxygen-evolving enhancer protein chloroplastic- (Blast2Go) } \\
33 \mathrm{kDa} \text { Subunit of oxygen evolving system of photosystem ii- (Blast2Go) } \\
33 \mathrm{kDa} \text { Thylakoid membrane protein- (Blast2Go) } \\
\text { oec } 33 \mathrm{kDa} \text { subunit- (Blast2Go) }\end{array}$ & Glycine $\max$ & 34.784 & 37,1 & $4,14 \mathrm{E}-54$ \\
\hline 224 & C6T7N2 & $0,0 \mathrm{E} 0$ & $\begin{array}{l}\text { Oxygen-evolving enhancer protein chloroplastic- (Blast2Go) } \\
33 \mathrm{kDa} \text { Subunit of oxygen evolving system of photosystem ii- (Blast2Go) } \\
33 \mathrm{kDa} \text { Thylakoid membrane protein- (Blast2Go) } \\
\text { Oec } 33 \mathrm{kDa} \text { subunit- (Blast2Go) }\end{array}$ & Glycine $\max$ & 34.628 & 47,9 & $1,52 \mathrm{E}-51$ \\
\hline 250 & I1JXF1 & $8,4 \mathrm{E}-148$ & $\begin{array}{l}\text { Haloacid dehalogenase-like hydrolase domain-containing protein } \\
\text { at3g48420-(Blast2Go) }\end{array}$ & Glycine max & 35.422 & 33,2 & $4,41 \mathrm{E}-36$ \\
\hline 288 & C6TJG0 & $5,0 \mathrm{E}-127$ & $\begin{array}{l}20 \mathrm{kDa} \text { Chloroplastic ((Blast2Go) } \\
\text { Chaperonin } 10 \text { (Blast2Go) } \\
\text { Chaperonin } 20 \text { (Blast2Go) }\end{array}$ & Glycine max & 26.656 & 66,4 & $9,23 \mathrm{E}-74$ \\
\hline 391 & C6T5M6 & $3,3 \mathrm{E}-90$ & $\begin{array}{l}\text { 2-Cys peroxiredoxin bas1-chloroplastic-(Blast2Go) } \\
\text { Thiol-specific antioxidant protein b- (Blast2Go) }\end{array}$ & Glycine max & 17.437 & 66 & $2,08 \mathrm{E}-43$ \\
\hline 399 & I1J732 & $1,8 \mathrm{E}-48$ & Hsp14_soybn ame: full= kda class i heat shock protein - (Blast2Go) & Glycine max & 16.372 & 45,8 & $3,83 \mathrm{E}-26$ \\
\hline $\begin{array}{l}400 \\
404\end{array}$ & С6T0B7 & 1,0E-99 & Glycine cleavage system h mitochondrial- (Blast2Go) & Glycine $\max$ & $\begin{array}{l}21.955 \\
21.955\end{array}$ & $\begin{array}{l}37,2 \\
37,2\end{array}$ & $\begin{array}{l}6,84 \mathrm{E}-42 \\
7,68 \mathrm{E}-41\end{array}$ \\
\hline
\end{tabular}

* $\mathrm{N}^{\mathrm{o}}$ de acesso de acordo com banco de dados do Uniprot.

* Descrição: realizada de acordo com o Uniprot ou pelo Blast2Go para as proteínas que não apresentavam anotações no Uniprot.

*PEP: Posterior Error Probability of the identification. 
Tabela 13. Spots exclusivos obtidos em BRSGO-7560 na condição não inoculada (NI), resultantes da análise comparativa inter cultivares com MSOY-8001 na condição não inoculada (NI).

\begin{tabular}{|c|c|c|c|c|c|c|c|}
\hline \multicolumn{3}{|c|}{$\begin{array}{c}\text { BRSGO-7560 (NI) } \\
\text { X } \\
\text { MSOY-8001 (NI) } \\
\end{array}$} & \multirow[t]{2}{*}{ *Descrição } & \multirow[t]{2}{*}{ Espécie } & \multirow{2}{*}{$\begin{array}{c}\text { Massa } \\
(k D a)\end{array}$} & \multirow{2}{*}{$\begin{array}{c}\text { Cobertura } \\
\qquad \%)\end{array}$} & \multirow[t]{2}{*}{ *PEP } \\
\hline Spot & $\begin{array}{c}{ }^{*} \mathrm{~N}^{0} \text { de acesso } \\
\text { (Uniprot) }\end{array}$ & $\begin{array}{c}\text { e-Value } \\
\text { (Blast 2GO) }\end{array}$ & & & & & \\
\hline 43 & I1L6W0 & $0,0 \mathrm{E} 0$ & Bisphosphoglycerate-independent phosphoglycerate mutase (Blast 2Go) & Glycine $\max$ & 60.868 & 21,1 & $1,11 \mathrm{E}-32$ \\
\hline $\begin{array}{l}102 \\
106\end{array}$ & C6TNM8 & $0,0 \mathrm{E} 0$ & Glutamine synthetase (Uniprot) & Glycine max & $\begin{array}{l}47.664 \\
47.664\end{array}$ & $\begin{array}{l}29,6 \\
27,5\end{array}$ & $\begin{array}{c}2,64 \mathrm{E}-123 \\
2,26 \mathrm{E}-84\end{array}$ \\
\hline 111 & C6TL29 & $0,0 \mathrm{E} 0$ & Phosphoribulokinase (Uniprot) & Glycine max & 45.329 & 23,3 & $2,36 \mathrm{E}-41$ \\
\hline 112 & I1J4L6 & $0,0 \mathrm{E} 0$ & Phosphoribulokinase (Uniprot) & Glycine $\max$ & 45.269 & 34,9 & $1,71 \mathrm{E}-51$ \\
\hline 122 & I1N1G8 & $5,1 \mathrm{E}-162$ & $\begin{array}{l}\text { 2-Methylene-furan-3-one reductase- (Blast2Go) } \\
\text { Enone oxidoreductase - (Blast2Go) }\end{array}$ & Glycine $\max$ & 41.969 & 44,8 & $2,83 \mathrm{E}-64$ \\
\hline 236 & С6Т5С9 & $9,3 \mathrm{E}-170$ & Stress responsive a b barrel domain protein (Blast 2Go) & Glycine $\max$ & 27.656 & 40,7 & $1,62 \mathrm{E}-63$ \\
\hline 380 & K7LQI0 & $8,3 \mathrm{E}-151$ & Disease resistance-dirigent domain protein (Blast 2Go) & Glycine $\max$ & 38.527 & 12,1 & $1,60 \mathrm{E}-14$ \\
\hline 381 & I1KRC3 & $0,0 \mathrm{E} 0$ & n-Acetylglucosaminyl phosphatidylinositol de-n-acetylase (Blast 2Go) & Glycine $\max$ & 29.839 & 11,9 & $1,30 \mathrm{E}-02$ \\
\hline 394 & C6T5U3 & $1,7 \mathrm{E}-103$ & HSP $11 \mathrm{kDa}$ class i heat shock protein (Blast2Go) & Glycine max & 17.485 & 68,6 & $5,69 \mathrm{E}-42$ \\
\hline 396 & I1JQF4 & $0,0 \mathrm{E} 0$ & NPL4-like protein 1 (Blast 2Go) & Glycine max & 46.534 & 9,0 & $8,33 \mathrm{E}-03$ \\
\hline
\end{tabular}

* $\mathrm{N}^{\mathrm{o}}$ de acesso de acordo com banco de dados do Uniprot.

* Descrição: realizada de acordo com o Uniprot ou pelo Blast2Go para as proteínas que não apresentavam anotações no Uniprot.

*PEP: Posterior Error Probability of the identification 
Tabela 14. Spots com abundância relativa aumentada obtidos em MSOY-8001 na condição não inoculada (NI), resultantes da análise comparativa inter cultivares com BRSGO-7560 na condição não inoculada (NI).

\begin{tabular}{|c|c|c|c|c|c|c|c|}
\hline \multicolumn{3}{|c|}{$\begin{array}{l}\text { MSOY-8001 (NI) } \\
\text { X } \\
\text { BRSGO-7560 (NI) }\end{array}$} & \multirow{2}{*}{ *Descrição } & \multirow{2}{*}{ Espécie } & \multirow{2}{*}{$\begin{array}{l}\text { Massa } \\
\text { (kDa) }\end{array}$} & \multirow{2}{*}{$\begin{array}{l}\text { Cobertura } \\
\quad(\%)\end{array}$} & \multirow{2}{*}{ *PEP } \\
\hline Spot & $\begin{array}{c}{ }^{*} \mathrm{~N}^{0} \text { de acesso } \\
\text { (Uniprot) }\end{array}$ & $\begin{array}{c}\text { e-Value } \\
\text { (Blast 2GO) }\end{array}$ & & & & & \\
\hline $\begin{array}{l}155 \\
234\end{array}$ & Q2PMV0 & $0,0 \mathrm{E} 0$ & $\begin{array}{l}\text { ATP synthase subunit beta, chloroplastic - (Uniprot) } \\
\text { ATP synthase F1 sector subunit beta) (F-ATPase subunit beta)- (Uniprot) }\end{array}$ & Glycine $\max$ & $\begin{array}{l}53.754 \\
53.754\end{array}$ & $\begin{array}{l}23,3 \\
10,4\end{array}$ & $\begin{array}{l}4,80 \mathrm{E}-25 \\
4,88 \mathrm{E}-26\end{array}$ \\
\hline $\begin{array}{l}197 \\
452\end{array}$ & P28759 & $0,0 \mathrm{E} 0$ & Superoxide dismutase [Fe], chloroplastic (Uniprot) & Glycine $\max$ & $\begin{array}{l}27.841 \\
27.841\end{array}$ & $\begin{array}{l}34,3 \\
44,0\end{array}$ & $\begin{array}{l}4,69 \mathrm{E}-29 \\
2,20 \mathrm{E}-66\end{array}$ \\
\hline 238 & $\mathrm{I} 1 \mathrm{M} 712$ & $1,3 \mathrm{E}-139$ & Oxygen-evolving enhancer protein- (Uniprot) & Glycine $\max$ & 28.597 & 23,5 & $1,89 \mathrm{E}-21$ \\
\hline $\begin{array}{l}277 \\
290 \\
292\end{array}$ & C6SVL2 & $1,1 \mathrm{E}-130$ & Ribulose bisphosphate carboxylase small chain- (Uniprot) & Glycine max & $\begin{array}{l}19.979 \\
19.979 \\
19.979 \\
\end{array}$ & $\begin{array}{l}28,1 \\
23,6 \\
19,7\end{array}$ & $\begin{array}{l}2,39 \mathrm{E}-16 \\
2,91 \mathrm{E}-31 \\
3,36 \mathrm{E}-27\end{array}$ \\
\hline 122 & I1LJ68 & $0,0 \mathrm{E} 0$ & Fructose-bisphosphate aldolase- (Uniprot) & Glycine $\max$ & 42.951 & 35,6 & $3,45 \mathrm{E}-46$ \\
\hline 108 & I1N5Q9 & $0,0 \mathrm{E} 0$ & $\begin{array}{l}\text { Protease do-like chloroplastic- (Blast2Go) } \\
\text { Protein degradation of periplasmic proteins 1- (Blast2Go) }\end{array}$ & Glycine max & 45.644 & 39,9 & $6,55 \mathrm{E}-65$ \\
\hline $\begin{array}{l}515 \\
220\end{array}$ & C6T8W8 & $4,6 \mathrm{E}-157$ & $\begin{array}{l}\text { Oxygen-evolving enhancer protein chloroplastic- (Blast2Go) } \\
23 \mathrm{kDa} \text { Subunit of oxygen evolving system of photosystem ii- (Blast2Go) } \\
23 \mathrm{kDa} \text { Thylakoid membrane protein- (Blast2Go) }\end{array}$ & Glycine $\max$ & $\begin{array}{l}28.447 \\
28.447\end{array}$ & $\begin{array}{c}32,8 \\
40\end{array}$ & $\begin{array}{l}5,55 \mathrm{E}-47 \\
4,94 \mathrm{E}-63\end{array}$ \\
\hline 67 & F4ZZ27 & $0,0 \mathrm{E} 0$ & 1-Deoxy-D-xylulose 5-phosphate reductoisomerase- (Uniprot) & Glycine $\max$ & 50.509 & 40,2 & $2,84 \mathrm{E}-79$ \\
\hline 99 & I1KTX8 & $0,0 \mathrm{E} 0$ & Phosphoglycerate kinase- (Uniprot) & Glycine max & 50.266 & 52,8 & $1,11 \mathrm{E}-148$ \\
\hline
\end{tabular}

* $\mathrm{N}^{\mathrm{o}}$ de acesso de acordo com banco de dados do Uniprot.

* Descrição: realizada de acordo com o Uniprot ou pelo Blast2Go para as proteínas que não apresentavam anotações no Uniprot.

*PEP: Posterior Error Probability of the identification. 
De acordo com o diagrama de Venn pode-se observar que na condição não inoculada inter cultivares ocorreu a presençã de 2 proteínas com abundância relativa aumentada em comum ( Q2PMV0 e F4ZZ27), (Figura 28).

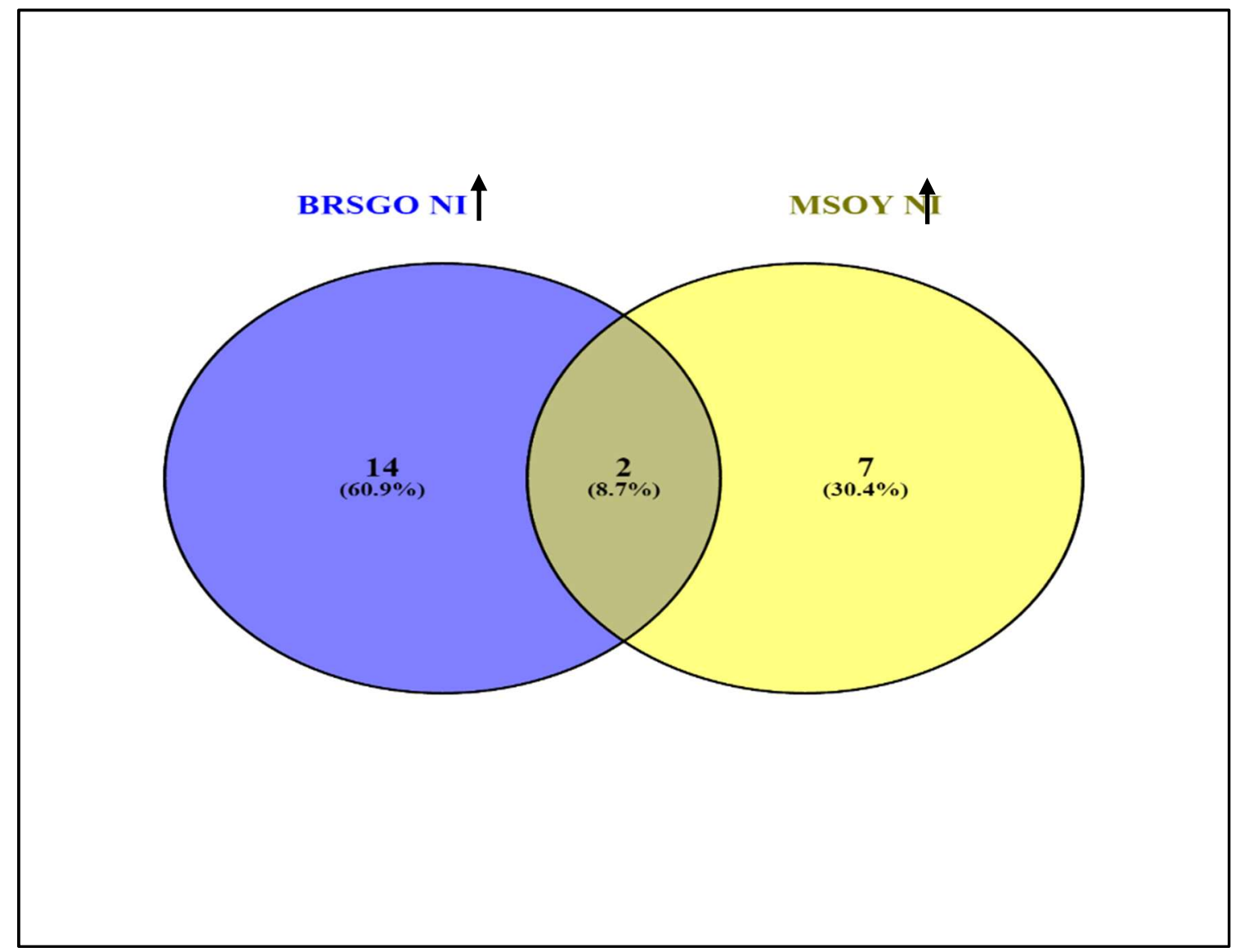

Figura 28. Diagrama de Venn de proteínas com abundância relativa aumentada $(\uparrow)$ resultantes da análise inter cultivares entre BRSGO-7560 e MSOY-8001 na condição não inoculada.

As proteínas com abundância relativa aumentada foram classificadas de acordo com os termos Go para função molecular, processos biológicos e compartimento celular, conforme figuras 29,30 e 31 , respectivamente.

De acordo com a função molecular, observou-se que a maioria das proteínas encontradas na análise inter cultivares para BRSGO-7560 não inoculada são capazes de se ligar a nucleotídeos (35\%), seguido por hidrolases (15\%), (Figura 29). E na cultivar MSOY-8001 para esta mesma condição, foi observado que a maior parte das proteínas se ligam a outras proteínas (23\%), e apresentam atividade catalítica (23\%), (Figura 29). 


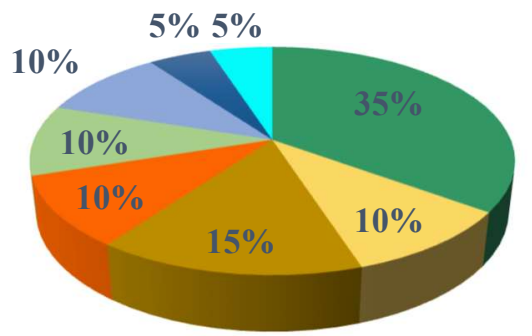
- Ligação a nucleotídeos
Atividade quinase
- Atividade hidrolase
- Atividade catalítica
Atividade transferase
- Ligação
- Atividade de transporte
- Ligação a proteínas

Função molecular MSOY-8001(NI) × BRSGO-7560 (NI)

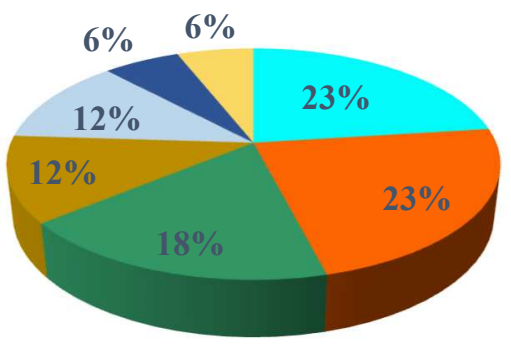

$$
\begin{array}{ll}
\square \text { Ligação a proteínas } & \square \text { Atividade catalítica } \\
\square \text { Atividade hidrolase } & \text { Ligação a RNA } \\
\square \text { Atividade quinase } &
\end{array}
$$$$
\text { - Ligação a nucleotídeos }
$$$$
\text { - Atividade de transporte }
$$

Figura 29. Distribuição das proteínas com abundância relativa aumentada em função de suas propriedades moleculares resultantes da análise inter cultivares entre BRSGO-7560 e MSOY-8001 na condição não inoculada (NI). A- não inoculada (BRSGO-7560); B- não inoculada (MSOY-8001).

Nos processos biológicos para a cultivar BRSGO-7560 na condição não inoculada foi observado que a maior parte das proteínas estavam relacionadas a processos metabólicos de carboidratos, processos biosintéticos e processos metabólicos contendo compostos de nucleobase $(15 \%)$ e em menor proporção processos metabólico de proteínase precursoras de metabolismo e energia (8\%) (Figura 29). 


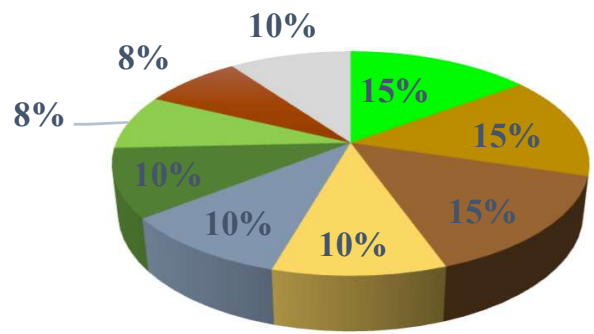

- Processos biosintéticos

- Geração de precursores de metabolismo e energia

- Processos metabólicos contendo compostos de nucleobase

$\square$ Processos metabólicos de carboidratos

- Processos catabólicos

- Processos metabólicos de lipídeos

- Fotossíntese

- Organização de componente celular

Outros

Processos biológicos MSOY-8001 (NI) × BRSGO-7560 (NI)

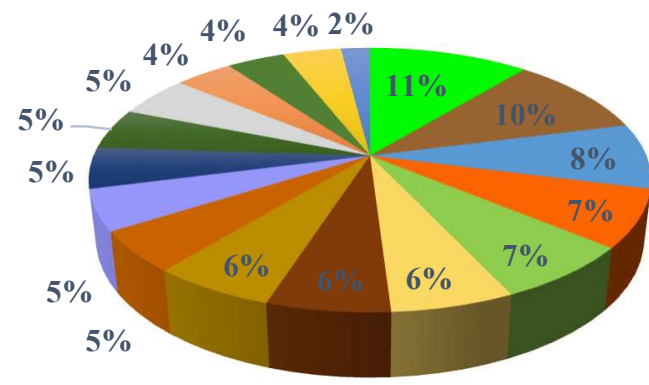

- Processos biosintéticos

- Processos metabólicos contendo compostos de nucleobase

- Resposta a estímulo abiótico

- Resposta a estresse

Fotossíntese

$\square$ Processos metabólicos de carboidratos

- Organização de componente celular

- Geração de precursores de metabolismo e energia

- Resposta a estímulo biótico

- Processos catabólicos

- Processos metabólicos secundários

- Resposta a estímulo externo

Resposta a estímulo endógeno

a Transporte

- Processos metabólicos de lipídeos

$\square$ Processos de modificação de proteína celular

- Outros

Figura 30. Distribuição das proteínas com abundância relativa aumentada em função dos processos biológicos resultantes da análise inter cultivares entre BRSGO-7560 e MSOY-8001 na condição não inoculada (NI). A- não inoculada (BRSGO-7560); B- não inoculada (MSOY-8001). 
A distribuição das proteínas nos compartimentos celulares para a cultivar BRSGO-7560 não inoculada está localizada principalmente nos plastídeos (25\%), seguidas por tilacóides (21\%) e membrana (18\%), (Figura 31). Em MSOY-8001 nesta mesma condição as proteínas ocorreram também principalmente nos plastídeos (20\%), tilacóides (18\%) e membrana (16\%), seguida por demais processos em menor proporção (Figura 31).

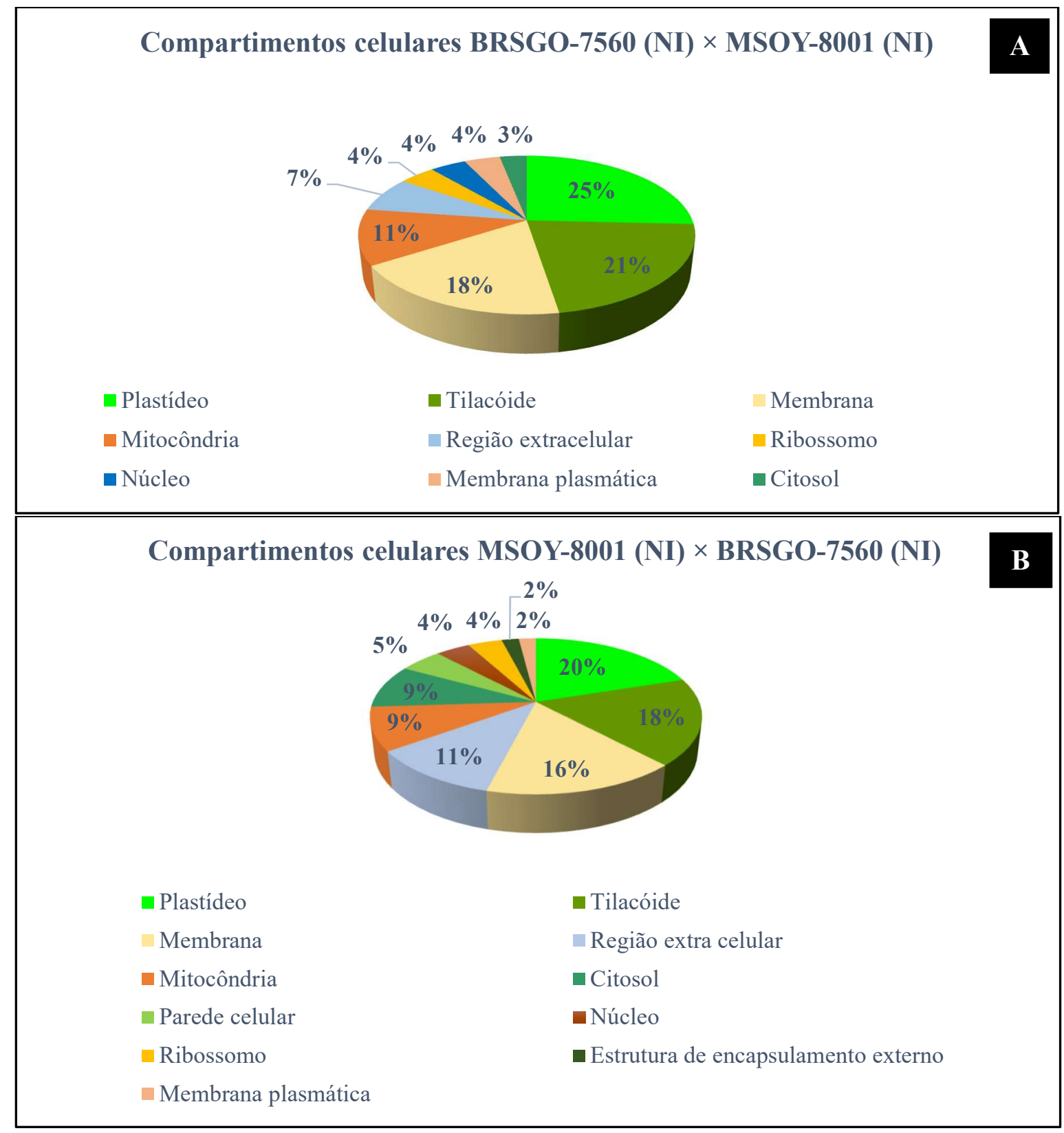

Figura 31. Distribuição das proteínas com abundância relativa aumentada em função dos compartimentos celulares resultantes da análise inter cultivares entre BRSGO-7560 e MSOY-8001 na condição não inoculada (NI). A- não inoculada (BRSGO-7560); B- não inoculada (MSOY-8001). 
As proteínas referentes aos spots exclusivos também foram classificadas quanto aos termos GO para função molecular, processos biológicos e compartimento celular, figuras 32,33 e 34 , respectivamente.

De acordo com a função molecular as proteínas da cultivar BRSGO-7560 não inoculada apresentaram maior relação com ligação a ATP (adenosina trifostato) e atividade fosforibuloquinase (22\%), (Figura 32). Nas demais funções apresentaram uma mesma proporção $(11 \%)$.

\section{Função molecular BRSGO-7560 (NI) × MSOY-8001 (NI) spots exclusivos}

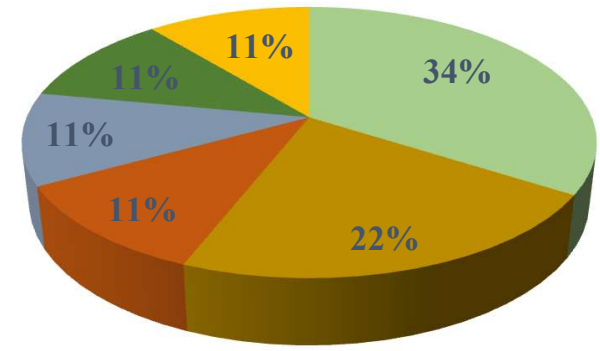
- Ligação com adenosina trifosfato (ATP)
- Atividade fosforibuloquinase
- Atividade fosfoglicerato mutase
Atividade deacetilase
- Ligação a ion de manganês
- Atividade de ligação glutamato-amônia

Figura 32. Distribuição das proteínas provenientes dos spots exclusivos em função de suas propriedades moleculares - resultante da análise inter cultivares entre BRSGO-7560 e MSOY-8001 na condição não inoculada (NI).

De acordo com os processos biológicos para a cultivar BRSGO-7560 não inoculada, foi observado que a maioria das proteínas estão relaciondas a processos metabólicos de carboidratos, processos biosintéticos e processos metabólicos contendo compostos de nucleobase (23\%), (Figura 33). 


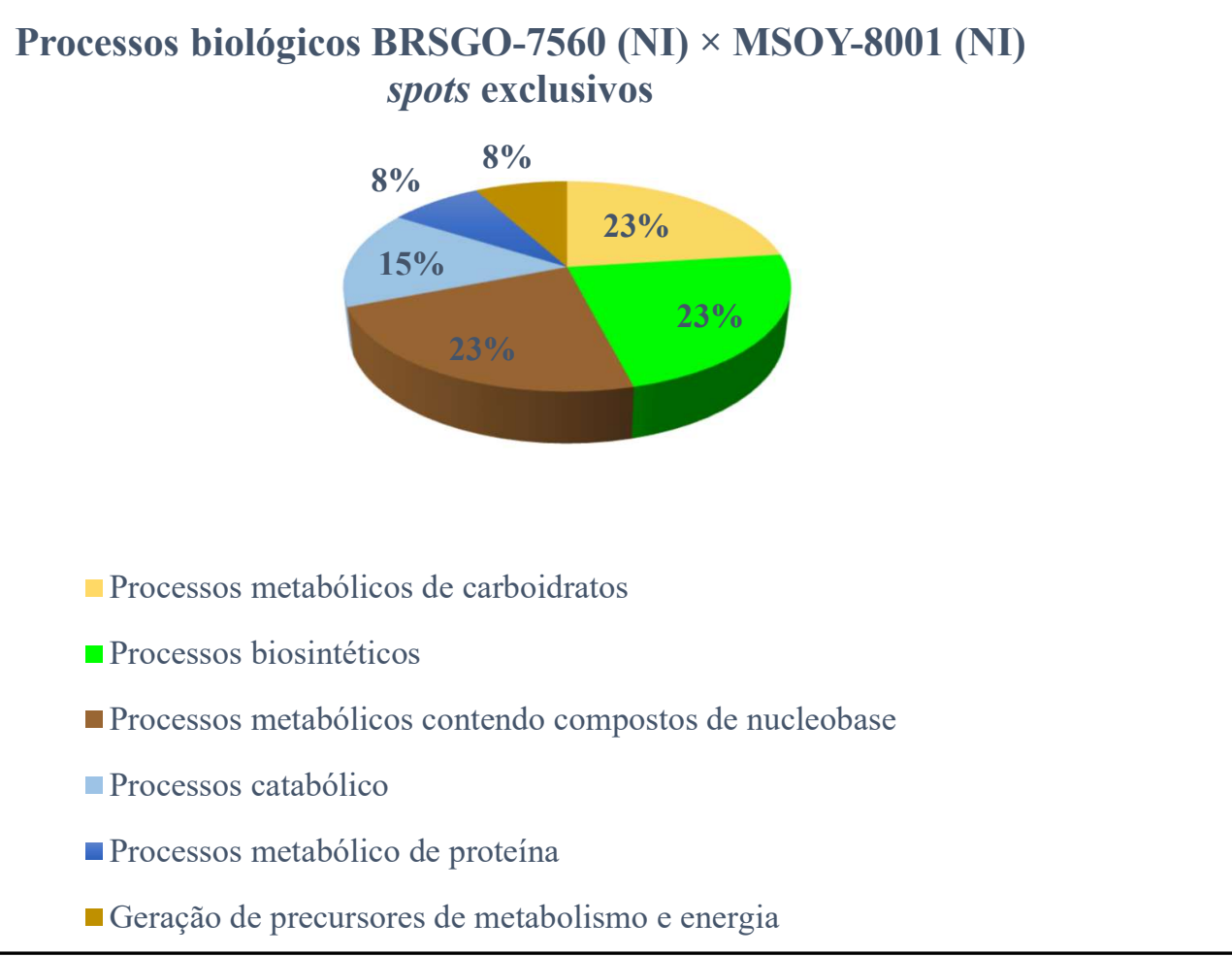

Figura 33. Distribuição das proteínas provenientes dos spots exclusivos em função dos processos biológicos- análise inter cultivares entre BRSGO-7560 e MSOY-8001 na condição não inoculada (NI).

Com relação aos compartimentos celulares as proteínas se concentraram em maior parte no apoplasto (16\%), seguido pelo envelope do cloroplasto, estroma do cloroplasto e membrana do tilacóide, todos respresentando 15\% para cada compartimento, (Figura 35).

\section{Compartimentos celulares BRSGO-7560 (NI) × MSOY-8001 (NI) spots exclusivos

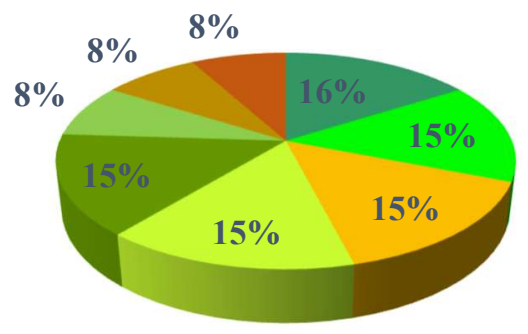 \\ - Apoplasto \\ - Envelope do cloroplasto \\ Estroma \\ Estroma do cloroplasto \\ - Membrana cloroplástica do tilacóide $\square$ Cloroplasto \\ Citoplasma \\ - Outros}

Figura 34. Distribuição das proteínas em função dos compartimentos celulares - análise inter cultivares entre BRSGO-7560 e MSOY-8001 na condição não inoculada (NI). 
Na tabela 15 encontra-se a descrição dos spots identificados com abundância relativa aumentada na análise inter cultivares entre BRSGO-7560 e MSOY-8001 na condição inoculada com P. pachyrhizi. Dos 32 spots observador na cultivar BRSGO-7560, 18 foram descritos de acordo com o Blast2Go e os demais descritos de acordo com o Uniprot, (Tabela 15). Os spots exclusivos identificados na análise inter cultivares entre BRSGO7560 e MSOY-8001 na condição inoculada com $P$. pachyrhizi estão apresentados na tabela 16. As 2 proteínas encontradas para esta condição foram descritas de acordo com o Blast2Go, pois não possuíam caracterização pelo banco de dados do Uniprot.

A descrição para os spots com abundância relativa aumentada na análise inter cultivares entre MSOY-8001 e BRSGO-7560 na condição inoculada com P. pachyrhizi estão relacionados na tabela 17 . Dos 13 spots observados, 10 foram identificados, 6 descritos pelo banco de dados do Uniprot e os demais pelo Blast2Go. Com relação aos spots exclusivos na análise inter cultivares entre MSOY-8001 e BRSGO-7560 inoculada, foi detectado apenas 1 spot exclusivo, o qual foi descrito pelo banco de dados do Blast2Go (Tabela 18). 
Tabela 15. Spots com abundância relativa aumentada obtidos em BRSGO-7560, resultantes da análise comparativa inter cultivares entre BRSGO-7560 e MSOY8001 na condição inoculada (I) com $P$. pachyrhizi.

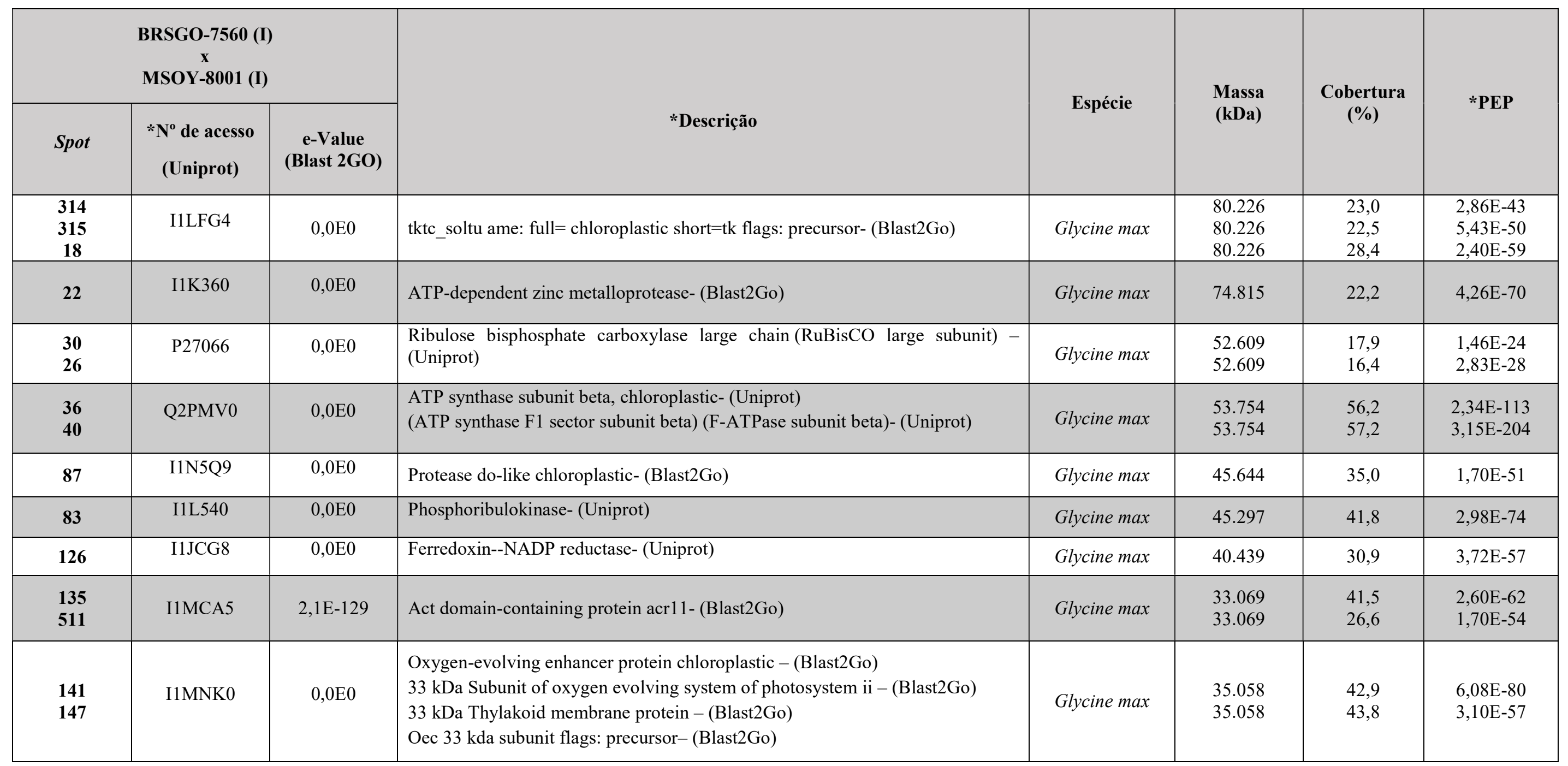




\begin{tabular}{|c|c|c|c|c|c|c|c|}
\hline 513 & C6T9I0 & $6.2 \mathrm{E}-78$ & RNA-binding protein chloroplastic- (Blast2Go) & Glycine max & 30,87 & 26,1 & $1,28 \mathrm{E}-13$ \\
\hline 168 & I1JXF1 & $8,4 \mathrm{E}-148$ & $\begin{array}{l}\text { Haloacid dehalogenase-like hydrolase domain-containing protein at3g48420 - } \\
\text { (Blast2Go) }\end{array}$ & Glycine max & 27.656 & 18,6 & $1,40 \mathrm{E}-26$ \\
\hline 196 & I1LBF9 & $1,1 \mathrm{E}-11$ & Chaperone protein- (Blast2Go) & Glycine max & 34,7 & 2,8 & $1,52 \mathrm{E}-02$ \\
\hline 209 & I1JT53 & $1,7 \mathrm{E}-13$ & Galactose oxidase - (Blast2Go) & Glycine max & 58.922 & 7,7 & $1,64 \mathrm{E}-02$ \\
\hline $\begin{array}{c}56 \\
422\end{array}$ & F4ZZ27 & $0,0 \mathrm{E} 0$ & 1-Deoxy-D-xylulose 5-phosphate reductoisomerase- (Uniprot) & Glycine max & $\begin{array}{l}50.509 \\
50.509\end{array}$ & $\begin{array}{l}25,6 \\
25,6\end{array}$ & $\begin{array}{l}4,90 \mathrm{E}-49 \\
9,33 \mathrm{E}-66\end{array}$ \\
\hline $\begin{array}{c}102 \\
88\end{array}$ & I1LPX6 & & Fructose-bisphosphate aldolase- (Uniprot) & Glycine max & $\begin{array}{l}42.869 \\
42.869 \\
\end{array}$ & $\begin{array}{l}33,2 \\
28,6\end{array}$ & $\begin{array}{l}3,72 \mathrm{E}-64 \\
5,83 \mathrm{E}-56 \\
\end{array}$ \\
\hline 80 & Q9FUK4 & $0,0 \mathrm{E} 0$ & Glutamine synthetase - (Uniprot) & Glycine max & 38,99 & 21,9 & $4,97 \mathrm{E}-21$ \\
\hline 76 & I1N5T2 & $0,0 \mathrm{E} 0$ & $\begin{array}{l}\text { Peptidyl-prolyl cis-trans isomerase chloroplastic - (Blast2Go) } \\
\text { Rotamase cyp38- (Blast2Go) } \\
\text { Tthylakoid lumen ppiase- (Blast2Go) }\end{array}$ & Glycine max & 48.731 & 45,6 & $6,12 \mathrm{E}-68$ \\
\hline 191 & Q76LA8 & $8,8 \mathrm{E}-152$ & Cytosolic ascorbate peroxidase 1- (Uniprot) & Glycine $\max$ & 27.868 & 42,8 & $1,29 \mathrm{E}-42$ \\
\hline 110 & I1LJ68 & $0,0 \mathrm{E} 0$ & Fructose-bisphosphate aldolase- (Uniprot) & Glycine max & 42.951 & 24,6 & $6,89 \mathrm{E}-36$ \\
\hline 74 & I1MJC7 & $0,0 \mathrm{E} 0$ & Phosphoglycerate kinase- (Uniprot) & Glycine max & 42.434 & 67,1 & $3,94 \mathrm{E}-103$ \\
\hline 132 & I1JMQ2 & $2,1 \mathrm{E}-92$ & $\begin{array}{l}\text { 50S Ribosomal protein chloroplastic- (Blast2Go) } \\
\text { R-protein 14- (Blast2Go) }\end{array}$ & Glycine $\max$ & 33.858 & 35,2 & $3,13 \mathrm{E}-40$ \\
\hline 84 & K7MF30 & $0,0 \mathrm{E} 0$ & $\begin{array}{l}\text { Probable inactive leucine-rich repeat receptor-like protein kinase at3g03770- } \\
\text { (Blast2Go) }\end{array}$ & Glycine max & 86.712 & 2,4 & $1,10 \mathrm{E}-02$ \\
\hline 167 & C6TLX7 & $1,7 \mathrm{E}-126$ & $\begin{array}{l}\text { Thioredoxin-like protein chloroplastic- (Blast2Go) } \\
\text { Chloroplastic drought-induced stress protein of } 32 \mathrm{kDa} \text {-(Blast2Go) }\end{array}$ & Glycine max & 33.129 & 18,5 & $5,51 \mathrm{E}-38$ \\
\hline 220 & I1KXW9 & $8,2 \mathrm{E}-162$ & $\begin{array}{l}\text { Oxygen-evolving enhancer protein chloroplastic- (Blast2Go) } \\
23 \mathrm{kDa} \text { Subunit of oxygen evolving system of photosystem ii- (Blast2Go) } \\
23 \mathrm{kDa} \text { Thylakoid membrane protein- (Blast2Go) }\end{array}$ & Glycine max & 28.229 & 32,1 & $3,76 \mathrm{E}-25$ \\
\hline
\end{tabular}

* $\mathrm{N}^{\circ}$ de acesso de acordo com banco de dados do Uniprot.

* Descrição: realizada de acordo com o Uniprot ou pelo Blast2Go para as proteínas que não apresentavam anotações no Uniprot.

*PEP: Posterior Error Probability of the identification. 
Tabela 16. Spots exclusivos obtidos em BRSGO-7560, resultantes da análise comparativa inter cultivares entre BRSGO-7560 e MSOY-8001 na condição inoculada (I) com P. pachyrhizi.

\begin{tabular}{|c|c|c|c|c|c|c|c|}
\hline \multicolumn{3}{|c|}{$\begin{array}{c}\text { BRSGO-7560 (I) } \\
x \\
\text { MSOY-8001 (I) }\end{array}$} & \multirow[t]{2}{*}{ *Descrição } & \multirow{2}{*}{ Espécie } & \multirow{2}{*}{$\begin{array}{c}\text { Massa } \\
(\mathbf{k D a})\end{array}$} & \multirow{2}{*}{$\begin{array}{c}\text { Cobertura } \\
(\%)\end{array}$} & \multirow{2}{*}{ *PEP } \\
\hline Spot & $\begin{array}{c}{ }^{*} \mathrm{~N}^{0} \mathrm{de} \\
\text { acesso } \\
\text { (Uniprot) }\end{array}$ & $\begin{array}{c}\text { e-Value } \\
\text { (Blast 2GO) }\end{array}$ & & & & & \\
\hline 121 & С6ТВ98 & $1,1 \mathrm{E}-6$ & Probable protein pop3- (Blast 2Go) & Glycine max & 33.927 & 29,7 & $3,51 \mathrm{E}-29$ \\
\hline 161 & С6T5C9 & $7,2 \mathrm{E}-171$ & Isoflavone reductase homolog- (Blast 2Go) & Glycine max & 27.656 & 37,9 & $2,34 \mathrm{E}-69$ \\
\hline
\end{tabular}

* $\mathrm{N}^{\mathrm{o}}$ de acesso de acordo com banco de dados do Uniprot.

* Descrição: realizada de acordo com o Uniprot ou pelo Blast2Go para as proteínas que não apresentavam anotações no Uniprot.

*PEP: Posterior Error Probability of the identification 
Tabela 17. Spots com abundância relativa aumentada obtidos na análise comparativa inter cultivares entre MSOY-8001 e BRSGO-7560 na condição inoculada com $P$. pachyrhizi.

\begin{tabular}{|c|c|c|c|c|c|c|c|}
\hline \multicolumn{3}{|c|}{$\begin{array}{c}\text { MSOY-8001 (I) } \\
x \\
\text { BRSGO-7560 (I) }\end{array}$} & \multirow[t]{2}{*}{ *Descrição } & \multirow{2}{*}{ Espécie } & \multirow{2}{*}{$\begin{array}{l}\text { Massa } \\
\text { (kDa) }\end{array}$} & \multirow{2}{*}{$\begin{array}{l}\text { Cobertura } \\
\quad(\%)\end{array}$} & \multirow{2}{*}{ *PEP } \\
\hline Spot & $\begin{array}{c}\mathrm{N}^{\circ} \text { de acesso } \\
\text { (Uniprot) }\end{array}$ & $\begin{array}{c}\text { e-Value } \\
\text { (Blast 2GO) }\end{array}$ & & & & & \\
\hline 47 & F4ZZ27 & $0,0 \mathrm{E} 0$ & 1-Deoxy-D-xylulose 5-phosphate reductoisomerase - (Uniprot) & Glycine $\max$ & 50.509 & 37,8 & $5,89 \mathrm{E}-58$ \\
\hline 242 & Q2PMV0 & $0,0 \mathrm{E} 0$ & $\begin{array}{l}\text { ATP synthase subunit beta, chloroplastic- (Uniprot) } \\
\text { (ATP synthase F1 sector subunit beta) (F-ATPase subunit beta) }\end{array}$ & Glycine $\max$ & 53.754 & 61,4 & $2,35 \mathrm{E}-100$ \\
\hline 170 & C6T8W8 & $0,0 \mathrm{E} 0$ & Oxygen-evolving enhancer protein chloroplastic- (Blast2Go) & Glycine $\max$ & 53.754 & 23,8 & $1,12 \mathrm{E}-23$ \\
\hline 198 & K7LWI4 & $0,0 \mathrm{E} 0$ & ATP synthase subunit alpha - (Uniprot) & Glycine max & 55.737 & 18,2 & $5,94 \mathrm{E}-38$ \\
\hline 213 & C6SVL2 & $9,0 \mathrm{E}-131$ & Ribulose bisphosphate carboxylase small chain- (Uniprot) & Glycine $\max$ & 19.979 & 20,2 & $1,40 \mathrm{E}-31$ \\
\hline 240 & I1MJU7 & $0,0 \mathrm{E} 0$ & Stromal $70 \mathrm{kDa}$ heat shock-related chloroplastic- (Blast2Go) & Glycine max & 73.754 & 51,5 & $2,18 \mathrm{E}-140$ \\
\hline 278 & I1MZ53 & $0,0 \mathrm{E} 0$ & Sedoheptulose chloroplastic- (Blast2Go) & Glycine max & 41.732 & 37 & $2,78 \mathrm{E}-61$ \\
\hline 292 & C6T7V6 & $0.0 \mathrm{E} 0$ & Triosephosphate chloroplastic- (Blast2Go) & Glycine max & 33.123 & 39,5 & $1,10 \mathrm{E}-47$ \\
\hline 293 & I1N5Q1 & $0,0 \mathrm{E} 0$ & Carbonic anhydrase- (Uniprot) & Glycine max & 36.749 & 9,7 & $6,47 \mathrm{E}-07$ \\
\hline 407 & I1M3Y7 & $1,6 \mathrm{E}-153$ & Cytochrome b6-f complex iron-sulfur subunit- (Uniprot) & Glycine max & 24.177 & 18,9 & $7,26 \mathrm{E}-11$ \\
\hline
\end{tabular}

* $\mathrm{N}^{\mathrm{o}}$ de acesso de acordo com banco de dados do Uniprot.

* Descrição: realizada de acordo com o Uniprot ou pelo Blast2Go para as proteínas que não apresentavam anotações no Uniprot.

*PEP: Posterior Error Probability of the Identification. 
Tabela 18. Spot exclusivo obtido em MSOY-8001, resultante da análise comparativa inter cultivares entre MSOY-8001 (cultivar suscetível) e BRSGO7560 (cultivar resistente) na condição inoculada (I).

\begin{tabular}{|c|c|c|c|c|c|c|c|}
\hline \multicolumn{3}{|c|}{$\begin{array}{l}\text { MSOY-8001 (I) } \\
\qquad x \\
\text { BRSGO-7560 (I) }\end{array}$} & \multirow[t]{2}{*}{ *Descrição } & \multirow[t]{2}{*}{ Espécie } & \multirow[t]{2}{*}{$\begin{array}{c}\text { Massa } \\
(\mathbf{k D a})\end{array}$} & \multirow[t]{2}{*}{$\begin{array}{c}\text { Cobertura } \\
(\%)\end{array}$} & \multirow[t]{2}{*}{ *PEP } \\
\hline Spot & $\begin{array}{c}\mathbf{N}^{0} \text { de acesso } \\
\text { (Uniprot) }\end{array}$ & $\begin{array}{c}\text { e-Value } \\
\text { (Blast 2GO) }\end{array}$ & & & & & \\
\hline 284 & C6SXP1 & $1,6 \mathrm{E}-76$ & $\begin{array}{l}\text { Elongation factor 1-delta - (Blast 2Go) } \\
\text { Elongation factor 1b-beta- (Blast 2Go) } \\
\text { EEF-1b beta- (Blast 2Go) }\end{array}$ & Glycine max & 25.087 & 47,4 & $6,97 \mathrm{E}-32$ \\
\hline
\end{tabular}

* $\mathrm{N}^{\mathrm{o}}$ de acesso de acordo com banco de dados do Uniprot.

* Descrição: realizada de acordo com o Uniprot ou pelo Blast2Go para as proteínas que não apresentavam anotações no Uniprot.

*PEP: Posterior Error Probability of the Identification.

Na figura 35 pode ser observado pelo diagrama a presença de duas proteínas com abundância relativa aumentada em comum na análise inter cultivares entre BRSGO-7560 e MSOY-8001 na condição inoculada., provenientes de spots distintos (Q2PMV0 e F4ZZ27). 


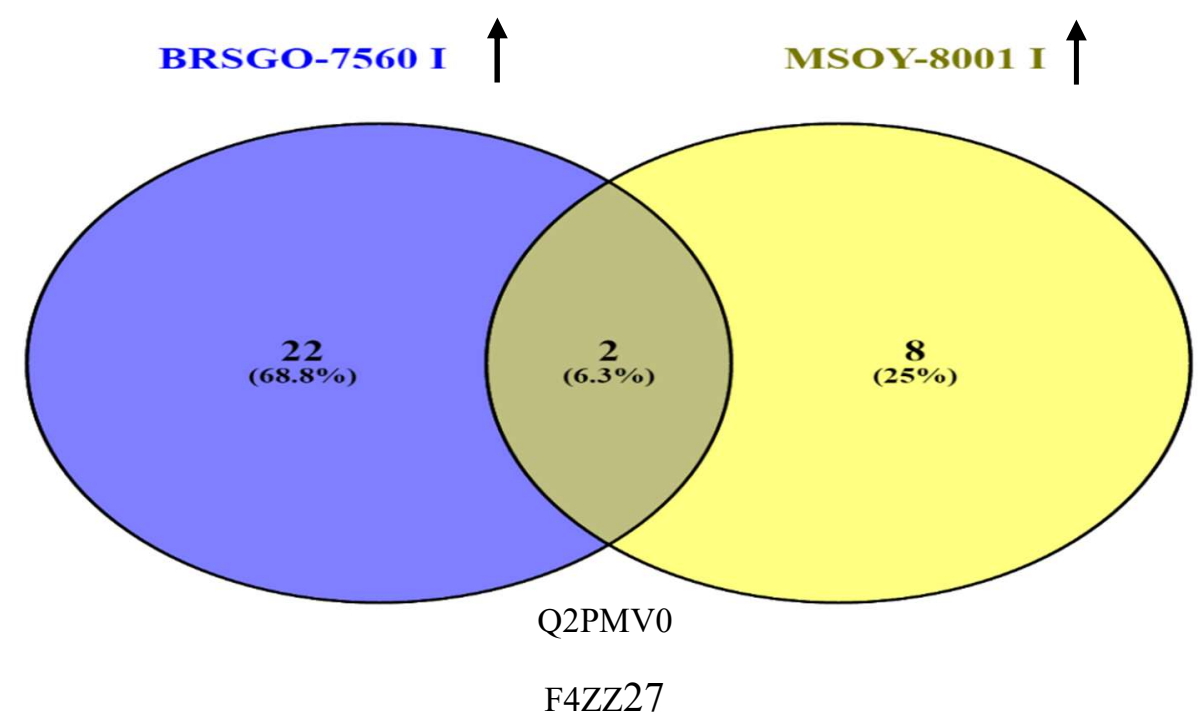

Figura 35. Diagrama de Venn de proteínas com abundância relativa aumentada $(\uparrow)$ resultantes da análise inter cultivares para BRSGO-7560 e MSOY-8001 na condição inoculada (I).

As proteínas identificadas na análise inter cultivares para BRSGO-7560 e MSOY8001 na condição incoulada foram classificadas de acordo com os termos Go para função molecular, processos biológicos e compartimento celular, conforme figuras 36, 37 e 38, respectivamente.

A função molecular da maior parte das proteínas observadas tanto na cultivar BRSGO-7560 quanto em MSOY-8001 na análise inter cultivares na condição inoculada estão relacionadas a atividade catalítica (20\% e 30\%, respectivamente) e a proteínas que se ligam a nucleotídeos (20\% em ambas cultivares), conforme figura 36. 


\section{Função molecular BRSGO-7560 (I) × MSOY-8001 (I)}

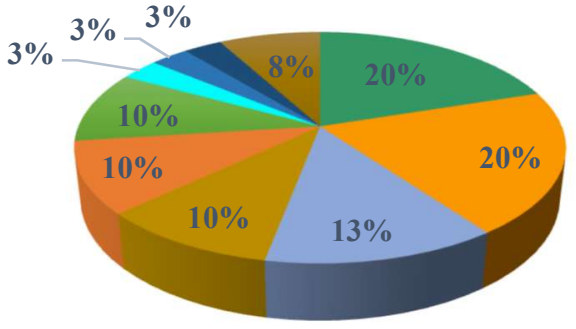

- Ligação a nucleotídeos

- Atividade catalítica

- Ligação

- Atividade hidrolase

- Atividade quinase

- Atividade transferase

- Ligação a proteína

- Ligação a RNA

- Atividade de transporte

- Outros

Função molecular MSOY-8001 (I) × BRSGO-7560 (I)

- Atividade catalítica

- Atividade hidrolase

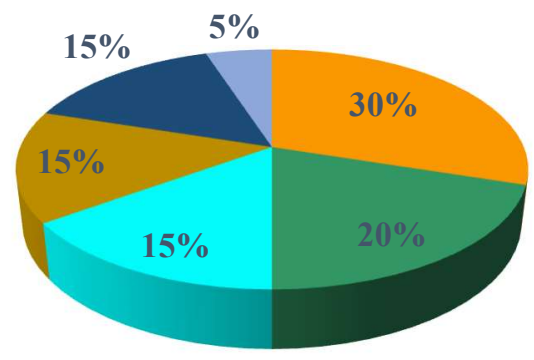

• Ligação a nucleotídeos

- Atividade de transporte
- Ligação a proteínas

- Ligação

Figura 36. Distribuição das proteínas com abundância relativa aumentada em função de suas propriedades moleculares resultantes da análise inter cultivares entre BRSGO-7560 e M-SOY 80001 na condição inoculada (I) com P. pachyrhizi. A- condição inoculada (BRSGO-7560); B- condição inoculada (MSOY-8001).

De acordo com os processos biológicos na cultivar BRSGO-7560 na análise inter cultivares na condição inoculada as proteínas estavam relacionadas em maior parte a processos biosintéticos, fotossíntese e precursosas de geração de metabólitos e energia (11\%), também foi observado a presença de proteínas relacionadas a morte celular (2\%) e transdução de sinais (2\%), conforme figura 37. De forma semelhantes a cultivar MSOY-8001 na análise inter cultivares inoculada apresentou proteínas relacionadas principalmente à processos biosintéticos, seguidos por fotossíntese e compostos metabólicos contendo nucleobase, todos proporcionais a $11 \%$ em cada categoria, conforme figura 37 . 
Processos biológicos BRSGO-7560 (I) × MSOY-8001 (I)

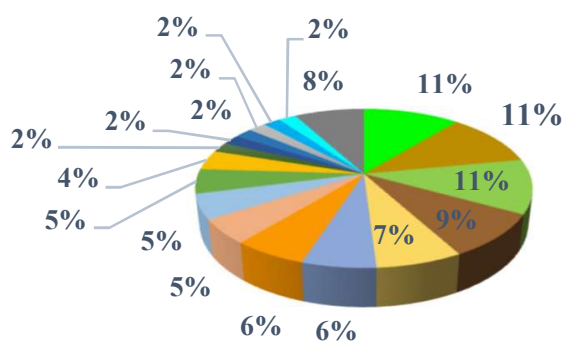

processos biosintéticos

- Geração de precursores de metabolismo e energia

Fotossíntese

- Processos metabólicos contendo compostos de nucleobase

Processos metabólicos de carboidratos

Processos catabólicos

Resposta a estresse

- Organização de componente celular

- Resposta a estímulo abiótico

- Processos metabólicos de lipídeos

- Desenvolvimento pos-embrionário

- Morte celular

- Transdução de sinal

- Transporte

Resposta a estímulo biótico

- Resposta a estímulo externo

Resposta a estímulo endógeno

- Outros

Processos biológicos MSOY-8001 (I) × BRSGO-7560 (I)

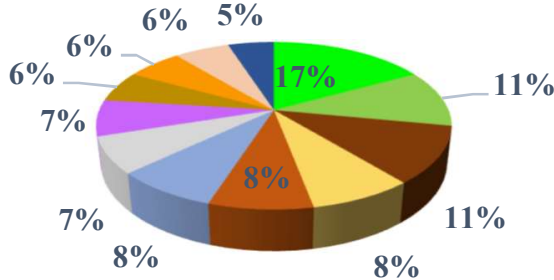

- Processos biosintéticos

- Fotossíntese

- Processos metabólicos contendo compostos de nucleobase

- Processos metabólicos de carboidratos

- Processos metabólicos de lipídeos

- Resposta a estímulo abiótico

$\square$ Desenvolvimento de organismo multicelular

- Processos metabólico proteico

- Geração de precursores de metabolismo e energia

- Resposta a estresse

- Organização de componente celular

- Transporte

Figura 37. Distribuição das proteínas com abundância relativa aumentada em função dos processos biológicos resultantes da análise inter cultivares entre BRSGO-7560 e MSOY-8001 na condição inoculada (I). A- condição inoculada (BRSGO-7560); B- condição inoculada (MSOY-8001). 
Com relação aos compartimentos celulares na cultivar BRSGO-7560 na condição inoculada, observamos maior parte das proteínas presente nos plastídeos $(28 \%)$, tilacóides (20\%) e em membrana (18\%), (Figura 39). Da mesma forma, na cultivar MSOY-8001 a maior parte das proteínas encontram-se nos plastídeos (32\%), seguida por tilacóides (27\%), (figura $38)$.

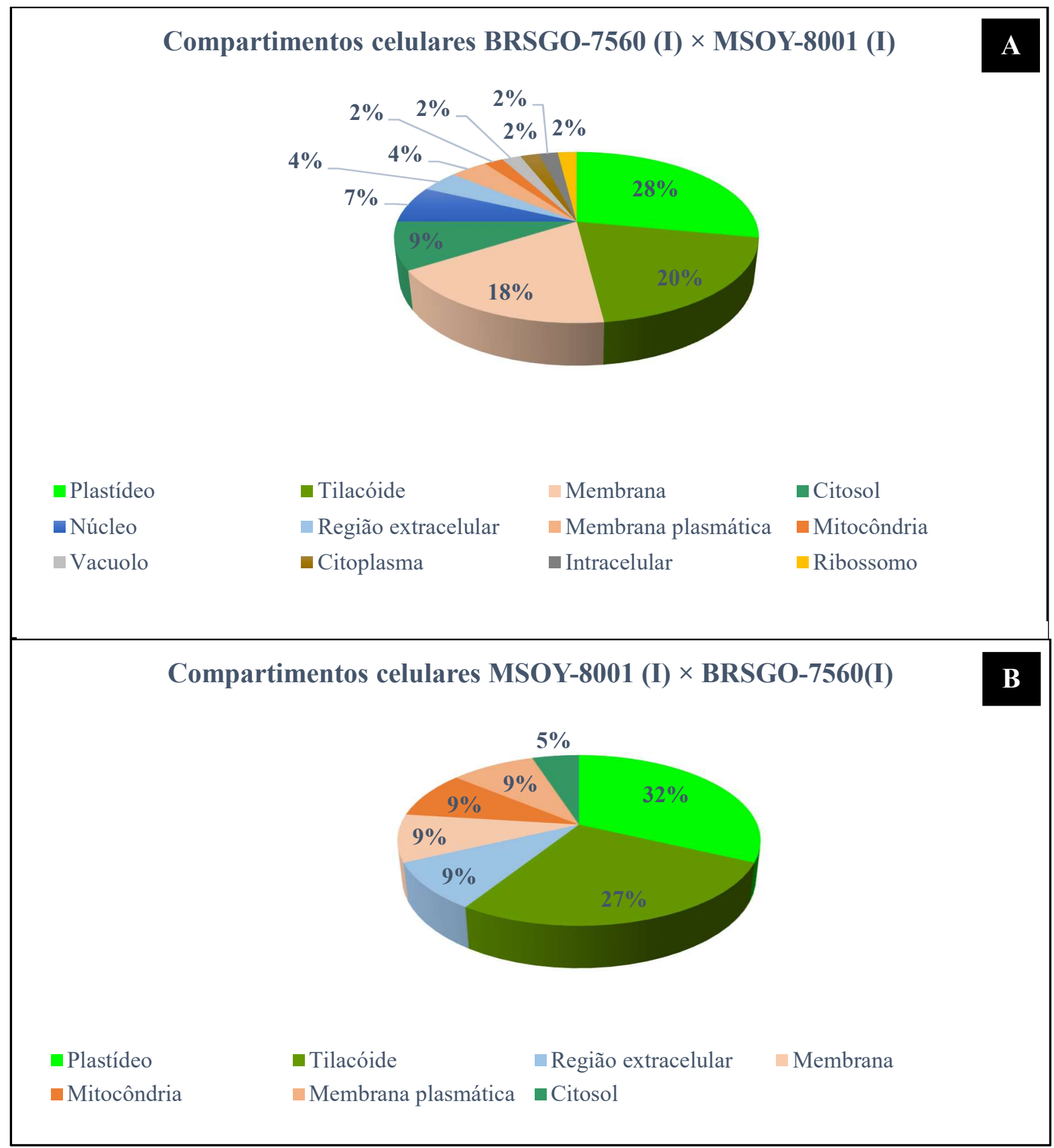

Figura 38. Distribuição das proteínas com abundância relativa aumentada em função dos compartimentos celulares resultantes da análise inter cultivares entre BRSGO-7560 e MSOY-8001 na condição inoculada (I) com P. pachyrhizi. A- condição inoculada (BRSGO-7560); B- condição inoculada (MSOY-8001). 
As proteínas identificadas nos spots exclusivos também foram classificadas de acordo com os termos Go para função molecular, processos biológicos e compartimento celular, conforme figuras 39,40 e 41 , respectivamente.

Com relação a função molecular na cultivar BRSGO-7560 na análise inter cultivares na condição inoculada, as proteínas apresentaram maior atividade catalítica $(50 \%)$ e proteínas que se ligam a metais de íon (50\%), conforme figura 39. Na cultivar MSOY-8001 a única proteína encontrada apresentou função relacionada a proteínas que se ligam a outras proteínas $(50 \%)$ e proteínas com fator de atividade de tradução/que se ligam a RNA (50\%), figura 39).

\section{Função molecular BRSGO-7560 (I) $\times$ MSOY(I)} spots exclusivos

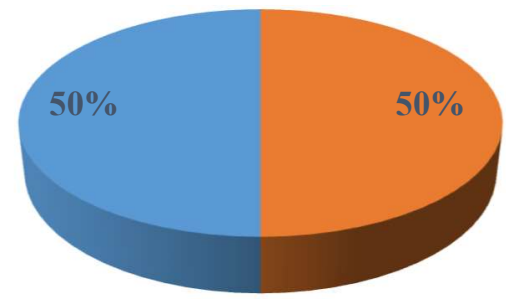
spot exclusivo

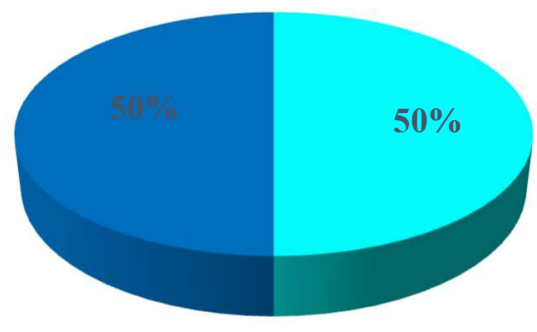

- Ligação a outras proteínas

- Atividade de tradução/ligação a RNA

Figura 39. Distribuição das proteínas provenientes dos spots exclusivos em função das suas propriedades moleculares resultantes da análise inter cultivares entre BRSGO-7560 e M-SOY 80001 na condição inoculada (I) com P. pachyrhizi. A- condição inoculada (BRSGO-7560); B- condição inoculada (MSOY-8001). 
Quantos aos processos biológicos na cultivar BRSGO-7560 inoculada na análise inter cultivares foi observado que as proteínas apresentaram atividades referentes aos seguintes processos: resposta ao estresse, processos biosintéticos, processos catabólicos, processos metabólicos secundários, bem como processos celulares, todos representando $20 \%$. Assim não houve predominândia de um determinado processo, pois de modo geral nesta cultivar os processos envolvidos se apresentaram de forma semelhante, (figura 40). Na cultivar MSOY 8001 para esta mesma condição quando comparada a BRSGO-7560 a única proteína encontrada está relacionada a translational elongation.

\section{Processos biológicos BRSGO-7560 (I) × MSOY-8001 (I) spots exclusivos}
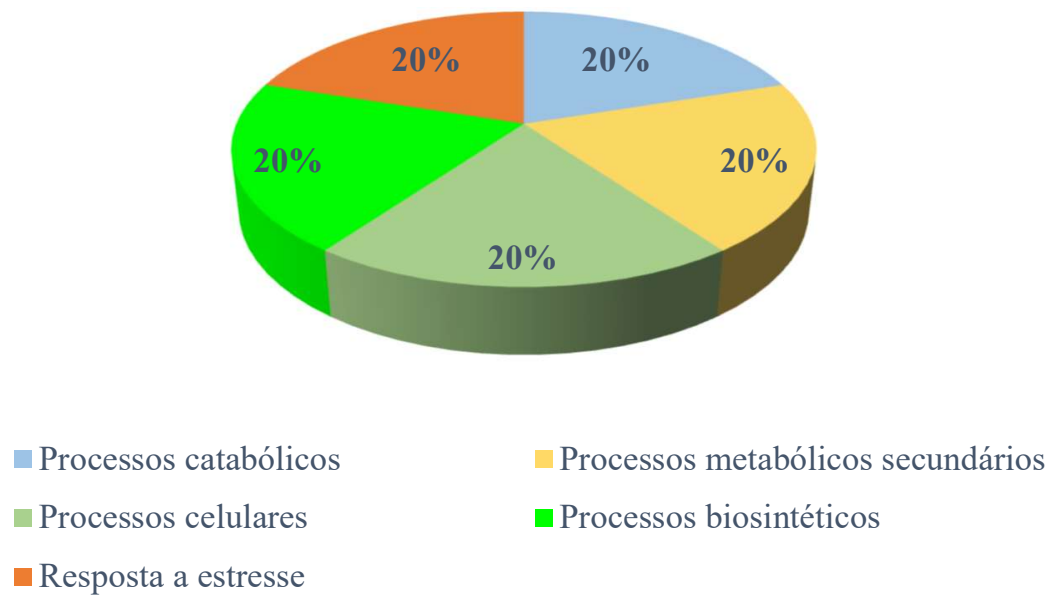

Figura 40. Distribuição das proteínas provenientes dos spots exclusivos em função dos processos biológicos resultantes da análise inter cultivares entre BRSGO-7560 e MSOY-8001 na condição inoculada (I).

Nos compartimentos celulares para a cultivar BRSGO-7560 na condição inoculada inter cultivares as proteínas localizaram-se principalmente na membrana plasmática (40\%), conforme figura 41. Na cultivar MSOY-8001 inoculada a única proteína encontrada, apresentou uma distribuição similar entre os compartimentos com resultados entre 14 a $15 \%$. Nesta condição podemos notar que não houve predominância por um compartimento em particular, (Figura 41). 


\section{Compartimentos celulares BRSGO-7560 (I) $\times$ MSOY-8001 (I) spots exclusivos}

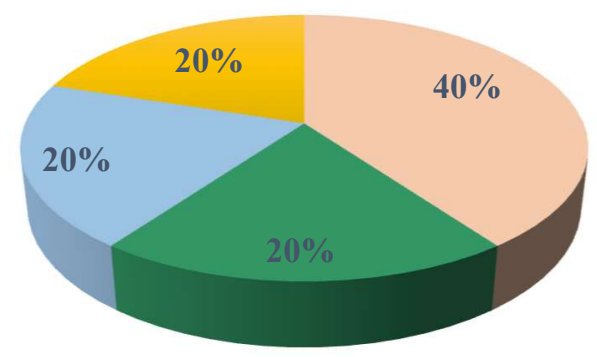

Membrana plasmática $\square$ Citosol $\square$ Citoplasma $\square$ Cloroplasto

Compartimentos celulares MSOY-8001 (I) $\times$ BRSGO-7560 (I) spot exclusivo
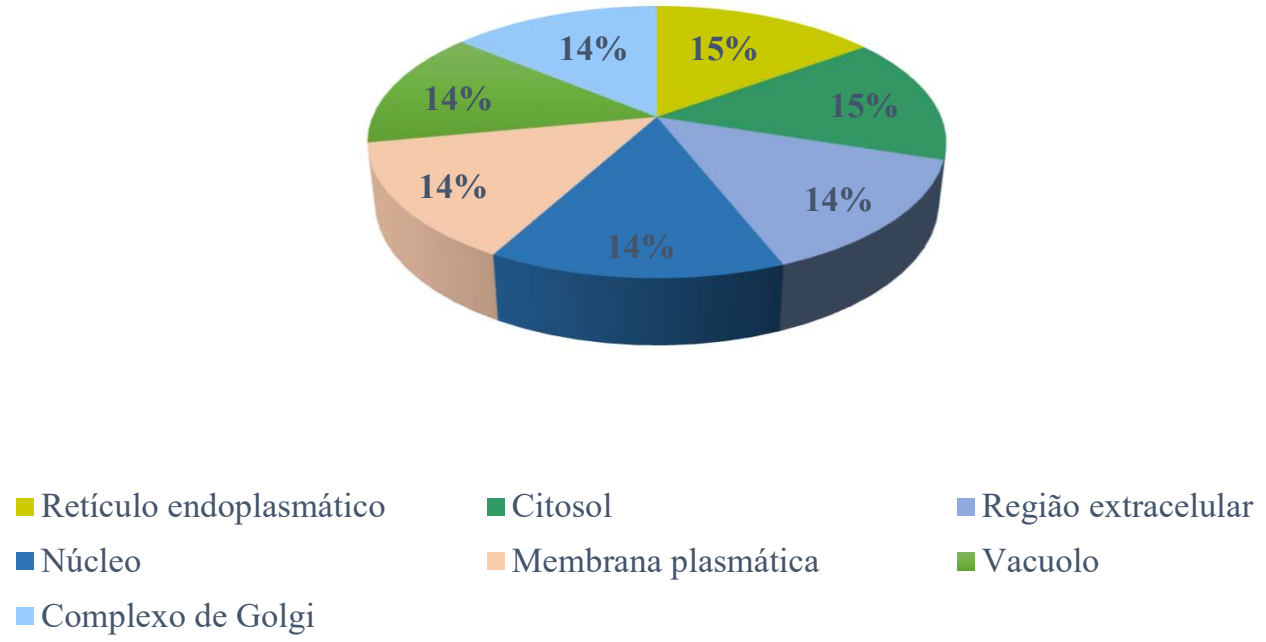

Figura 41. Distribuição das proteínas provenientes dos spots exclusivos em função dos compartimentos celulares resultantes da análise inter cultivares entre BRSGO-7560 e MSOY-8001 na condição inoculada (I) com $P$. pachyrhizi. A- condição inoculada (BRSGO-7560); B- condição inoculada (MSOY-8001).

$\mathrm{Na}$ figura 42 observa-se no diagrama a presença de 2 proteínas em comum com abundância relativa aumentada entre MSOY-8001 inoculada e BRSGO-7560 provenientes de spots distintos na condição não incoulada resultantes da análise inter cultivares (I1LJ68 e I1N5Q9). Também observa-se a presença de duas proteínas em comum na condição não inoculada para as cultivares BRSGO-7560 e MSOY-8001 (Q2PMV0 e F4ZZ27). E proteínas em comum entre MSOY-8001 não inoculada e inoculada (C6SVL2 e C6T8W8). 


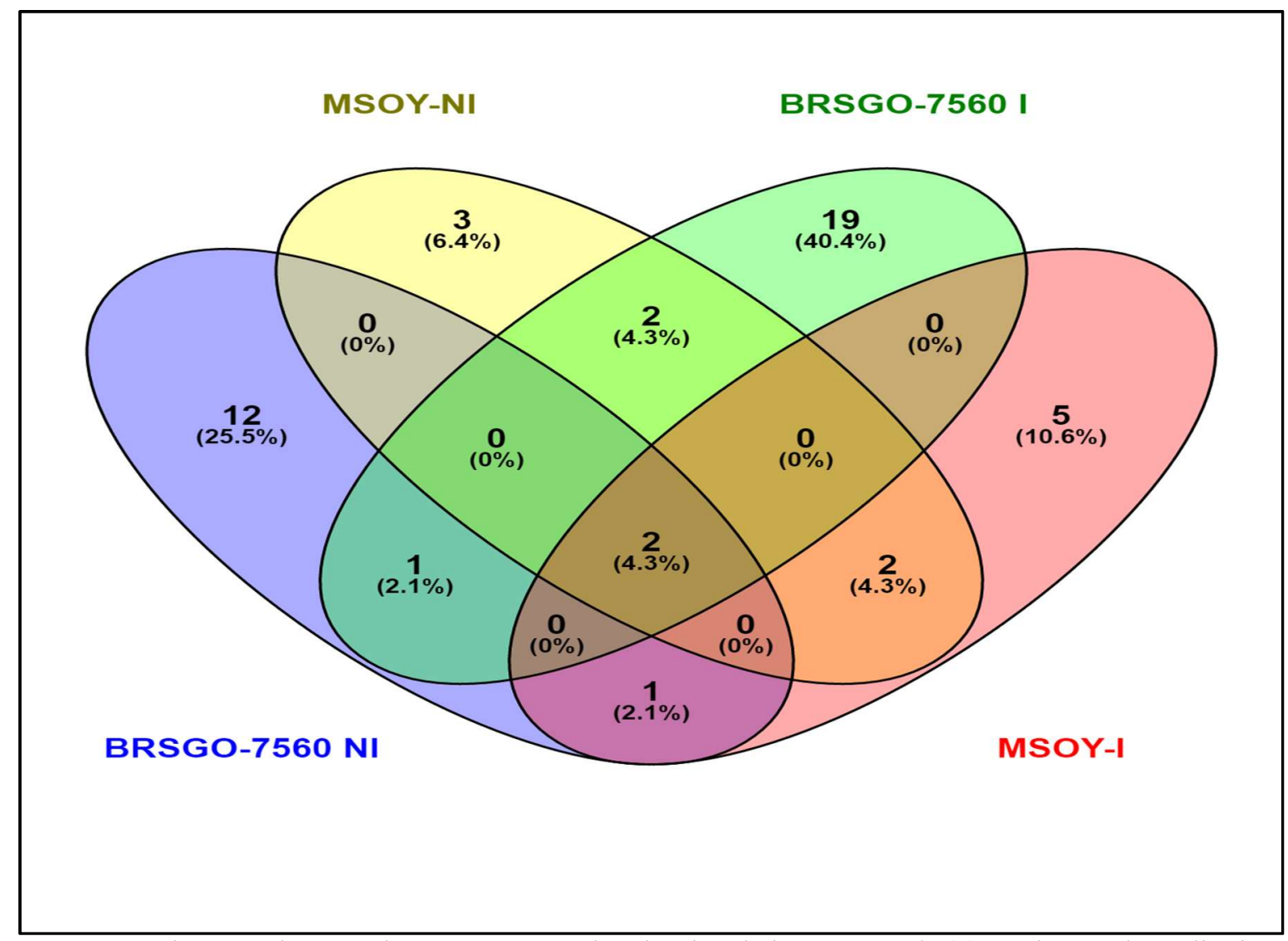

Figura 42. Diagrama de Venn de proteínas com abundância relativa aumentada ( $\uparrow$ ) resultantes da análise inter cultivares entre BRSGO-7560 e MSOY-8001 nas condições não inoculada e inoculada com $P$. pachyrhizi. 


\section{DISCUSSÃO}

As cultivares BRSGO-7560 (resistente à ferrugem asiática) e MSOY-8001 (cultivar suscetível) foram avaliadas na condição não inoculada e inoculada com Phakopsora pachyrhizi, com a finalidade de compara-las quanto ao perfil proteômico, tanto intra-cultivar quanto intercultivar.

Estudos proteômicos comparando-se cultivares de soja resistente e suscetível podem conduzir à identificação de proteínas que podem estar diretamente envolvidas na resistência à ferrugem da soja. Neste estudo, proteínas diferencialmente expressas em ambas as cultivares foram identificadas, além de proteínas exclusivas nas condições avaliadas, o que pode indicar possíveis respostas específicas resultantes da interação planta-patógeno.

A maioria das proteínas identificadas no presente estudo estão envolvidas nos processos de fotossíntese e metabólicos e, em sua maior parte, apresentaram um aumento nas suas quantidades. Além disso, também foram encontradas algumas proteínas relacionadas a resposta de defesa da planta contra o ataque do patógeno. Estas proteínas serão listadas a seguir conforme cada condição estudada e descritas quanto as suas principais funções.

\subsection{Proteínas com abundância relativa diferencial identificadas a partir dos mapas proteicos bidimensionais}

\section{- Proteinas de choque térmico (heat shock protein)}

As proteínas de choque térmico (HSPs) foram identificadas pela primeira vez em Drosophila melanogaster na resposta ao estresse de choque térmico (CASHIKAR et al., 2005). Estas proteínas são agrupadas em famílias de proteínas de elevada massa molecular, compreendendo a HSP100, HSP90, HSP70/HSP60 e DnaK/GroE e famílias de baixa massa 
molecular, incluindo as proteínas de choque térmico 20 (HSP20) e as proteínas de choque térmico pequenas (HSPs) de 15-42 kDa (SARKAR et al., 2009). Essas famílias HSP foram referidas como estando envolvidas na estabilidade das proteínas $\mathrm{R}$, morte celular e regulação positiva da imunidade (KIM et al, 2007; VAN OOIJEN et al., 2010.; LIU; WHITHAM, 2013).

Ao avaliarmos a cultivar BRSGO-7560 foram identificadas proteínas de choque térmico HSP70 (stromal 70 kda heat shock-related chloroplastic), tanto na análise intra não inoculada (spots 37 e 761, tabela 4) quanto inoculada com abundância relativa aumentada (spot 130, tabela 5). Esta proteína também foi encontrada na análise inter cultivares em BRSGO-7560 na condição não inoculada (spot 37, tabela 12). E na análise inter cultivares para MSOY-8001 inoculada (spot 240) (tabela 17). Os genes que codificam HSP do grupo de $70 \mathrm{kDa}$ (HSP70) foram os primeiros a serem isolados e extensivamente estudados em diversos organismos. As proteínas 70-kDa heat shock (HSP70s) são chaperonas moleculares envolvidas em uma variedade de processos celulares, incluindo dobramento de proteínas, transporte de proteínas através de membranas, a modulação da atividade de proteínas, regulação da degradação de proteínas e prevenção de agregação irreversível de proteínas (PAI-HSIANG; HSOU-MIN, 2008). As proteínas HSP70s são codificadas por uma família de múltiplos genes. Análises de sequências de genes de famílias HSP70 vegetais revelaram quatro subgrupos principais, cada uma localizada em um dos compartimentos subcelulares: citosol, retículo endoplasmático, plastídeos e mitocôndrias (SUNG et al 2001).

Em estudos realizados por Salavati et al. (2012) com raízes de feijão (Phaseolus vulgaris) após inoculação com Rhizobium etili, a proteína de choque térmico HSP70 apresentou aumento em sua abundância relativa durante a fase inicial de interação simbiótica. Os resultados de tal estudo sugerem que chaperoninas como HSP70 são essenciais nas fases iniciais da simbiose, bem como, que estas proteínas podem funcionar para o transporte de outras proteínas através da membrana e promovendo seu dobramento e sua correta montagem (SALAVATI et al., 
2012). A indução de proteínas de choque térmico durante a simbiose (OEHRLE et al., 2008) e em resposta a agentes patogênicos (COLDITZ et al., 2004) têm sido relatadas.

Também foi observado aumento da abundância relativa da proteína $20 \mathrm{kDa}$ chloroplastic na cultivar BRSGO-7560 tanto na análise intra cultivar (spot 677, tabela 5) quanto inter cultivares na condição não inoculada (spot 288 da tabela 12). A atividade das HSP20s (chaperonin 20) é especialmente importante em culturas como a soja, cultivada em grandes áreas ao redor do mundo, a qual é constantemente afetada por diferentes condições de estresse. Este grupo de proteínas, chamadas chaperonas ou chaperoninas, podem ajudar outras a manter a conformação nativa das cadeias de polipeptídeos nascentes e na reorganização de proteínas desnaturadas conduzindo-a a sua conformação nativa (SHIRASU, 2009). A ligação entre a imunidade da planta e proteínas de choque térmico, bem como outros chaperonas moleculares tem sido identificada em muitas espécies de plantas (SHIRASU 2009; CHEN; SHIMAMOTO 2011). A atividade das chaperonas, de proteínas de choque térmico durante estresse biótico tem demonstrado ser importante para a estabilidade e acúmulo de proteínas de resistência (proteínas R) e pela coordenação de toda cascata de sinalização de defesa (BOTER et al., 2007).

Um gene HSP20 que é responsivo ao estresse biótico foi identificado em plantas de soja. Este gene foi mapeado para um local de características quantitativas (QTL) responsável por resistência a Meloidogyne javanica e encontrado diferencialmente expressos entre genótipos de soja resistentes e suscetíveis (FUNGANTI et al., 2004). Estas proteínas são consideradas alvos ideais para melhoramento de novas variedades de soja que são tolerantes a uma ampla gama de condições de estresse ou combinação de estresses (LOPES-CAITAR et al., 2013).

Sobhanian et al. (2010), conduzindo análise proteômica de folhas, hipocótilos e raízes de soja em condições de estresse ao alumínio, observaram aumento de expressão da chaperonina de $20 \mathrm{kDa}$, sugerindo que a proteção de proteínas por esta chaperona em soja é muito importate para prevenir a desnaturação proteica durante condições de estresse por alumínio. 
No presente trabalho também foi observado a presença de proteínas de choque térmico de baixa massa molecular nas diferentes condições avaliadas. Na cultivar BRSGO-7560, tanto nas análises intra cultivar quanto inter cultivares na condição não inoculada, observou-se a presença de proteínas de choque térmico de baixa massa molecular: spot 367 da tabela 4, onde identificou-se a proteína hsp16_kDa class I heat shock protein e no spot 399 da tabela 12 observa-se a hsp14_kDa class I heat shock protein, as quais apresentaram abundância relativa aumentada. Além disso, pode-se notar que a maioria das proteínas exclusivas observadas na cultivar BRSGO-7560 não inoculada na análise intra cultivar (spots 391, 393, 394, 482, 488 e 732 da tabela 5) foram todas descritas como proteínas de choque térmico.

As proteínas de choque térmico de baixa massa molecular têm sido relatadas na literatura relacionadas tanto a condições de estresses abióticos quanto bióticos. Análises genéticas indicam que, em plantas estas proteínas são codificadas por seis famílias de genes bem definidas. Cada família codifica proteínas localizadas em compartimentos celulares diversos, incluindo citoplasma (classes I e II), cloroplasto (classe III), endomembranas (classes IV e V) e mitocôndria (classe VI) (LAFAYETTE et al., 1996; WATERS et al., 1996). Em plantas, este grupo de proteínas tem merecido atenção especial, devido principalmente a sua abundância (podendo alcançar 1 a $2 \%$ da proteína total da folha) e por sua diversidade (WATERS et al., 1996; LIN et al., 1984, CHOU et al., 1989). Apesar da grande maioria das proteínas de baixa massa molecular serem sintetizadas apenas em condições de estresse, também já foi observada a expressão específicas destas proteínas em condições normais, durante determinadas fases de desenvolvimento da planta, principalmente em dicotiledôneas (MANSFIELD; KEY 1987). Como em nosso estudo, este grupo de proteínas também foi observado mesmo em condições normais (plantas não inoculadas pelo patógeno). 
- Rubisco large subunit-binding protein, Ribulose bisphosphate carboxylase large chain (RuBisCO large subunit) e Ribulose bisphosphate carboxylase small chain

No presente estudo foi encontrada a subunidade grande da rubisco (rubisco large subunitbinding protein), esta proteína foi observada em ambas as cultivares na condição não inoculada na análise intra cultivar com aumento em sua abundância relativa, em BRSGO-7560 nos spots: 42, 44 e 48 (Tabela 4), e em MSOY-8001 no spot 335 (Tabela 8). E também encontrada na análise inter cultivares entre BRSGO-7560 e MSOY-8001 na condição não inoculada (spot 44 e 48, tabela 12).

A proteína rubisco está envolvida no processo fotossintético. Em estudos realizados por Wang et al. (2012), foi observada uma redução na expressão desta proteína quando a cultivar de soja resistente foi inoculada com $P$. pachyrhizi. Podemos inferir que na condição infecciosa a planta tem um maior consumo de energia ocorrendo assim uma maior atividade catabólica. No nosso estudo por meio das análises comparativas citadas anteriormente, pode-se notar maior abundância desta proteína nas plantas não inoculadas havendo desta forma um estímulo à atividade anabólica. Em plantas, as infecções causam frequentemente alterações fisiológicas e dentre elas as mais importantes envolvem perturbações metabólicas (HEIDEL et al. 2004, VAN LOON, 1987).

Também foi detectado aumento na quantidade da ribulose bisphosphate carboxylase large chain (RuBisCO large subunit) na cultivar BRSGO-7560 na condição não inoculada na avaliação intra cultivar (spot 64, tabela 4). Por outro lado, também detectou-se aumento na quantidade desta proteína tanto na análise intra quanto inter cultivares para BRSGO-7560 na condição inoculada, (spots 70 e 68, tabela 6 e spots 30 e 26, tabela 15). 
A proteína de ligação à subunidade grande da rubisco é homóloga a HSP60 que foi encontrada auxiliando na montagem de uma ampla gama de proteínas de cloroplastos incluindo a rubisco e a sua função principal proposta é evitar a agregação e auxiliar no dobramento correto de proteínas (GATENBY; ELLIS 1990; BUKAU; HORWICH 1998). A expressão induzida da proteína de ligação à subunidade grande da rubisco foi relatada em muitas espécies de plantas sob várias condições de estresse bióticos e abióticos (DEMIREVSKA-KEPOVA; FELLER 2004; FUJIWARA et al. 2006; DEMIREVSKA et al, 2008). A rubisco é uma das principais enzimas presentes em folhas que participa na assimilação de $\mathrm{CO}_{2}$ em plantas pelo ciclo de Calvin (FRIDLYAND, 1999). Esta enzima foi observada em trabalho realizado por Ganinger (2013) onde a mesma apresentou aumento na abundância relativa em linhagens de soja resistente à ferrugem após inoculação com $P$. pachyrhizi.

A cadeia pequena da ribulose bisfosfato carboxilase também foi encontrada neste estudo com abundância relativa aumentada na análise inter cultivares tanto em MSOY-8001 na condição não inoculada (spots 277, 290 e 292, tabela 14) quanto inoculada (spot 213, tabela 17). De modo semelhante em condição inoculada com $P$. pachyrhizi, Tremblay et al. (2010) verificou uma redução na acumulação de transcrito correspondente à uma subunidade pequena da rubisco na cultivar de soja Williams 82, 10 dias após a inoculação. A rubisco por ser uma enzima que participa dos processos de produção de energia pela planta, é esperado que tenha sido observada em ambas as cultivares tanto na análise intra quanto inter cultivares e em ambas as condições avaliadas.

\section{- Adenosina trifosfato - (ATP synthase subunits alpha and beta, chloroplastic)}

Observou-se o aumento na quantidade de ATP sintase subunidade beta na condição inoculada em BRSGO-7560 tanto na análise intra, spots: 158, 231, 237 (Tabela 6), quanto inter 
cultivares, spots: 36, 40 (Tabela 15). Tra et al (2015) ao avaliar a cultivar de soja DT 2000 após inoculada também observou abundância relativa aumentada de ATP synthase subunit beta em análise proteômica de folhas de soja.

Em MSOY-8001 na condição inoculada inter cultivares esta enzima também foi observada (spot 242, tabela 17). Já na condição não inoculada apresentou abundância relativa aumentada apenas em MSOY-8001 na análise intra cultivares (spot 242).

A subunidade alfa de ATP sintase foi encontrada apenas em MSOY-8001 na condição inoculada na análise inter cultivares (spot 198, tabela 17).

\section{- 1-Deoxy-D-xylulose 5-phosphate reductoisomerase}

Na cultivar BRSGO-7560 detectou-se a presença desta enzima tanto na análise intra (spot 88, tabela 4) quanto inter cultivares na condição não inoculada (spots 86,87 e 107, tabela 12).

Esta enzima também foi observada com aumento em sua abundância relativa em MSOY8001 tanto na condição não inoculada (spot 67, tabela 14), quanto na condição inoculada na análise inter cultivares (spot 47, tabela 17).

Em estudos realizados por Pereira et al. (2013) foi observado aumento desta enzima em plantas de soja suscetível a $P$. pachyrhizi. Algumas enzimas estavam envolvidas em vias metabólicas relacionadas com defesa contra agentes patogênicos e entre estas a 1-deoxi-Dxilulose-5-fosfato reductoisomerase foi relatada. 


\section{- Glutamina sintetase-(Glutamine synthetase)}

No presente estudo, observou-se aumento na abudância relativa de glutamina sintetase na cultivar BRSGO-7560 não inoculada na análise intra cultivar (spots 95 e 106, tabela 4), quanto na análise inter cultivares na condição inoculada ( $\operatorname{spot} 80$, tabela 15).

A disponibilidade de nitrogênio tem um impacto significativo no desenvolvimento de doenças em plantas e a glutamina sintetase é uma das enzimas chave do metabolismo do nitrogênio nas células vegetais (PAGEU et al., 2006). Uma baixa disponibilidade de nitrogênio geralmente aumenta a suscetibilidade de plantas as doenças (SOLOMON et al., 2003). Glutamine sinthetase foi o primeiro purificado caracterizada a partir de plantas em 1956. Uma característica particular importante é a sua elevada afinidade para amônia e assim a sua capacidade para incorporar de forma eficiente amônia de forma orgânica (MIFLIN et al, 2002).

Esta enzima também foi detectada com abundância relativa aumentada em estudos realizados por Pereira et al. (2013) 72 horas após a inoculação com P. pachyrhizi em genótipo de soja com gene de resistência (PI561356). Da mesma forma, no presente estudo, ao se comparar as cultivares BRSGO-7560 e MSOY-8001 na condição inoculada, um aumento na sua abundância relativa foi observado na cultivar resistente (spot 80 , tabela 15 ), enquanto MSOY-8001 apresentou uma redução para esta mesma proteína (spot 80, tabelas 15). Tremblay et al. (2010) também observaram um padrão de redução no acúmulo de transcritos correspondentes a esta enzima em genótipo de soja suscetível (Williams 82) 10 dias após a inoculação com P. pachyrhizi. 


\section{- Glutathiona S-transferase (Glutathione S-transferase)}

Entre as proteínas identificadas, observa-se a presença da enzima glutationa-S-transferase, conhecida por estar envolvida na via de resistência a doenças (FOYER; NOCTOR 2005). Em estudos realizados por Wang et al. (2012), foi observado aumento na abundância relativa desta enzima em cultivar de soja com gene de resistência após inoculação com $P$. pachyrhizi. Por outro lado, neste estudo esta enzima foi observada na análise intra cultivar em BRSGO-7560 na condição não inoculada (spot 291, tabela 4).

\section{- 2-cys peroxiredoxina bas 1 (2-cys peroxiredoxin bas1-chloroplastic)}

No presente estudo foi observado aumento na abundância relativa da 2-cys peroxiredoxina bas 1 na condição não inoculada na análise intra cultivar para BRSGO-7560 (spot 318, tabela 4). E também na análise inter cultivares entre BRSGO-7560 e MSOY-8001 na mesma condição (spot 391, tabela 12). Esta mesma enzima foi observada na condição inoculada na análise intra cultivar em BRSGO-7560 (spot 529, tabela 7). Nos estudos realizados por Wang et al. (2012), foi observado uma redução na abundância relativa desta enzima em cultivar de soja com gene de resistência quando inoculada com P. pachyrhizi.

\section{- Superóxido dismutase (Superoxide dismutase)}

Foi observado o aumento na abundância relativa da enzima superóxido dismutase na análise intra cultivar na condição inoculada para a cultivar BRSGO-7560 (spots 203 e 498, tabela 6). Também foi possível observar a presença desta enzina com a presença de $(\mathrm{Fe})$ nesta mesma condição (spot 488, tabela 6). Foi observado também que esta mesma enzima associada a (Fe) 
estava presente na cultivar MSOY-8001 na condição não inoculada na análise inter cultivares (spots 197 e 452, tabela 14).

Superóxido dismutases (SODs) são enzimas que contém metais que catalisam a dismutação (conversão) de radicais superóxido para oxigênio ou peróxido de hidrogênio. Esta enzima tem sido encontrada em todos os organismos aeróbios examinados, onde desempenha um papel importante na defesa contra espécies reativas de oxigênio tóxicas, que são gerados como subprodutos de muitos processos de oxidações biológicas (ASADA, 1999; BOWLER et al., 1994).

Em estudos realizados por Ganinger (2013), esta enzima apresentou aumento na sua abundância relativa em linhagens de soja suscetível quando inoculadas com $P$. pachyrhizi. Por outro lado, esta mesma enzima apresentou redução em sua abundância relativa quando avaliada na linhagem resistente inoculada. A localização desta enzima foi atribuída ao cloroplasto (GANINGER, 2013). Esta enzima está distribuída principalmente nos cloroplastos, mitocôndrias, citoplasma, núcleos e apoplastos (OGAWA ET AI. 1996; ASADA 2006; RODRÍGUEZ-SERRANO et al. 2007).

\section{- Oxygen-evolving enhancer protein chloroplastic}

Observou-se aumento na abundância relativa da proteína relacionada ao aumento de oxigenação no cloroplasto para BRSGO-7560 na condição inoculada tanto na análise intra (spots 233 e 246, tabela 6) quanto inter cultivares (spots 141, 147 e 220, tabela 15). Por outro lado, ao se avaliar a cultivar BRSGO-7560 na condição não inoculada na análise inter cultivares também se encontrou a presença desta proteína com aumento em sua abundância relativa (spots 212 e 224, tabela 12). Além disso, esta proteína foi encontrada em MSOY-8001 tanto na análise 
intra (spot 627, tabela 8) quanto inter cultivares (spots 515 e 520, tabela 14) na condição não inoculada, bem como quando inoculada na análise inter (spot 170, tabela 17).

Em estudos realizados por Wang et al (2012) esta proteína também foi encontrada como tendo sua abundância relativa aumentada em cultivar de soja resistente após inoculação com $P$. pachyrhizi. O aumento na quantidade desta proteína pode auxiliar a planta na geração de espécies reativas de oxigénio para a reação de hipersensibilidade (HR) durante o processo de infecção da ferrugem.

\section{- Frutose bifosfato aldolase (Fructose-bisphosphate aldolase)}

No presente estudo verificou-se o aumento na abundância relativa da enzima frutose bifosfato aldolase em BRSGO-7560 na análise intra cultivar inoculada (spots 88, 102 e 373, tabelas 6), bem como na análise inter cultivares na condição não inoculada (spots 133, tabela 12). E também em MSOY-8001 quando comparada a BRSGO-7560 na condição não inoculada (spot 122, tabela 14).

Esta enzima faz parte das vias das pentoses fosfato. Esta via metabólica é uma das principais rotas da produção de compostos fenólicos, a qual é responsável por ativar mecanismos de defesa (TREMBLAY et al., 2010).

Esta enzima também foi detectada nos estudos realizados por Pereira et al. (2013), onde foi observado aumento nos níveis desta enzima no genótipo de soja com gene de resistência (PI561356) 72 horas após a inoculação com P. pachyrhizi. Estes autores relatam não terem encontrado esta mesma enzima em plantas não inoculadas e atribuem isto ao fato das limitações da técnica de eletroforese $2 \mathrm{DE}$, que tende a não permitir a detecção de proteínas com baixa abundância. Porém, em nosso estudo, esta enzima foi detectada na cultivar de soja BRSGO7560, cultivar com gene de resistência na condição não inoculada e também na cultivar 
suscetível MSOY-8001. Wang et al. (2012) também detectaram aumento nos níveis de frutose bisfosfato aldolase em uma cultivar resistente de soja (SX6907) inoculadas com P pachyrhizi, 12 e 24 horas após a inoculação.

Por outro lado, Tremblay et al. (2010) verificaram que os níveis de transcritos correspondentes a proteínas desta via foram menores em plantas de soja não inoculadas, e frutose bisfosfato aldolase estava entre estas proteínas. Os autores atribuem estes resultados ao fato de terem trabalhado com uma cultivar suscetível (cv. Williams 82), a qual não poderia contribuir com um eficiente mecanismo de defesa. Em estudos realizados por Khatoon et al (2012) estes observaram aumento nos níveis da frutose bifosfato aldolase em raízes de soja em condições de estresse por baixa oxigenação em condições de alagamento.

Esta enzima apresenta função relacionada a energia e possui localização no citosol.

\section{- Cytosolic ascorbate peroxidase 1}

Esta enzima apresentou aumento na sua abundância relativa em BRSGO-7560 tanto na análise intra cultivar (spot 190, tabela 6) quanto inter cultivares na condição inoculada (spot 191, tabela 15).

O aumento na abundância relativa observado apenas na cultivar de soja portadora do gene de resistência indica diferenças de resposta entre as cultivares e sugere que a resposta antioxidante possa ter um papel importante na defesa da planta contra o patógeno. Esta enzima está amplamente distribuída no citosol da planta, mitocôndrias, cloroplastos e outros compartimentos celulares. 


\section{- Elongation factor 1-delta}

Observou-se aumento na abundância relativa desta proteína na análise intra cutivar em MSOY-8001 após inoculação com P. pachyrhizi (spot 284, tabela 10). Por outro lado, Pereira et al (2012), trabalhando com plantas de soja resistentes a P. pachyrhizi, observaram uma redução na abundância relativa desta proteína.

\section{- Anidrase carbônica (Carbonic anhydrase)}

De acordo com os resultados obtidos para a cultivar MSOY-8001 quando inoculada com P. pachyrhizi, tanto na análise intra cultivar (spot 293, tabela 10) quanto inter (spot 293, tabela 17), detectou-se um aumento na abundância relativa desta enzima. Da mesma forma, esta enzima foi altamente acumulada 192 horas após inoculação em genótipo de soja suscetível (Embrapa 48) a P. pahcyrhizi (PEREIRA et al., 2013).

As plantas C3, em geral, apresentam maior atividade da enzima anidrase carbônica associada com a área foliar. A anidrase carbônica é uma metaloenzima que catalisa a condensação de $\mathrm{CO}_{2}$ e $\mathrm{H}_{2} \mathrm{O}$ em ácido carbônico $\left(\mathrm{H}_{2} \mathrm{CO}_{3}\right)$ que se dissocia formando $\mathrm{HCO}_{3}{ }^{-} \mathrm{e}^{+}$. Em plantas C3, como soja, a anidrase carbônica permite a difusão do carbono entre o citosol e estroma na forma de $\mathrm{HCO}_{3}{ }^{-}$, convertendo-o em $\mathrm{CO}_{2}$ apenas no momento da fixação de carbono através do ciclo de Calvin (BADGER; PRICE, 1994).

Existem várias evidências que relatam a anidrase carbônica envolvida com mecanismos de defesa moleculares de plantas contra patógenos. Esses resultados, somados aos encontrados nos estudos realizados por Pereira et al. (2013), indicam uma possível função da anidrase carbônica nos mecanismos metabólicos envolvidos na defesa da planta contra patógenos. A acumulação diferencial da anidrase carbónica, por exemplo, indica que a resistência sistêmica 
adquirida (SAR) foi ativada após a inoculação do patógeno na cultivar suscetível a $P$. pachyrhizi.

\section{- Phosphoglycerate kinase}

Esta enzima foi encontrada com aumento em sua abundância relativa na análise inter cultivares em BRSGO-7560 tanto na condição não inoculada (spot 118, tabela 12) quanto inoculada (spot 74, tabela 15). Também se observou aumento na abundância relativa desta enzima na análise inter cultivares na condição não inoculada para MSOY-8001 (spot 99, tabela 14).

Em condições de estresse abiótico (estresse por alagamento), esta enzima foi observada em raiz, hipocótilo e folhas de soja, sendo que em raiz e hipocótilo esta enzima apresentou uma redução em sua abundância relativa (KHATOON et al., 2012).

Esta enzina possui função relacionada aos processos metabólicos e encontra-se localizada na mitocôndria.

\section{- $\quad$ Fosforibuloquinase (Phosphoribulokinase)}

Esta enzima foi encontrada com aumento em sua abundância relativa na análise inter cultivares em BRSGO-7560 quando inoculada com P. pachyrhizi (spot 83, tabela 15). Em estudo protêomico realizados por Tra et al (2015) esta enzima também foi encontrada em cultivar de soja após inoculada com P. pachyrhizi apresentando abundância relativa aumentada.

Fosforibuloquinase é uma enzima que pertence à família uridina quinase e atua como transferase e quinase (PANTHER, 2016). Sua principal função é a atividade catalítica (UNIPROT, 2016). Em geral, são enzimas de plantas ativadas pela luz pelo sistema 
tioredoxina/ferredoxina (INTERPRO, 2016). Está relacionada ao processo de fixação de carbono em organismos fotossintéticos.

\section{- Outras proteínas com abundância relativa alteradas}

Outras proteínas com abundância relativa alteradas também foram observadas neste estudo, no entanto, como elas ainda não apresentam descrições detalhadas quanto as suas funções e demais aspectos fisiológicos, não foram discutidas neste trabalho.

\subsection{Proteínas identificadas nos spots exclusivos}

Neste estudo também foram observadas proteínas exclusivas em ambas as cultivares nas condições avaliadas, que sugere possíveis respostas específicas da interação planta-patógeno.

Ao se analisar os resultados das identificações dos spots exclusivos na análise intra cultivar para BRSGO-7560 na condição não inoculada, observou-se a presença de uma oxidorredutase (spot 122), uma proteína transportadora (spot 373) e proteínas de choque térmico da família HSP20 (spots 391, 393, 394,482, 488 e 732), conforme tabela 5.

Na condição inoculada para BRSGO-7560 na análise intra cultivar, observou-se a presença de uma carboxilase (Ribulose bisphosphate carboxylase large chain), (spot 369, tabela 7). Esta enzima está relacionada ao processo de fotossíntese e, em decorrência da infecção, como resultado, a planta é submetida a uma condição elevada de estresse, aumentando assim a demanda por energia de modo a garantir a defesa contra o patógeno (BERGER et al., 2007).

$\mathrm{Na}$ análise intra cultivar para MSOY-8001, o único spot exclusivo encontrado na condição não inoculada (spot 214, tabela 9) apresentou descrição relacionada à enzima NADH desidrogenase (tabela, 15). Esta enzima também foi encontrada por Trembley et al (2013) em 
estudo com cultivar de soja suscetível a $P$. pachyrhizi, cuja cultivar foi inoculada e avaliada em quatro tempos.

Na análise inter cultivares entre BRSGO-7560 e MSOY-8001 na condição não inoculada, entre as proteínas exclusivas encontradas, constatou-se a presença das enzimas glutamina sintetase (spots 102 e 106), fosforibuloquinase (spots 111 e 112), uma proteína relacionada à resistência a doenças (spot 380) e uma proteína de choque térmico (spot 394), conforme tabela 13. O papel biológico dessas proteínas foi discutido no sub-item 7.1.

As proteínas exclusivas encontradas na condição inoculada em BRSGO-7560 e MSOY8001, C6TB98 (spot 121, tabela 16) e C6T5C9 (spot 161, tabela 16), ainda não foram caracterizadas, porém a proteína C6TB98 está relacionada a uma provável proteína pop3 e C6T5C9 a uma isoflavona redutase de acordo com dados obtidos pelo Blast2GO, (Tabela 16).

Em estudos realizados por Santana (2012) na análise proteômica de raízes de soja cultivar Conquista (resistente ao nematoide Meloidogyne javanica) em resposta à inoculação, foi possível observar alteração na quantidade da enzima isoflavona redutase em resposta a essa interação. Esta enzima catalisa uma redução NADPH-dependente, envolvida na biossíntese de compostos derivados da via dos fenilpropanóides. Esta é uma enzima especifica da via de biossíntese dos isoflavonóides, encontrada tipicamente em leguminosas. França et al. (2001) também observou a importância dessa enzima no sistema de defesa de plantas. Pereira (2014) também encontrou esta enzima na interação entre feijão (Phaseolus vulgaris) e Trichoderma harzianum ALL 42 e com os fungos fitopatogênicos Fusarium solani e Rhizoctonia solani. Nestas interações foi possível observar elevada produção de compostos secundários, que possuem funções antioxidantes e protetivas, como o fortalecimento da parece celular vegetal através da produção de fitoalexinas e ligninas, contribuindo, por sua vez, na resistência à $R$. solani. 
Recentemente, em estudos com Arabidopsis com folhas tratadas com Cerato-platanin (CP), uma família de proteínas liberadas por fungos que atuam como fatores de virulência e/ou como indutores de resposta a defesa, foi possível observar resposta de defesa, podendo atribuir esta resposta a uma provável proteína pop3 (LUTI et al., 2016). Da mesma forma, no presente estudo certamente a interação entre a planta e o patógeno promoveu a ativação desta proteína responsável por defesa contra o patógeno, uma vez que a cultivar BRSGO-7560 é portadora de gene de resistência a P. pachyrhizi.

A única proteína exclusiva encontrada na análise comparativa entre MSOY-8001 e BRSGO-7560 na condição inoculada (spot 284) está relacionada ao fator de elongação delta 1. As proteínas classificadas como fatores de elongação são responsáveis pela precisão no processo de tradução (INTERPRO, 2016), o que pode estar associado a uma maior demanda por proteínas para impedir a instalação do patógeno no hospedeiro vegetal. 


\section{CONCLUSÕES}

- O estudo proposto permitiu identificar proteínas com abundância relativa significativas que desempenham papel relevante na defesa da planta contra o agente causal da ferrugen asiática da soja.

- Proteínas relacionadas a defesa contra o patógeno foram encontradas, entre estas: proteínas de choque térmico como a HSP70, 1-Deoxy-D-xylulose 5-phosphate reductoisomerase, glutamine synthetase, DHAR class glutathione S-transferase, superoxide dismutase, oxygen-evolving enhancer protein chloroplastic, fructosebisphosphate aldolase, cytosolic ascorbate peroxidase 1 e carbonic anhydrase.

- A cultivar MSOY-8001 apresentou uma proteína em particular com abundância relativa aumentada (anidrase carbônica) na condição inoculada tanto na análise intra quanto inter cultivares.

- Proteínas exclusivas relacionadas à defesa foram identificadas na cultivar BRSGO7560 na condição inoculada na análise inter cultivares, entre estas: uma provável proteína pop3 e uma isoflavona redutase na condição inoculada. 


\section{REFERÊNCIAS BIBLIOGRÁFICAS}

AEBERSOLD, R., MANN, M. Mass spectrometry-based proteomics. Nature, 422 (6928):198207. 2003.

AGRIOS, G. N. Plant Pathology. 4th Edition. Academic Press, New York, 1997.

AHERN, K., P roteomic database s p lay increasing role. Genet. Eng. News, 24, 3 4-37. 2004. ALMEIDA, A.M.R.; FERREIRA, L.P.; YORINORI, J.T.; SILVA, J.F.V.; HENNING, A.A.; GODOY, C.V.; COSTAMILAN, L.M.; MEYER, M.C. Doenças da soja. In: Kimati, H.; Amorim, L.; Bergamim Filho, A.; Camargo, L.E.A. Manual de Fitopatologia: doenças das plantas cultivadas. São Paulo: Agronômica Ceres,. cap. 64:569-588. 2005.

ANDERSON, N. G.; ANDERSON, N. L. Twenty years of Two-dimensional electrophoresis: past, present and future. Electrophoresis, v. 17, p. 443-453, 1996.

ARIAS, C.A.A.; RIBEIRO, A.S.; YORINORI, J.T.; BROGIN, R.L.; OLIVEIRA, M.F.; TOLEDO, J .F.F. Inheritance of resistance of soybea $\mathrm{n}$ to rust (Phakopsora pachyrhizi Sidow). In: Moscardi et al. (EDs.). World Soybean Research Conference, International Soybean Processing and Utilization Conference, Congresso Brasileiro de Soja, Foz do Iguaçu. Abstracts of contribuited papers and posters. Londrina: Embrapa soybean, p. 100. (Embrapa Soja. Documentos, 228). 2004.

ASADA K. The water-water cycle in chloroplasts: scavenging of active oxygens and dissipation of excess photons. Annual Review of Plant Biology.50:601-639, 1999.

AZEVEDO, L. A. S., JULIATTI, F. C., BALARDIN, R. S.; SILVA, O. C. Programa Syntinela: Monitoramento da dispersão de Phakopsora pachyrhizi e alerta contra a ferrugem asiática da soja. Campinas, Emopi Gráfica e Editora, 2004.

BADGER M.R., PRICE G.D., The role of carbonic anhydrase in photosynthesis, Annu. Rev. Plant Physiol. Plant Mol. Biol., 45, 369-392, 1994.

BERGAMIN FILHO, A.; AMORIM, L. Doenças de plantas tropicais: epidemiologia e controle econômico. São Paulo: Agronômica Ceres, 289p, 1996.

BERGER S., SINHA A.K., ROITSCH T. Plant physiology meets phytopathology: plant primary metabolism and plant-pathogen interactions. Journal of Experimental Botany. 58:4019- 4026. DOI: 10.1093/jxb/erm298, 2007.

BEVAN, M., BANCROFT, I., BENT, E., LOVE, K., GOODMAN, H., DEAN, C., DROST, L. Analysis of $1.9 \mathrm{Mb}$ of contiguous sequence from chromosome 4 of Arabidopsis thaliana. Nature, 391(6666), 485-488, 1998. 
BIRON, D., B. C, et al. The pitfalls of proteomics experiments without the correct use of bioinformatics tools. Proteomics, v.6, n.20, p.5577-5596. 2006.

BHATTARAI, K. K., LI, Q., LIU, Y., DINESH-KUMAR, S. P. AND KALOSHIAN, I. 2007. The MI-1-mediated pest resistance requires Hsp90 and Sgt1. Plant Physiol. 144:312-323.

BRASIL. Ministério da Agricultura, Pecuária e Abastecimento; Cadeia produtiva da soja. Secretaria de Política Agrícola, Instituto Interamericano de Cooperação para a Agricultura. Brasília: IICA: MAPA/SPA, 2007.

BONDE, M. R., NESTER, S. E., BERNER , D . K ., FREDERICK, R. D., Comparative susceptibilities of legume species to infection by Phakopsora pachyrhizi . Plant Dis., 92, 3036. 2008.

BONDE, M. R., BERNER, D. K., NESTER, S. E., FREDERICK, R. D., Effects of temperature on urediniospore germination, germ tube growth, and initiation of infection in soybean by Phakopsora isolates. Phytopathology, 97, 997-1003. 2007.

BONDE, M. R., NESTER, S. E., AUSTIN, C. N., STONE, C. L., FREDERICK, R. D., HARTAMN, G. L., MILES, M. R. Evaluation of virulence of Phakopsora pachyrhizi and $P$. meibomiae isolates. Plant Dis. 90:708-716. 2006.

BOSTON, R. S., VIITANEN, P. V., VIERLING, E. Molecular chaperones and protein folding in plants. Plant Mol. Biol. 32:191-222. 1996.

BOTER M, AMIGUES B, PEART J, BREUER C, KADOTA Y, CASAIS C, MOORE G, KLEANTHOUS C, OCHSENBEIN F, SHIRASU K, GUEROIS R: Structural and functional analysis of SGT1 reveals that its interaction with HSP90 is required for the accumulation of Rx, an R protein involved in plant immunity. Plant Cell, 19:3791-3804, 2007.

BOWLER C., VAN CAMP W., VAN MONTAGU M., INZÉ D., ASADA K. Superoxide dismutase in plants. Critical Reviews in Plant Sciences 13:199-218., 1994.

BRADFORD, M .M., A rapid and sensitive method for the quantitation of microgram quantities of protein utilizing the principle of protein-dye binding. Anal. Biochem. 72, 248-254. 1976.

BREIMAN, A. 2014. Plant Hsp90 and its co-chaperones. Curr. Protein Pept. Sci. 15:232-244.

BROMFIELD, K. R. Soybean Rust. Monogr. No. 11. American Phytopathological Society, St. Paul, MN. 1984.

BROMFIELD, K.R; HARTWIG, E.E. Resistance to soybean rust and mode of inheritance. Crop Science, 20: 254-255. 1980. 
BUKAU B, HORWICH A. The Hsp 70 and Hsp 60 chaperone machines. Cell. 92:351-366, 1998.

BURDON, J.J.; SPEER, S.S. A set of differential Glycine hosts for the identification of races of Phakopsora pachyrhizi Syd. Euphytica, v.33, p.891-896, 1984.

CAMARGO, L. E. A. Analise genética da resistência e da patogenicidade. In: BERGAMIN FILHO, A.; KIMATI, H.; AMORIM, L. Manual de fitopatologia: princípios e conceitos. São Paulo: Ceres, p. 470-491,1995.

CARPENTIER, S. C., WITTERS, E., LAUKENS, K., DECKERS, P., SWENNEN, R., PANIS, B. Preparation of protein extracts from recalcitrant plant tissues: An evaluation of different methods for two-dimensional gel electrophoresis analysis. Proteomics, 5, 2497-2507. 2005.

CASHIKAR AG, DUENNWALD M, LINDQUIST SL: A chaperone pathway in proteindisaggregation: Hsp26 alters the nature of protein aggregates tofacilitate reactivation by Hsp104. J Biol Chem. 280:23869-23875, 2005.

CASTRO, M., et al. Proteome Analysis of Resting Human Neutrophils. Protein and Peptide Letters. Brasil, 2006.

COLDITZ, F.; NYAMSUREN, O.; NIEHAUS, K.; EUBEL, H.; BRAUN, H.P.;KRAJINSKI, F. Proteomic approach: identification of Medicago truncatula proteins induced in roots after infection with the pathogenic oomycete Aphanomyces euteiches. Plant Mol. Biol. 55, 109-120, 2004.

CONAB. Acompanhamento da safra brasileira: Grãos. Décimo segundo levantamento, setembro/2015., Brasília, 2015.

CONESA, A., GÖTZ, S. Blast2GO: A comprehensive suite for functional analysis in plant genomics. International journal of plant genomics, 2008.

COOPER, B., CAMPBELL, K. B., FENG, J., GARRETT, W. M., \& FREDERICK, R. Nuclear proteomic changes linked to soybean rust resistance. Molecular BioSystems, 7(3), 773-783, 2011.

COX, J.; MANN, M..MaxQuant enables high peptide identification rates, individualized ppbrange mass accuracies and proteome-wide protein quantification. Nature biotechnology, v. 26, n. 12, p. 1367-1372, 2008.

DANI, V. et al. Changes in the tobacco leaf apoplast proteome in response to salt stress. Proteomics, v.5, p.737-745, 2005. 
DEMIREVSKA-KEPOVA K, FELLER U. Heat sensitivity of Rubisco activase and Rubisco binding protein in higher plants. Acta Physiol Plant. 26:103-114, 2004.

DEMIREVSKA K, SIMOVA-STOILOVA L, VASSILEVA V, FELLER U. Rubisco and some chaperone protein responses to water stress and rewatering at early seedling growth of drought sensitive and tolerant wheat varieties. Plant Growth Regul. 56:97-106, 2008.

DURANTI, M. Grain legume proteins and nutraceutical properties. Fitoterapia 77:67-82. 2006.

EDWARDS, H., BONDE, M. R., Phakopsora pachyrhizi host penetrat ion strategy. Phytopathology, 98, S49. 2008.

EMBRAPA. BRSGO-7560: cultivar de soja para o manejo da ferrugem. Londrina: Embrapa, Seagro-GO, CTPA, 1 folder, 2009.

EMBRAPA - Centro Nacional de Pesquisa de Soja. In: Tecnologias de produção de soja- Paraná 2007. Londrina. 2006.

EMBRAPA., 2016: Disponível em: https://www.embrapa.br/soja/cultivos/sojal/dadosconomicos.

FARIAS NETO, A.L.de, SOUZA, P.I.M., MOREIRA., C.T., BROGIN, R.L., CORDEIRO, L.C., SANTIN, M.R., ALBUQUERQUE, B., DIANESE, A.C., SILVA, S.A. Reação de cultivares de soja à ferrugem asiática, causada pelo fungo Phakopsora pachyrhizi Sydow. In: CONGRESSO BRASILEIRO DE SOJA, MERCOSOJA, 5, 2009. GOIÂNIA-GO. Resumos. Londrina: Embrapa Soja,. p.234, 2009.

FRANÇA, S. C.; ROBERTO, P. G.; MARINS, M. A.; PUGA, R. D.; RODRIGUES, A.; PEREIRA, J. O. Biosynthesis of secondary metabolites in sugarcane. Genetics and Molecular Biology, 24:243-250, 2001.

FOYER CH, NOCTOR G. Oxidant and antioxidant signalling in plants: a re-evaluation of the concept of oxidative stress in a physiological context. Plant Cell Environ. 28:1056-1071, 2005.

FUNDAÇAO MATO GROSSO. Disponível em: http://www.fundacaomt.com.br/soja/Acesso em 18 maio 2012.

FUGANTI, R., BENEVENTI, M.A, SILVA J.F.V., ARIAS C.A.A., MARIN S.R.R, BINNECK, E, NEPOMUCENO, A. L. Identificação de marcadores moleculares de microssatélites para a seleção de genótipos de soja resistentes a Meloidogyne javanica. Nematologia Brasileira, 28:125-130, 2004. 
FUJIWARA M, UMEMURA K, KAWASAKI T, SHIMAMOTO K. Proteomics of Rac GTPase signaling reveals its predominant role in elicitor-induced defense response of cultured rice cells. Plant Physiol. 140:734-745, 2006.

GANIGER, Mala. Proteomics-based study of host-fungus interaction between soybean and Phakopsora pachyrhizi using recombinant inbred line (RIL) derived sister lines. Tese de Doutorado. University of Agricultural Sciences, 2013.

GARCIA, A.; CALVO, É.S.; KIIHL, R.A. de S.; HARADA, A.; HIROMOTO, D.M.; VIEIRA, L.G.E. Molecular mapping of soybean (Phakopsora pachyrhizi) resistance genes: discovery of novel locus and alleles. Theoretical and Applied Genetics, v.117, p.545-553, 2008.

GATENBY, A.A, ELLIS, R.J. Chaperone function: The assembly of ribulose bisphosphate carboxy lase-oxygenase. Annu Rev Cell Biol. 6:125-149, 1990.

GEPTS, P,, BEAVIS, W.D., BRUMMER, E.C, SHOEMAKER, R.C, STALKER, H.T., WEEDEN, N. F, YOUNG,N. D. Legumes as a model plant family.Genomics for food and feed report of the cross-legume advances through genomics conference. Plant Physiol, 137:12281235. 2005.

GODOY. C.V et al. Eficiência de fungicidas para o controle da ferrugem-asiática da soja, Phakopsora pachyrhizi, na safra 2011/12: resultados sumarizados dos ensaios cooperativos. CIRCULAR TÉCNICA 93. Londrina:Embrapa Soja, 2012.

GODOY, C. V.; ARIAS, C.A.A. Resistência quebrada. Cultivar, Uberlândia, v.5,n.55, p. 2829,2003 .

GUTIERREZ-GONZALEZ, J.J., WU, X. , GILLMAN, J.D. , LEE , J.D. , ZHONG, R., SHANNON, J.G., et al . Intricate environment-modulated genetic networks control isoflavone accumulation in soybean seeds. BMC Plant Biol. (in press). 2010.

HAJDUCH, M., GNAPATHY, A., STEIN, J.W., THELEN, J.J. A systematic proteomic study of seed filling in soybean. Establishment of high-resolution two-dim ensional reference maps, expression profiles, and an interactiv e proteome database. Plant Physiol; 137:1397 - 419. 2005.

HARTMAN, G.L.; MILES, M.R.; FREDERICK, R.D. Breeding for resistance to soybean rust. Plant Disease, v.89, p.664-665, 2005.

HARTMAN, G.L.; WANG, T.C.; SHANMUGASUNDARAM, S. Soybean rust research: progress and future prospects. In: WORLD SOYBEAN RESEARCH CONFERENCE, 5., 1994, Chiang Mai. Proceedings. Bangkok: Kasetsart University Press,. p.180-186. 1997. 
HARTWIG, E.E. Identification of a fourth major gene conferring resistance to soybean rust. Crop Science, 26: 1135-1136. 1986.

HARTWIG, E.E; BROMFIELD, K.R. Relationships among 3 genes conferring specific resistance to rust in soybeans. Crop. Science. 23, 237-239. 1983

HEALTHCARE, GE. 2-D eletrophoresis. Principle and Methods. Handbooks from GE.Heathcare. Germany, 2004.

HEBERT, B.R. Advances in protein solubilisation for two-dimensional electrophoresis. Electrophoresis, v. 20, p. 660 a 663, 1999.

HEIDEL AJ, CLARKE JD, ANTONOVICS J, DONG X. Fitness costs of mutations affecting the systemic acquired resistance pathway in Arabidopsis thaliana. Genetics. 168:2197-2206, 2004.

HENNINGS, P. Some new Japanese Uredinales. IV. Hedwigia (Suppl.):107-108. (In German.). 1903.

HERMAN. E.M., HELM, R.M., JUNG, R. KINNEY, A.J. Genetic modification removes an immunodominant allergen from soybean. Plant Physiol.; 132, p.36-43, 2003.

HILL, J., NELSON, E., TILMAN, D., POLASKY, S., TIFFANY, D. Environ-mental, economic, and energetic costs and benefits of biodiesel and ethanol biofuels. Proc Natl Acad Sci USA 103:11206- 11210. 2006.

HONG-MEI, Q. I. U., CHUN-YAN, L. I. U., ZHANG, D. J., XIN, X. J., JIA-LIN, W. A. N. G., JING, W. A. N. G., ... \& QING-SHAN, C. H. E. N. Proteome analysis of resistance to Phytophora root rot in soybean. Acta Agronomica Sinica, 35(3), 418-423, 2009.

HYTEN, D.L, SMITH, J.R, FREDERICK, R.D., TUCHEKR, M.L., SONG, Q., CREGAN, P.B. Bulked segregant analysis using the Golden Gate assay to locate the Rpp3 locus that confers resistance to soybean rust in soybean. Crop Science, 49: 265-271. 2009.

HYTEN, D.L, HARTMAN, G.L, NELSON, R.L., FREDERICK, R.D, CONCIBIDO, V.C, NARVEL, J.M., CREGAN, P.B. Map location of the Rpp1 locus that confers resistance to soybean rust in soybean. Crop Science, 47: 837-838. 2007.

INDEX

FUNGORUM

Disponívelem:http://www.indexfungorum.org/Names/namesrecord.asp?RecordID=121037.

KIM, H. J., HWANG, N. R. AND LEE, K. J. 2007. Heat shock responses for understanding diseases of protein denaturation. Mol. Cells 23:123-131. 
KIM, S.T., KIM, S.G., HWANG, D.H, KANG, S.Y, KIM, H.J, LEE, B.H, LEE, J.J., KANG, K.Y Proteomic analysis of pathogen-responsive proteins from rice leaves induced by rice blast fungus, Magnaporthe grisea. Proteomics. 4:3569-3578. 2004

KHATOON, A., REHMAN, S., HIRAGA, S., MAKINO, T., \& KOMATSU, S. Organ-specific proteomics analysis for identification of response mechanism in soybean seedlings under flooding stress. Journal of proteomics, 75(18), 5706-5723, 2012.

KIRK, P. M.; P. F. CANNON; D. W. MINTER \& J. A. STALPERS. Dictionary of the Fungi. 10th ed. Wallingford, CABI. 2008.

KOMATSU, S., AHSAN, N. Soybean proteomics and its application to functional analysis. Journal of Proteomics, 72, p.325-336. 2009.

KONISHI, H. et al. A proteomics approach towards understanding blast fungus infection of rice grown under different levels of nitrogen fertilization. Proteomics, v.1, p.1162-1171. 2001.

LAPERUTA, L. D. C., ARIAS, C.A.A., RIBEIRO, A.S., RACHID, B. F., PIEROZZI, P.H.B., TOLEDO, J.F.F.De., PÍPOLO, A.E., CARNEIRO, G.E. De. S. New genes conferring resistance to Asian soybean rust: allelic testing for the Rpp2 and Rpp4 loci. Pesquisa Agropecuária. Brasileira, Brasília, v.43, n.12, p.1741-1747, dez. 2008.

LEVY, C. Epidemiology and chemical control of soybean rust in southern Africa. Plant Dis. 89:669-674. 2005.

LI, S, SMITH, J.R, RAY, J.D, FREDERICK, R.D. Identification of a new soybean rust resistance genes in PI 567102B. Theor Appl Genet 125:133-142, 2012.

LINDQUIST, S. The Heat Shock Response. Annu. Rev. Biochemistry, v.55, p.11511-11591, 1986. Lindquist, S. \& Craig, E. A. The Heat Shock Proteins. Annu. Rev. Genetics, v.22, p.631677, 1988.

LINDQUIST, S., CRAIG, E. A. The Heat Shock Proteins. Annu. Rev. Genetics, v.22, p.631677, 1988.

LIN, C-Y.; ROBERTS, J. K. \& KEY, J. L. Acquisition os thermotolerance in soybean seedling, synthesis and accumulation of heat shock proteins and their cellular localization. Plant Physiol, v.74, p.152-160, 1984.

LIU, J. Z.; WHITHAM, S. A. Overexpression of a soybean nuclear localized type-III DnaJ domain-containing HSP40 reveals its roles in cell death and disease resistance. Plant J. 74:110$121,2013$. 
LÓPEZ, J.L. et al. A proteomic approach to the study of the marine mussels Mytilus edulis and M. galloprovincialis. Marine Biology, v.141, n.2, p.217-223, 2002.

LUTI, Simone et al. PAMP Activity of Cerato-Platanin during Plant Interaction: An-Omic Approach. International Journal of Molecular Sciences, v. 17, n. 6, p. 866, 2016.

McLEAN, R.J; BYTH, D.E. Inheritance of resistance to rust (Phakopsora pachyrhizi) in soybeans. Australian Journal of Agricultural Research, 31: 951-956. 1980.

MAGAREY, R. D., FOWLER, G. A., BORCHERT, D. M., Sutton, T. B., COLUNGAGARCIA, M., SIMPSON, J. A. NAPPFAST: An internet system for the weather-based mapping of plant pathogens. Plant Dis. 91:336-345. 2007.

MAMONE, G. et al. Analysis of food proteins and peptides by mass spectrometry-based techniques. Journal of Chromatography, v. 1216, n. 43, p. 7130-7142. 2009.

MANAVALAN, L.P., GUTTIKONDA, S.K., TRAN, L.S; NGUYEN, H.T. Physiological and molecular approaches to improve drought resistance in soybean. Plant Cell Physiol., 50: 12601276. 2009.

MANSFIELD, M. A.; KEY, J. L. Synthesis of the Low Molecular Weight Heat Shock Proteins in Plants. Plant Physiol, v.84, p. 1007-1017, MAGER, W. H. \& FERREIRA, M. P. Stress response of yeast. Biochemestry, 1987.

MARCHETTI, M. A., MELCHING, J. S., BROMFIELD, K. R., The effects of temperature and dew period on germination andinfection by urediniospores of Phakopsora pachyrhizi. Phytopathology, 66, 461-463, 1976.

MATIELLO, R.R., BARBIERI, R.L., de CARVALHO, F. I.F. Resistência de plantas a moléstias fúngicas. Ciência Rural, Santa Maria, v.27, n.1, p.161-168, 1997.

MELCHING, J. S., DOWLERr, W. M., KOOGLE, D. L.; ROYER, M. H. Effects of dura-tion, frequency, and temperature of leaf wet-ness periods on soybean rust. Plant Dis.73:117-122. 1989.

MIFLIN, B. J., \& HABASH, D. Z. The role of glutamine synthetase and glutamate dehydrogenase in nitrogen assimilation and possibilities for improvement in the nitrogen utilization of crops. Journal of experimental botany, 53(370), 979-987, 2002.

MILES, M. R., FREDERICK, R. D., HARTMAN, G. L. Evaluation of soybean germplasm for resistance to Phakopsora pachyrhizi. Plant Health Progress: doi:10.1094.PHP-2006=010401-RS. 2006 
MORELL, W., YORINORI, J. T. Situacion de la roja de la soja en el Paraguay. Bol de Diulgacion No. 44. Ministerio de Agricultura y Granaderia, Centro Regional de investigacion Agricola, Capitan Miranda, Paraguay. 2002.

NATARAJAN, S., XU, C., BAE, H., CAPERNA, T.J, GARRET, W.M. Characterization of storage proteins in wild (Glycine soja) and cultivated (Glycine max) soybean seeds using proteomic analysis. J Agric Food Chem; 54:3114 - 20. 2006.

NATARAJAN, S. XU, C., CAPERNA, T.J., GARRET, W. Comparison of protein solubilization methods suitable for proteomic analysis of soybean seed proteins. Analytical Biochemistry, 342, p. 214-220. 2005.

NEWSHOLME, S.J., MALEEFT, B.F., STEINER, S., ANDERSON, N.L., SCHWARTZ, L.W. Two-dimensional electrophoresis of liver proteins: characterization of a drug-induced hepatomegaly in rats. Electrophoresis, 21, 2122-2128, 2000.

NUCLEIC ACIDS RES. 2015 Jan;43(Database issue):D204-12. doi: 10.1093/nar/gku989. Epub 2014 Oct 27.

O'BRIAN, M.R., VANCE, C.P. Legume biology: sequence to seeds. Plant Physiol. 144:537, 2007.

O'FARREL, P. H. High resolution two-dimensional electrophoresis of proteins. Journal of Biological Chemistry, Bethesda, USA, v. 250, p. 4007-4021. 1975.

OEHRLE, N.W.; SARMA, A.D.; WATERS, J.K.; EMERICH, D.W. Proteomic analysis of soybean nodule cytosol. Phytochemistry, 69, 2426-2438, 2008.

PAGEAU K., REISDORF-CREN M., MOROT-GAUDRY J.F., MASCLAUXDAUBRESSE, C. The two senescence-relatedmarkers, GS1 (cytosolic glutamine synthetase) and GDH (glutamate dehydrogenase), involved in nitrogen mobilization, are differentially regulated during pathogen attacka nd by stress hormones and reactive oxygen species in Nicotiana tabacum L. leaves, J. Exp. Bot., 57(3), 547-557, 2006.

PANDEY, A.; MANN, M. Proteomics to study genes and genomes. Nature, v. 405, p. 837846, 2000.

PENNINGTON, S.R.; DUNN. M.J. Proteomics: from protein sequence to function. New York: Springer-Verlag e BIOS scientific Plubishers, 1v. 2001.

PEREIRA, M. R., GOUVÊA, B. C., MARCELINO-GUIMARÃES, F. C., RAMOS, H. J. D. O., MOREIRA, M. A., \& BARROS, E. G. D. Proteomic analysis of soybean leaves in a compatible and an incompatible interaction with Phakopsora pachyrhizi. Organelles Proteomics, 1(1), 2013. 
PEREIRA, J. L. Análise da interação entre Phaseolus vulgaris, Trichoderma harzianum ALL 42 e os fungos fitopatogênicos Fusarium solani e Rhizoctonia solani, (Tese de doutorado). 2014.

PIEROZZI, P.H.B., RIBEIRO, A.S., MOREIRA, J.U.V., LAPERUTA, L.C., RACHID,B.F., LIMA, W.F, ARIAS, C.A.A., OLIVEIRA, M.F., TOLED, J.F.F. New soybean (Glycine max, Fabales, Fabaceae) sources of qualitative genetic resistance to Asian soybean rust caused by Phakopsora pachyrhizi (Uredinales, Phakopsoraceae). Genetics and Molecular Biology, 31: 505-511. 2008.

PIVONIA, S., YANG, X. B. Assessment of the potential year-round establishment of soybean rust throughout the world. Plant Dis. 88:523-529. 2004.

POSADA-BUITRAG, M. L., FREDERICK, R. D. Expressed sequence tag analysis of the soybean rust pathogen Phakopsora pachyrhizi. Fungal Genet. Biol., 42, 949-962. 2005.

RABILlOUD, T.; ADESSI, C.; GIRAUDEL, A.; LUNARDI, J. Improvement of the solublization of proteins in two-dimensional electrophoresis with immobilized $\mathrm{pH}$ gradients. Electrophoresis, Weinheim, Germany. v. 18, p.307 - 316, 1997.

REIS, E.M.; CASA, R.T.; MICHEL, C. Ocorrência de epidemia da ferrugem da soja no Rio Grande do Sul na safra 2001/2002. Fitopatologia Brasileira, v. 27, supl., p. 198, 2002.

REIS, E. M.; BRESOLIN, A. C. R.; CARMONA, M. Doenças da soja I: Ferrugem asiática. Passo Fundo: Ed. Universidade de Passo Fundo, 2006. 48 p.

ROBINSON, R.A. Disease resistance terminology. Review of Applied Mycology, Surrey, V.48, p. 593-606, 1969.

ROSE, J.K, BASHIR, S., GIOVANNONI, J.J., JAHN, M.M., SARAVANAN, R.S. Tackling the plant proteome: Practical approaches, hurdles and experimental tools. Plant J, 39:715-733. 2004.

ROSSI, R.L. First report of Phakopsora pachyrhizi, the causal agent of soybean rust in the province of Misione, Argentina. Plant. Dis. 87:102. 2003.

SAHNOUN, I.; DÉHAIS, P.; MONTAGU, M.V.; ROSSIGNOL, M.; ROUZÉ, P. PPMdb: a plant plasma membrane database. J. Biotechnology, v. 78, p. 235-246, 2000.

SALAVATI, A., TALEEI, A., AKBAR SHAHNEJAT BUSHEHRI, A., KOMATSU, S. Analysis of the proteome of common bean (Phaseolus vulgaris L.) roots after inoculation with Rhizobium etli. Protein and peptide letters, 19(8), 880-889, 2012. 
SALEKDEH, G.H.; KOMATSU, S. Crop proteomics: aim at sustainable agriculture of tomorrow. Proteomics, v.7, n.16, p.2976-2996, 2007.

SALEKDEH, G.H., SIOPONGCO, J., WADE, L.J., GHAREYAZIE, B., BENNET, J. Proteomic analysis of rice leaves during drought stress and recovery. Proteomics, 2: 11311145. 2002.

SANTOS, J.A., JUliATTI, F.C., SANTOS, V.A., POLIZEL, A.C, JULIATTI, F.C., HAMAWAKI, O.T. Caracteres epidemiológicos e uso da análise de agrupamento para resistência parcial à ferrugem da soja. Pesquisa Agropecuária Brasileira 42: 443-447. 2007.

SANTANA, F. A. (Tese de Doutorado). Análise proteômica de raízes de soja em resposta à inoculação com nematoides de galha. (2012).

SARAVANAN, R.S., ROSE, J.K. A critical evaluation of sample extraction techniques for enhanced proteomic analysis of recalcitrant plant tissues. Proteomics, 4:2522-2532. 2004.

SARKAR, N.K, KIM Y-K, GROVER A: Rice sHsp genes: genomic organization and expression profiling under stress and development. BMC Genomics, 393:1471-2164, 2009.

SARMA, A.D, OEHRLE, N.W, EMERCH, D.W. Plant protein isolation and stabilizat ion for enhanced resolut ion of two-dimensional polyacrylamide gel electrophoresis. Anal Biochem; 379:192 - 5. 2008.

SCHAFER, J.F. Tolerance to plant disease. Annual Review of Phytopathology 9: 235-252. 1970.

SCHNEIDER, R. W., HOLLIER, C. A., WHITAN, H. K., PALM, M. E., McKEMY, J. M., HERNANDEZ, J. R., LEVY, L., DeVRIES-PATERSON, R. First report of soybean rust caused by Phakopsora pachyrhizi in the continental United States. Plant Dis. 89:774. 2005.

SHIRASU K: The HSP90-SGT1 Chaperone Complex for NLR Immune Sensors. Annu Rev Plant Biol 2009, 60:139-164.

SILVA, D.C.G, YAMANAKA, N., BROGIN, R.L, ARIAS, C.A.A, NEPOMUCENO, A.L, Di MAURO, A.O., PEREIRA, S.S, NOGUEIRA, L.M, PASSIANOTO, A.L.L., ABDELNOOR, R.V. Molecular mapping of two loci that confer resistance to Asian rust in soybean. Theoretical and Applied Genetics, 117: 57-63. 2008.

SINCLAIR, J. B.; HARTMAN, G. L. Soybean rust. In: HARTMAN, G. L.; SINCLAIR, J. B.; RUPE, J. C. (Eds.). Compendium of soybean diseases. 4. ed. Saint Paul: APS Press, p. 25-26. 1999. 
SLAMINKO, T. L., MILES, M. R., FREDERCIK, R. D., BONDE, M. R., HARTMAN, G. L. New legume hosts of Phakopsora pachyrhizi based on greenhouse evaluations. Plant Dis. 92:767-771. 2008.

SOBHANIAN, H., RAZAVIZADEH, R., NANJO, Y., EHSANPOUR, A. A., JAZII, F. R., MOTAMED, N., KOMATSU, S. Proteome analysis of soybean leaves, hypocotyls and roots under salt stress. Proteome Science, 8(1), 1, 2010.

SOLOMON, P.S., TAN, K.C., OLIVER, R.P., The nutrient supply of pathogenic fungi; a fertile field for study, Mol. Plant Pathol., 4, 203-210, 2003.

SOUZA, P.I.M.; TOLEDO, J.F.F.; MOREIRA. C.T.; FARIAS NETO, A.L.; ABUD, S.; ARANTES, N.E.; MELlO FILHO, O.L.; CARNEIRO, G.E. de S.; MONTEIRO, P.M.F.O.; ARIAS, C.A.A.; KASTER, M.; OLIVEIRA, M.F.; PÍPOLO, A.E.; BROGIN, R.L.; NUNES JÚNIOR, J.; ABDELNOOR, R.V.; ALMEIDA, A.M.R.; MEYER, M.C.; ANDRADE, P.J.M.; CARRÃO-PANIZI, M.C.; DIAS, W.P.; MOREIRA, J.U.V.; NEIVA, L.C.S.; NUNES, M.R.; SEII, A.H.; SILVA, L.O.; SILVA, N.S. ${ }^{1}$; TEIXEIRA, R.N.; SOARES, R.M.; TOLEDO, R.M.C.P.; VIEIRA, N.E. BRSGO 7560: Primeira cultivar de soja resistente à ferrugem asiática indicada pela embrapa e parceiros. In: CONGRESSO BRASILEIRO DE SOJA 5., 2009; MERCOSOJA, Goiânia. Anais... Londrina: Embrapa Soja, 2009. Seção Trabalhos, t. 426. 1 CD-ROM. 2009.

SPSS® 13.0. Base User's Guide. Chicago, USA.2004.

STESSL, M.; NOE, C. R.; LACHMANN, B. Influence of image-analysis software on quantitation of two-dimensional gel electrophoresis data. Electrophoresis, v. 30, n. 2, p. 325328, Jan 2009.

SULE, A. et al. Proteomic analysis of small heat shock protein isoforms in barley shoots. Phytochemistry, v.65, p.1853-1863, 2004.

SUNG, D.Y, KAPLAN, F., GUY., C.L. Plant Hsp70 molecular chaperones: protein structure, gene family, expression and function. Physiol Plant, 113: 443-451, 2001.

TECNOLOGIAS de produção de soja - região central do Brasil 2012 e 2013. Londrina: Embrapa Soja, 261p. (Embrapa Soja. Sistemas de produção, 15). 2011.

TOUZET, P. et al. Characterizing allelic proteins for genome mapping in maize. Electrophoresis, v.16, p.1289-1294, 1995. 
TRA, V. T., LIEN, T. T. P., MAU, C. H. Proteomic characterization of soybean leaf proteins from cultivar DT2000 with rust-resistant ability in Vietnam. International Journal of Biosciences (IJB), 6(2), 468-477, 2015.

TRAN, L.S, NGUYEN, H.T. Future Biotechnology of Legumes. In: EMERICH, W.D , KRISHNN, H ( eds) Nitrogen fixation in crop production. ASA-CSA-SSSA, Madison, pp 265308. 2009.

TREMBLAY A., HOSSEINI P., ALKHAROUF N.W., LI S., MATTHEWS B.F., Transcriptome analysis of a compatible response by Glycine max to Phakopsora pachyrhizi infection, Plant Sci., 179, 183-193, 2010.

TSCHANZ, A.T.; WANG, T.C. Interrelationship between soybean development, resistance, and Phakopsora pachyrhizi. In: INTERNATIONAL CONGRESS OF THE SOCIETY FOR THE ADVANCED OF BREEDING RESEARCH IN ASIA AND OCEANIA, 5., Bangkok. Proceedings. Bangkok: Society for the Advanced of Breeding Research in Asia and Oceania, 1985. p.14-20. 1985.

TSCHURTSCHENTHALER, N. N., VIEIRA, E.S.N., NORA, T.D., SCHUSTER, I. Variabilidade genética de Phakopsora pachyrhizi avaliada por meio de marcadores microssatélites. Pesquisa Agropecuária Brasileira, Brasília, v.47, n.2, p.181-186, fev.2012.

USDA- United StatesDepartment ofAgriculture.Crop Production 2015 Summary, January, 2016.

VAN DER PLANK, J.E. Host pathogen interaction in plant disease. New York: Academic, 1982.

VAN DER PLANK, J.E. Principies of plant infection. New York: Academic, 1975. 216 p.

VAN LOON, L. Disease induction by plant viruses. Adv Virus Res 33:205-256,1987.

VAN OOIJEN, G., LUKASIK, E., VAN DEN BURG, H. A., VOSSEN, J. H., CORNELISSEN, B. J., TAKKEN, F. L. The small heat shock protein 20 RSI2 interacts with and is required for stability and function of tomato resistance protein I-2. Plant J.63:563-572, 2010 .

VIERLING, E. The role of Heat Shock Proteins in Plants. Ann. Rev. Plant Physiology Plant Mol. Biology, v.42 p.579-620, 1991.

XU, P., JIANG, L., WU, J., LI, W., FAN, S., \& ZHANG, S. Isolation and characterization of a pathogenesis-related protein 10 gene (GmPR10) with induced expression in soybean (Glycine max) during infection with Phytophthora sojae. Molecular biology reports, 41(8), 4899-4909, 2014. 
XU, C, SULLIVAN, J.H, GARRET, W.M, CAPERNA, T.J, NATARAJAN, S. Impact of solar ultraviolet-B on the proteome in soybean lines differing in flavonoid conte nts. Phytochemistry; 69: 38-48. 2008.

XU, C, GARRET, W.M, SULLIVAN, J.H, CAPERNA, T.J, NATARAJAN, S. Separation and identificat ion of soybean leaf proteins by two-dim ensional gel elec trophoresis and mass spectrometry. Phytochemistry; 67:2431-40. 2006.

YAMAOKA, Y.; FUJIWARA, Y.; KAKISHIMA, M.; KATSUYA, K.; YAMADA, K.; HAGIWARA, H.I. Pathogenic races of Phakopsora pachyrhizi on soybean and wild host plants collected in Japan. Journal of General Plant Pathology, v.68, p.52-56, 2002.

YANG, X. B.; TCHANZ, A. T. DOWLER, D. W.; WANG, T. C. Development of yield loss models in relation to reduction of components of soybean infected with Phakopsora pachyrhizi. Phytopathology, v. 81, p. 1420-1426, 1991.

YAN, S.P., TANG, Z.C, SU, W., SUN, W.N. Proteomic analysis of salt stress-responsive proteins in rice root. Proteomics, 5: 235-244. 2005

YORINORI, J. T. A ferrugem "asiática" da soja no continente americano: evolução, importância econômica e estratégias de controle. In: JULIATTI, C. F.; POLIZEL, C. A.; HAMAWAKI, T. O. 1. ed. I Workshop brasileiro obre a ferrugem asiática: Coletânea. Uberlândia: EDUFU, p. 21-37. 2005.

YORINORI, J.T., NUNES JÚNIOR, J.; LAZZAROTTO, J.J. Ferrugem asiática da soja no Brasil: evolução, importância econômica e controle. In. Empresa Brasileira de Pesquisa Agropecuária. Documentos 247. Embrapa Soja, pp 36. 2004.

YORINORI, J. T.; GODOY, C. V.; PAIVA, W. M.; FREDERICK, R. D.; COSTAMILAN, L. N.; BERTAGNOLLI, P. F.; NUNES JR., J. Evolução da ferrugem da soja (Phakopsora pachyrhizi) no Brasil, de 2001 a 2003. In: CONGRESSO BRASILEIRO DE FITOPATOLOGIA, 36., 2003, Uberlândia. Suplemento. Uberlândia:UFU, p.210. 2003.

YORINORI, J. T., PAIVA, W. M., FREDERICK, R. D., COSTAMILAN, L. M., BERTAGNOLli, P. F., HARTMAN, G. L., Goday, C. V., and Nunes, J. J. 2003. Epidemics of soybean rust (Phakopsora pachyrhizi) in Brazil and Paraguay from 2001 to. Plant Dis. 89:675-677. 2003.

YORINORI, J.T., YORINORI, M.A. \& GODOY, C.V. Seleção de cultivares de soja resistentes à ferrugem "asiática" (Phakopsora pachyrhizi). Anais, XXX Reunião Sul de Soja da Região Sul. Cuz Alta, RS. p.94. 2002. 
YORINORI, J.T.; PAIVA, W. M.; FREDERICK, R.D.; COSTAMILAN, L.M.; BERTAGNOLLI, P.F. Epidemia da ferrugem da soja (Phakopsora pa-chyrhizi) no Brasil e no Paraguai, em safras 2001 e 2002. Fitopatologia Brasileira, Brasília, DF, v.27, suplemento, p. 178-1 79, 2002.

WANG, Y., YUAN, X., HU, H., LIU, Y., SUN., W., SHAN, Z., ZHOU, X. Proteomic Analysis of Differentially Expressed Proteins in Resistant Soybean Leaves after Phakopsora pachyrhizi Infection. Journal Phytopatholy, 160:554-560 2012.

WANG, W., VINOCUR, B., SHOSEYOV, O., ALTMAN, A. Role of plant heat-shock proteins and molecular chaperones in the abiotic stress response. Trends Plant Sci. 9:244-252. 2004.

WANG, W. et al. Protein extraction for two-dimensional electrophoresis from olive leaf, a plant tissue containing high levels of interfering compounds. Electrophoresis, 24, 2369-2375. 2003.

WANG, T.C.; HARTMAN, G.L. Epidemiology of soybean rust and breeding for host resistance. Plant Protection Bulletin, v.34, p.109-149, 1992.

WASDE - World Agricultural Supply and Demand Estimates. June 10, 2016. Disponível em: http://www.usda.gov/oce/commodity/wasde/latest.pdf).

WILKINS, M.R.; APPEL, R.D.; WILLIAMS, K.L.; HOCHSTRASSER, D.F. Proteome Research: Concepts, Technology and Application. New York, 243p., 2008.

WILKINS, M. R.; WILliAMS, K. L.; APPEL, R. D.; HOCHSTRASSER, D. F. (Ed.) Proteome Research: New Frontiers in Functional Genomics (Principles and Practice). Berlin: Springer-Verlag, 1997. 243 p.

ZARKADAS, M. et al. Common allergenic foods and their labelling in Canada - A review. Can. J. Allergy Clin. Immunol, v. 4, n. 3, p. 118-141, 1999.

ZHANG, E. CHEN, X., LIANG, X. Resolubilization on TCA precipitated plant protein for 2D electrophoresis. Electrophoresis, 32, 696-698, 2011.

ZHANG, Y., ZHAO, J., XIANG, Y., BIAN, X., ZUO, Q., SHEN, Q., ... \& XING, H Proteomics study of changes in soybean lines resistant and sensitive to Phytophthora sojae. Proteome science, $9(1), 1,2011$.

ZHANG J, XIN L, SHAN B, CHEN W, XIE M, YUEN D, ZHANG W, ZHANG Z, LAJOIE G, MA B. PEAKS DB: De Novo sequencing assisted database search for sensitive and accurate peptide identification. Mol Cell Proteomics, 11: 10.1074/mcp.M111.010587, 1-8, 2012.

ZHEN, Y. et al. Comparative proteome analysis of differentially expressed proteins induced by Al toxicity in soybean. Physiologia Plantarum, v. 131, n. 4, p. 542-554. 2007. 


\section{LISTA DE ANEXOS}

Anexo 1. Análise estatística para spots com expressão aumentada em BRSGO-7560 (NI) na condição BRSGO-7560 (NI) x BRSGO-7560 (I) significativos de acordo com o teste de Mann Whitney.

\begin{tabular}{|c|c|c|c|}
\hline *Match ID & $\begin{array}{c}\text { Razão das médias } \\
\qquad \geq 2\end{array}$ & $\begin{array}{l}\text { Significância estatística } \\
\qquad \leq \leq 0,05\end{array}$ & Presença em géis \\
\hline 37 & 2,24 & 0,034 & 8 \\
\hline 42 & 3,029 & 0,000 & 9 \\
\hline 44 & 2,401 & 0,010 & 9 \\
\hline 48 & 4,423 & 0,004 & 8 \\
\hline 62 & 6,417 & 0,004 & 8 \\
\hline 64 & 4,730 & 0,038 & 7 \\
\hline 77 & 2,561 & 0,004 & 8 \\
\hline 88 & 2,452 & 0,024 & 9 \\
\hline 95 & 6,241 & 0,033 & 6 \\
\hline 106 & 2,289 & 0,036 & 9 \\
\hline 175 & 12,371 & 0,005 & 7 \\
\hline 229 & 8,124 & 0,024 & 6 \\
\hline 291 & 3,748 & 0,034 & 6 \\
\hline 318 & 13,135 & 0,010 & 6 \\
\hline 360 & 6,993 & 0,020 & 6 \\
\hline 367 & 55,271 & 0,001 & 8 \\
\hline 381 & 106,996 & 0,000 & 9 \\
\hline 673 & 3,890 & 0,021 & 7 \\
\hline 677 & 4,933 & 0,026 & 6 \\
\hline 705 & 6,264 & 0,005 & 7 \\
\hline 761 & 14,821 & 0,026 & 7 \\
\hline
\end{tabular}

*Match ID- Os números representam a numeração dos spots feita pelo Image Master. 
Anexo 2. Análise estatística dos spots com expressão aumentada em BRSGO-7560 (I) na condição BRSGO-7560 (I) x BRSGO-7560 (NI) significativos de acordo com o teste de Mann Whitney.

\begin{tabular}{|c|c|c|c|}
\hline *Match ID & $\begin{array}{c}\text { Razão das médias } \\
\qquad \mathbf{v} \geq 2\end{array}$ & $\begin{array}{l}\text { Significância estatística } \\
\qquad \leq 0,05\end{array}$ & Presença em géis \\
\hline 130 & 6,428 & 0,012 & 7 \\
\hline 148 & 2,773 & 0,002 & 9 \\
\hline 158 & 2,019 & 0,006 & 8 \\
\hline 203 & 2,147 & 0,004 & 9 \\
\hline 231 & 4,697 & 0,001 & 9 \\
\hline 233 & 4,457 & 0,001 & 9 \\
\hline 237 & 4,119 & 0,012 & 8 \\
\hline 246 & 2,326 & 0,024 & 9 \\
\hline 255 & 2,015 & 0,038 & 9 \\
\hline 70 & 7,001 & 0,000 & 9 \\
\hline 373 & 4,490 & 0,006 & 8 \\
\hline 425 & 2,774 & 0,031 & 8 \\
\hline 88 & 3,389 & 0,002 & 9 \\
\hline 102 & 2,244 & 0,007 & 9 \\
\hline 488 & 3,945 & 0,024 & 7 \\
\hline 498 & 3,928 & 0,024 & 7 \\
\hline 190 & 7,968 & 0,011 & 7 \\
\hline 529 & 2,157 & 0,047 & 8 \\
\hline 627 & 3,557 & 0,026 & 7 \\
\hline 68 & 8,236 & 0,000 & 9 \\
\hline
\end{tabular}

*Match ID- Os números representam a numeração dos spots feita pelo Image Master. 
Anexo 3. Análise estatística dos spots com abundância relativa aumentada em MSOY 8001 (NI) na condição MSOY 8001 (NI) x MSOY 8001 (I) significativos de acordo com o teste de Mann Whitney.

\begin{tabular}{|c|c|c|c|}
\hline Match ID & $\begin{array}{c}\text { Razão das médias } \\
\mathbf{v} \geq \mathbf{2}\end{array}$ & $\begin{array}{c}\text { Significância estatística } \\
\mathbf{P} \leq \mathbf{0 , 0 5}\end{array}$ & Presença em géis \\
\hline 48 & 4,305 & 0,002 & 9 \\
\hline 47 & 2,311 & 0,007 & 9 \\
\hline 627 & 1,994 & 0,024 & 6 \\
\hline 335 & 5,479 & 0,050 & 8 \\
\hline
\end{tabular}

*Match ID- Os números representam a numeração dos spots feita pelo Image Master.

Anexo 4. Análise estatística dos spots com abundância relativa aumentada em MSOY 8001 (I) na condição MSOY 8001 (I) x MSOY 8001 (NI) significativos de acordo com o teste de Mann Whitney.

\begin{tabular}{|c|c|c|c|}
\hline Match ID & $\begin{array}{c}\text { Razão das médias } \\
v \geq 2\end{array}$ & $\begin{array}{l}\text { Significância estatística } \\
\qquad \leq \leq 0,05\end{array}$ & Presença em géis \\
\hline 91 & 5,241 & 0,001 & 8 \\
\hline 93 & 1,988 & 0,040 & 7 \\
\hline 112 & 1,986 & 0,031 & 8 \\
\hline 120 & 2,161 & 0,050 & 9 \\
\hline 138 & 2,160 & 0,006 & 9 \\
\hline 152 & 5,559 & 0,050 & 6 \\
\hline 160 & 8,148 & 0,000 & 9 \\
\hline 176 & 2,533 & 0,019 & 9 \\
\hline 201 & 5,003 & 0,050 & 7 \\
\hline 210 & 4,337 & 0,019 & 7 \\
\hline 265 & 6,885 & 0,019 & 7 \\
\hline 284 & 5,346 & 0,019 & 7 \\
\hline 293 & 3,559 & 0,014 & 9 \\
\hline 321 & 7,363 & 0,001 & 9 \\
\hline 331 & 6,559 & 0,031 & 6 \\
\hline 367 & 3,260 & 0,014 & 8 \\
\hline 385 & 4,151 & 0,050 & 6 \\
\hline 388 & 6,820 & 0,024 & 6 \\
\hline 398 & 15,602 & 0,024 & 6 \\
\hline 417 & 6,439 & 0,031 & 6 \\
\hline
\end{tabular}

*Match ID- Os números representam a numeração dos spots feita pelo Image Master. 
Anexo 5. Análise estatística dos spots com com abundância relativa aumentada em BRSGO-7560 (NI) na condição BRSGO-7560 (NI) x MSOY 8001 (NI) significativos de acordo com o teste de Mann Whitney.

\begin{tabular}{|c|c|c|c|}
\hline *Match ID & $\begin{array}{c}\text { Razão das médias } \\
\qquad \mathbf{v} \geq 2\end{array}$ & $\begin{array}{c}\text { Significância estatística } \\
\qquad \leq 0,05\end{array}$ & Presença em géis \\
\hline 37 & 2,376 & 0,017 & 8 \\
\hline 44 & 3,392 & 0,015 & 9 \\
\hline 48 & 5,633 & 0,004 & 8 \\
\hline 62 & 5,984 & 0,006 & 8 \\
\hline 86 & 13,925 & 0,000 & 9 \\
\hline 87 & 2,283 & 0,009 & 9 \\
\hline 97 & 2,555 & 0,009 & 9 \\
\hline 100 & 33,669 & 0,000 & 9 \\
\hline 107 & 2,383 & 0,007 & 9 \\
\hline 118 & 2,104 & 0,041 & 8 \\
\hline 133 & 5,530 & 0,022 & 9 \\
\hline 148 & 2,819 & 0,039 & 8 \\
\hline 208 & 74,901 & 0,010 & 6 \\
\hline 212 & 3,874 & 0,019 & 9 \\
\hline 224 & 16,918 & 0,038 & 9 \\
\hline 248 & 6,951 & 0,001 & 9 \\
\hline 250 & 2,884 & 0,005 & 9 \\
\hline 288 & 2,163 & 0,001 & 9 \\
\hline 296 & 12,217 & 0,005 & 7 \\
\hline 391 & 2,947 & 0,015 & 8 \\
\hline 399 & 7,299 & 0,034 & 6 \\
\hline 400 & 6,349 & 0,020 & 6 \\
\hline 404 & 2,724 & 0,024 & 8 \\
\hline
\end{tabular}

*Match ID- Os números representam a numeração dos spots feita pelo Image Master. 
Anexo 6. Análise estatística dos Spots com abundância relativa aumentada em MSOY 8001 (NI) na condição MSOY 8001 (NI) x BRSGO-7560 (NI) significativos de acordo com o teste de Mann Whitney.

\begin{tabular}{|c|c|c|c|}
\hline *Match ID & $\begin{array}{c}\text { Razão das médias } \\
\qquad \mathbf{v} \geq 2\end{array}$ & $\begin{array}{l}\text { Significância estatística } \\
\qquad \mathbf{P} \leq 0,05\end{array}$ & Presença em géis \\
\hline 155 & 4,196 & 0,007 & 8 \\
\hline 197 & 2,109 & 0,002 & 9 \\
\hline 238 & 2,513 & 0,019 & 9 \\
\hline 234 & 4,180 & 0,012 & 8 \\
\hline 277 & 8,711 & 0,024 & 6 \\
\hline 122 & 2,057 & 0,005 & 9 \\
\hline 108 & 7,074 & 0,012 & 8 \\
\hline 452 & 5,502 & 0,016 & 7 \\
\hline 428 & 6,609 & 0,031 & 7 \\
\hline 515 & 4,342 & 0,003 & 9 \\
\hline 67 & 5,668 & 0,006 & 8 \\
\hline 220 & 3,143 & 0,013 & 9 \\
\hline 292 & 2,585 & 0,023 & 8 \\
\hline 290 & 2,213 & 0,033 & 8 \\
\hline 99 & 2,183 & 0,046 & 9 \\
\hline
\end{tabular}

*Match ID- Os números representam a numeração dos spots feita pelo Image Master. 
Anexo 7. Análise estatística dos spots com abundância relativa aumentada em BRSGO-7560 (I) na condição BRSGO-7560 (I) x MSOY 8001 (I) significativos de acordo com o teste de Mann Whitney.

\begin{tabular}{|c|c|c|c|}
\hline *Match ID & $\begin{array}{c}\text { Razão das médias } \\
\qquad \geq 2\end{array}$ & $\begin{array}{l}\text { Significância estatística } \\
\qquad \leq 0,05\end{array}$ & Presença em géis \\
\hline 314 & 4,192 & 0,023 & 7 \\
\hline 22 & 2,159 & 0,012 & 8 \\
\hline 30 & 1,915 & 0,023 & 8 \\
\hline 36 & 4,662 & 0,000 & 9 \\
\hline 40 & 3,452 & 0,000 & 9 \\
\hline 87 & 2,540 & 0,030 & 8 \\
\hline 83 & 3,532 & 0,004 & 9 \\
\hline 84 & 21,47 & 0,001 & 9 \\
\hline 126 & 2,119 & 0,009 & 9 \\
\hline 135 & 2,253 & 0,002 & 9 \\
\hline 141 & 2,065 & 0,009 & 9 \\
\hline 147 & 2,344 & 0,043 & 7 \\
\hline 513 & 3,924 & 0,001 & 9 \\
\hline 168 & 8,756 & 0,006 & 7 \\
\hline 196 & 3,154 & 0,000 & 9 \\
\hline 209 & 2,550 & 0,000 & 9 \\
\hline 315 & 4,724 & 0,018 & 7 \\
\hline 18 & 4,104 & 0,027 & 7 \\
\hline 26 & 5,115 & 0,008 & 7 \\
\hline 56 & 2,816 & 0,009 & 8 \\
\hline 422 & 2,492 & 0,010 & 9 \\
\hline 102 & 13,523 & 0,000 & 9 \\
\hline 88 & 1,945 & 0,038 & 9 \\
\hline 80 & 2,536 & 0,000 & 9 \\
\hline 76 & 4,304 & 0,009 & 9 \\
\hline 511 & 4,142 & 0,014 & 7 \\
\hline 191 & 2,371 & 0,047 & 7 \\
\hline 110 & 2,902 & 0,017 & 8 \\
\hline 74 & 2,457 & 0,021 & 8 \\
\hline 132 & 2,883 & 0,050 & 7 \\
\hline 167 & 14,676 & 0,003 & 7 \\
\hline 220 & 2,528 & 0,023 & 9 \\
\hline
\end{tabular}

*Match ID- Os números representam a numeração dos spots feita pelo Image Master. 
Anexo 8. Análise estatística dos spots com abundância relativa aumentada em MSOY 8001 (I) na condição MSOY 8001 (I) x BRSGO-7560 (I) significativos de acordo com o teste de Mann Whitney.

\begin{tabular}{|c|c|c|c|}
\hline *Match ID & $\begin{array}{c}\text { Razão das médias } \\
\mathbf{v} \geq \mathbf{2}\end{array}$ & $\begin{array}{c}\text { Significância estatística } \\
\mathbf{P} \leq \mathbf{0 , 0 5}\end{array}$ & Presença em géis \\
\hline 47 & 4,609 & 0,003 & 9 \\
\hline 138 & 2,552 & 0,014 & 9 \\
\hline 160 & 2,048 & 0,047 & 9 \\
\hline 170 & 2,865 & 0,024 & 6 \\
\hline 176 & 1,967 & 0,007 & 8 \\
\hline 198 & 4,876 & 0,033 & 9 \\
\hline 213 & 2,256 & 0,045 & 7 \\
\hline 240 & 2,759 & 0,002 & 9 \\
\hline 242 & 2,394 & 0,043 & 8 \\
\hline 278 & 3,778 & 0,001 & 9 \\
\hline 292 & 24,552 & 0,001 & 8 \\
\hline 293 & 1,965 & 0,030 & 9,018 \\
\hline 407 & 2,317 & 0 & \\
\hline
\end{tabular}

*Match ID- Os números representam a numeração dos spots feita pelo Image Master. 